

\section{DISCLAIMER}

This report was prepared as an account of work sponsored by an agency of the United States Government. Neither the United States Government nor any agency Thereof, nor any of their employees, makes any warranty, express or implied, or assumes any legal liability or responsibility for the accuracy, completeness, or usefulness of any information, apparatus, product, or process disclosed, or represents that its use would not infringe privately owned rights. Reference herein to any specific commercial product, process, or service by trade name, trademark, manufacturer, or otherwise does not necessarily constitute or imply its endorsement, recommendation, or favoring by the United States Government or any agency thereof. The views and opinions of authors expressed herein do not necessarily state or reflect those of the United States Government or any agency thereof. 


\section{DISCLAIMER}

Portions of this document may be illegible in electronic image products. Images are produced from the best available original document. 
Issued by Sandia National Laboratories, operated for the United States Department of Energy by Sandia Corporation.

NOTICE: This report was prepared as an account of work sponsored by an agency of the United States Government. Neither the United Stales Government nor any agency thereof nor any of their employees, nor any of their contractors, subcontractors, or their employees, makes any warranty, express or implied, or assumes any leyal liahility or esponsibility for the arciuracy, completeriess, us useruiness of any information, apparatiss, product, or process disclosed, $n r$ represents that its use would not infringe privately owned rights. Reference herein to any specific commercial product, process, or service by trade name, trademark, manufacturer, or otherwise, does not necessarily constitute or imply its endorsement, recommendation, or favoring by the United States Government, any agency thereof or any of their contractors or subcontractors. The views and opinions expressed herein do not necessarily state or reflect those of the United State

Printed in the United States of America

Available from

National Technical Information Service

U. S. Department of Commerce

5285 Port Royal Road

Springfield, VA 22161

NTIS price codes

Printed copy: $\$ 9.00$

Microfiche copy: A01 


\section{PAGES $\mathrm{i}$ to $\mathrm{ii}$ WERE INTENTIONALLY LEFT BLANK}


Distribution

Category UC-63d

\author{
SAND81-7030 \\ Unlimited Release \\ Printed July 1981
}

\title{
INVESTIGATION OF A FAMILY OF POWER CONDITIONERS INTEGRATED INTO A UTILITY GRID: FINAL REPORT CATEGORY I
}

\author{
P. Wood \\ R. P. Putkovich \\ Westinghouse Electric Corporation \\ Research and Development Center \\ Pittsburgh, PA 15235
}

ABSTRACT

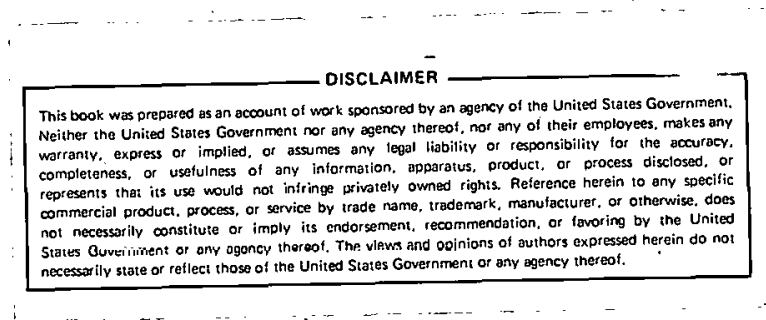

As part of the effort under DOE contract \#DE-AC02-

79-ET29359, a study was conducted of the require-

ments for and technologies applicable to power conditioning equipment in residential solar photovoltaic systems. The conclusions are that the designs investigated in the study will meet, or with slight improvement could meet, short term efficiency goals. Long term efficiency goals could be met if an isolation transformer were not required in the power conditioning equipment. None of the technologies studies can meet cost goals unless further improvements are possible. Three additional reports by other contractors are also being published. The work on the contract covered by this report was directly funded by DOE/EES with Sandia serving as the technical manager.

Prepared for the Department of Energy under contract No. DE-AC02-79ET29359; under Sandia National Laboratories Technical Direction. 
1. EXECUTIVE SUMMARY. . . . . . . . . . . . . . . . . . 1

2. OBJECTIVES AND APPROACHES. . . . . . . . . . . . . . 7

3. REVIEW AND EVALUATION OF POWER CONDITIONING TECHNOLOGY . . . 10

3.1 Survey of Manufacturers . . . . . . . . . . . . 10

3.2 Types of Equipment and Performance Limitations. . . . . . 12

3.3 Efficiency Data . .. . . . . . . . . . . . 16

3.4 Cost Data... . . . . . . . . . . . . . 17

3.5 Size and Weight Data. . . . . . . . . . . . 19

4. INTERFACE REQUIREMENTS . . . . . . . . . . . . . . 20

4.1 General Considerations. . . . . . . . . . . . 20

4.2 The DC Interfface. . . . . . . . . . . . . . 20

4.3 The AC Interface. . . . . . . . . . . . . . . 28

4.4 Operational Considerations. . . . . . . . . . . . 47

4.5 Baseline Specification. . . . . . . . . . . . . 48

5. BASELINE DESIGN. . . . . . . . . . . . . . . 50

6. Alternative teChNOLOGIES ................ 61

6.1 Current-Sourced Converter with Filtering and VAR

Correction. . . . . . . . . . . . . . . . 64

6.2 HF Front-End Current-Sourced Converter. . . . . . . . . 72

6.3 Three-Phase Current-Sourced Converters. . . . . . . . . 78

6.4 Multiple-Pattern Programmed-Waveform Converter. . . . . 80

7. POSSIBLE COST IMPROVEMENTS . . . . . . . . . . . . 85

8. INFORMATION MATRIX SUPPORTING THE CONCIUSIONS. . . . . . . . 93

APPENDIX A - STATEMENT OF WORK . . . . . . . . . . . . . A-1 


\section{EXECUTIVE SUMMARY}

The work executed to date and reported herein has addressed only Category I (residential) power conditioning. However, many of the results and conclusions with reguard to interfacing requirements are also applicable directly or with minor modifications, to Category II (light commercial and industrial) equipment.

In accordance with the contract work statement, effort was devoted to five tasks. In order of address, these were:

1) A survey of power conditioning presently marketed which might be (or in a few instances is) made suitable for solar photovoltaic applications

2) A study of the dc (array) and ac (utility) interface and operational requirements and derivation of baseline specifications for the power conditioning equipment

3) The execution of a baseline conceptual design using wellestablished power conversion technology to meet the specified requirements and estimation of the cost and efficiency of that baseline design

4) The exploration of alternative conversion technologies and improvements to established technologies with the objective of providing intormation on the development needed and the best path to pursue in trying to reach DOE's cost and efficiency goals for power conditioning equipment

5) The execution of a conceptual design for the power conversion technology chosen as being most likely to meet or surpass DOE's goals with cost and efficiency projections and identification of any development effort needed. 
The survey showed that, with few exceptions equipment manufactured today does not meet the technical requirements of the application. However, most of the technologies in use can be adapted to solar photovoltaic system needs with little development. Present equipment costs for small quantities (1-10) generally exceed the DOE goal of $\$ 200 / \mathrm{kW}$ in 1000 quantities by factors ranging from three to eight, and would in most cases be higher were all application requirements met. Present equipment losses generally exceed those required to meet DOE goals by factors of 2 to 2.5; this situation would not be significantly affected by the design changes needed, in most cases, to meet application requirements. Obviously there is a need for significant cost reduction and efficiency improvement if power conditioning is to fulfill solar photovoltaic program needs.

The two key technical issues at the ac interface are power factor and harmonic distortion. The subsidiary issues of operating voltage range, transient voltage exposure and fault protection were easy to specify and can readily be addressed in power conditioning equipment design. We have concluded that equipment operating at significantly less than unity power factor is both technically and institutionally unacceptable for the application. It is technically unacceptable because the impact of significant conversion equipment VAR demand on system voltage regulation seriously degrades service to other consumers. It is institutionally unacceptable because the utility cannot reasonably be expected to bear the costs of supplying reactive power while it is supplying no real power, or perhaps buying real power from the cogenerator. This latter point causes us also to conclude that the power conditioning equipment will be institutionally unacceptable, within the present framework of consumers-utility rate structures and regulations pertaining thereto, if it cannot furnish the reactive power demand of household loads whenever power generation is occurring. The VAR demand of both loads and conversion equipment may become acceptable if the cogenerator can be billed for his reactive power consumption. Regulations currently in force do not permit this for residential customers. Thus it is our conclusion that unity power factor at the utility tie, not merely unity power factor converter operation is the appropriate requirement. 
Harmonics proved more difficult to specify because of the paucity of information both on existing levels and on the effects of harmonic distortion on utility equipment and consumers loads. We have used recently imposed European (CENELEC) regulations to derive a specification that we think is reasonable in that it does not impose undue cost and efficiency penalties on the power conditioning equipment and has a high probability of not creating problems with existing utility equipment or other consumers' loads. The figures, $5 \%$ total harmonic current distortion with a superposed limit on Individual components of $15 / \mathrm{N}$ amps, $\mathrm{N}$ the harmonic order, are. still considered tentative and subject to modification, either tightening or relaxation, resulting from further studies or field evidence on this particular issue. A current, rather than voltage, specification was opted because it is harmonic current that causes problems and because it is in some respects easier for an equipment manufacturer to demonstrate compliance with a current injection specification.

A further ac interface issue of considerable importance is the need or lack of need for an isolation transformer. We have concluded that isolation is in fact mandatory. This conclusion stems from three related concerns that arise when nonisolated connection is envisioned. First, we do not believe that all provisions of the various codes addressing the safety of residential installations can be met unless isolation is provided. Second, consumer and utility fault clearing devices are incapable of safely interrupting dc fault currents, so such a possibility must be obviated. Third, a converter fault with dc content is likely to saturate the distribution (pole-top) transformer and cause disruption of service to other consumers, both those on the same transformer and those on the same feeder since some primary fault clearing devices will then operate.

The key technical issues at the dc interface are fault detection and clearing, operating voltage ranges (absolute and relative) and ripple current injection into the solar-photovoltaic array. Our study of the latter indicates that moderate ripple current levels, up to $10 \%$ peak-to-peak, have an insignificant effect on array performance and levels up to $20 \%$ peak-to-peak may well be permissible. We selected a specification of $10 \%$ peak-to-peak. Consideration of array terminal voltage variations with 
changes in temperature, insolation and loading indicates that a dc operating voltage range of 1.7 to 1 should certainly be adequate to ensure negligible loss of energy production; it may be possible to specify a narrower range, but there are risks other than energy loss associated. with so doing and since the cost and loss penalties for this range are not severe in the photovoltaic application we have elected to specify it. The maximum absolute dc voltage attained with respect to ground is set by National Electric Code (Article 250-3) and UL requirements at $300 \mathrm{~V}$. Both cost and efficiency considerations in the power conditioning equipment dictate that it should be approached as $01 \mathrm{nsply}$ as 18 doemed prudent. We chose to specify $240 \mathrm{~V}$, allowing a reasonable margin for tolerances and occasional high insolation/low temperature conditions taking array voltage beyond the normal design range.

Fault detection and clearing at the array-converter interface is difficult because of the low short circuit current capability of the source and the high cost and poor service life of dc fault interrupting devices. However, since the source (array) proves no threat to the converter's active devices, the converter can be used to clear most dc side faults. For those which it cannot, or for catastrophic converter failures, we would opt for the application of a deliberate "auxiliary fault" (short circuiting switch) at the array terminals.

There arose, numerous operational issues in the course of the study of interface requirements and equipment design criteria; chief among there were automation of the control (sunup and sundown, startup and shutdown), control mode and equipment behavior in the event of utility system faults. The control isstes are easily dealt with by modern electric technology - it is very simple to implement automatic startup and shutdown procedures, the latter based on array power delivery, the former on array open circuit voltage. It is also very simple to arrange for the converter to be protected from damage in the event of an interruption of the utility supply. It is not so easy, with some converter technologies (including the most promising), to avoid load and personnel hazards, particularly the latter. We have not yet devised a completely satisfactory solution to this problem. 
As forecast, it proved quite easy to execute a conceptual baseline diagram meeting specifications with well-developed converter technology. Its' projected cost in 1000 quantities was seen to exceed goals by a factor of between 3.35 and 4 , depending on selling policy presumptions, and 1ts losses exceeded goals by a factor of 2.4. In a large part, the latter deficiency is due to the isolation transformer. So long as isolation is required, the efficiency goals (short term 91\%, long term 93\%) at full load, cannot be achieved.

The investigation of alternative technologies and technology improvements revealed that a number of candidate systems showed some promise of bettering the baseline design's cost and efficiency. On the basis of detail cost and loss calculations, it was determined that none were sufficiently better with present day component costs and manufacturing methods (for conversion equipment) to meet the goals. However, two showed more potential for achieving costs closer to the goals if improvements in manufacturing methods for both equipment and components were projected, and one eventually emerged as clearly the best long range candidate. It finds no difficulty in meeting the specifications, and would not be seriously impacted by more stringent harmonic specification at the ac interface. It does not introduce significant network problems as a result of design features needed to restrict harmonic injection and meet power factor requirements, and has by far the most to gain both from improvements in switching device capability and manufacture and in equipment manufacturing methods. Moreover, it is simple, elegant and represents the best in $d c$ to ac conversion technology, as evidenced by the rapid shift to its use in ac machine drives and low-power UPS systems.

We refer, of course, to the voltage-sourced programmed-wave converter, implemented with transistors as the controllable elements of its active switches (in the Category I power range). While projected present cost, in 1000 quantities, exceeds goals by a factor of 2.9 to 3.4 , and projected efficiency with present devices indicates that losses exceed goals by a factor of approximately 2, we have concluded that there are grounds for believing that costs can be brought within 1.5 times the goal. 
As long as isolation is required losses probably cannot be brought within 1.6 times its goal at best; detailed ownership cost studies are needed to determine the appropriate design on the basis of cost/loss trades in the power conditioning.

Little power circuit development is needed to 1mplement the technology, but substantial control development investment is recommended if its full potential is to be realized. It will not be possible to effect the projected cost reductions unless switching device development is undertaken in addition to an attack on equipment manufacturing methods. Although there is presently available equipment using the technology, at leastome example designed for solar photovoltaic applications, we estimate a lead time of 2 to $21 / 2$ years for a production prototype incorporating all the design improvements necessary and a total elapsed time of 4 to $51 / 2$ years before 1000 quantity production could be established at prices as close to the cost goal as will be achievable. 


\section{OBJECTIVES AND APPROACH}

The objectives of the studies performed are delineated in detail in the Work Statement from RFP-kDE-RPO2-79ET29019.S000 which was 1ncorporated in contract \#DE-AC02-79ET29359 and is included as Appendix A to this report. Only the objectives pertaining to Category I (residential) power conditioning equipment are addressed by the work performed to date and reported herein.

In performing Task 1, Review and Evaluation of Power Conditioning Technology, the approach was to conduct a survey of equipment manufacturers to acquire the data on available power conditioning units. Performance, cost and efficiency data was obtained readily; substantive reliability data proved unavailable. The data was appropriately collated and analyzed to develop cost and efficiency patterns relating to technologies used and equipment ratings and performance. Performance deficiencies relative to the solar photovoltaic application were assessed; a great deal of commonality existed in this area, since most units presently manufactured serve a single application (UPS) and are built to essentially common specifications.

Task 2, Investigation of Interface Requirements, was addressed. by first determining dc source and ac network characteristics through appropriate studies. For the dc sources, most particularly solar arrays, research of recent literature and contacts with manufacturers' engineering provided the data needed. For the ac network, previous Westinghouse generated studies and test results were combined with direct information from utilities and pertinent literature to provide the necessary data base. Once the information needed was in hand, it was collated and analyzed to provide a clear picture of the steady state behavior, transient characteristics and fault capacities and susceptibilities of the dc sources and ac networks to which power conditioning equipment must connect. These 
characteristics were then used to develop interface and operating spectfications for the power conditioning equipment. Power quality at both ac and dc terminals, fault protection and protective device coordination requirements, steady state and transient voltage and current conditions were stipulated. Also, the automatic control features needed for successful system integration were defined, so that a complete outline specification for power conditioning performance was developed.

In addressing Task 3, Selection and Conceptual Design of Baseline, we drew heavily on our previous experience and expertise in the pnwer conditioning field in addition to the information developed by Tasks 1 and 2. The approach was to select a technology which was highly developed and already extensively used but which could make good use of the best in available semiconductor switching devices. A conceptual design was executed, focusing mainly on power circuit configuration and components. Detailed assessment of control hardware was deemed unnecessary since the degree of complexity was known and the information nepied rnuld be extrapolated from existing hardware of similar character.

The design executed was subjected to cost and loss analysis. Approximate size and weight figures were calculated, and a comparative reliability estimate was made. The results of these calculations for the baseline design then were used as a yardstick to measure the achievements of subsequent tasks.

Task 4, Investigation of Advanced Power Conditioning Equipment, drew very heavily on the in-house expertise in the area in addition to information from hardware development contrarts currently in progress that relate to this application. A number of alternative technologies were investigated with regard to their potential to provide lower costs, higher efficiencies and better reliability than the baseline. It proved necessary to combine the effort with Task 5, Conceptual Design, since accurate quantitative assessment of the impact of various technology alternatives was not possible without the execution of conceptual designs incorporating those technologies. Because of the difficulties in making other than 
qualitative reliability assessments, attention was focused mainly on cost and efficiency calculations with performance specifications maintained constant in all cases (though some technologies inevitably produce "bonus" performance features above and beyond the application's needs).

The results of these efforts were used to identify developments which could further improve cost and efficiency, and projected estimates of attainable goals were made. The two most promising technologies emerging from the work on Tasks 4 and 5 were subjected to further, more penetrating examination under ongoing Task 5 effort so that a final selection could be made.

The address to Task 6, Results, Conclusions and Recommendations, appears in the pertinent section of this report. - All results are presented, and the rationales for the various decision and selections are fully explained. A firm recommendation is made regarding development of the most promising power conditioning technology, and the most fruitful areas for development effort are clearly identified.

The results have been presented with an organization clearly supporting these recommendations and providing the grounds for rejection of the various alternatives not selected for use. We discuss all results and rationales in more depth in the report sections dealing with the various specific efforts undertaken and completed, so that each methodology is fully documented and each decision fully explained in the body of the report. 


\section{REVIEW AND EVALUATION OF POWER CONDITIONING TECHNOLOGY}

\subsection{Survey of Manufacturers}

a letter was prepared and rirrulated to 35 s.mmanies knnwn or thought to manufacture power conditioning equipment which is or could be modified to be suitable for solar photovoltaic (and other dispersed source/storage technologies) applications. Two other manufacturers were solicited for responses at DOE instigation subsequent to the original survey. The manufacturers were requested to provide information regarding the types, ratings, costs, efficiencies, sizes, weights and reliabilities of their products. Twenty-two responded to the original solicitation, but only 13 provided useful information. The two later solicitations did not augment the data base originally generated to any significant extent.

of those not responding, six. advised that they did not make or plan to make applicable equipment. The remaining seven unresponsive solicitors made no reply whatsoever except in one instance, where an indication was given that response would be made only to a direct request from DOE because of possible violation of anti-trust laws in providing the information requested directly to a major competitor. The seven companies not responding were:

Alresearch

Bellman Engineering

Computer Power

Delta Electronic

Exide Power Systems

General Electric

Varo

of these, three are major manufacturers - Alresearch, Exide and General Electric. 
It was the latter who indicated a willingness to furnish the information to DOE but not to Westinghouse.

The six companies advising they did not make applicable equipment were:

A. L. S. Electronics

Control Products Corporation

Industrial Control Company

Industrial Test Equipment

Varian

T. B. Wood's Sons

None of these, with the possible exception of Varian, might have made a significant contribution.

The eight companies who responded but did not provide information that could be used to strengthen the data base were:

Avionic Instruments

California Instruments

Cleveland Machine Controls

Dynamic Electronic Controls

Robicon

Sola

Unitron

Wilmore Electronics Company

With the possible exceptions of Robicon and Sola, it is unlikely that more detailedinformation from these companies would have significantly influenced the data base and the conclusions drawn thus far.

Companies which provided information which could usefully be incorporated in the data base were:

Abacus

Advanced Conversion Devices

Clary

EMI McCarr Marine Electric

Compucer Power Inc.

Cyberex 
Deltec

Elgar

Franklin Electric

Nova

Pacific Power Source

Reliance

Topaz

Windworks

(Westinghouse)

In the case of Westinghouse, internal contacts were used to elicit the necessary information from the appropriate manufacturing divisions. Excepting Windworks, these companies gave information on UPS converters, or very close relations thereof; only Windworks and Westinghouse information related to the current-sourced converter technology most commonly used in dc machine drives.

of the above list of respondents, only Westinghouse and Reliance are major manufacturers; all others are small but active and have an aggressive interest in any dispersed generation market for their equipment.

The data furnished provided adequate information on costs, efficiencies, sizes and weights. No reliability data was provided by any solicitee; it appears that such data does not exist, or if it does is regarded as so confidential that it will not be disclosed. The former is more likely the case, since accurate records of field experience are rarely maintained. Equipment prices are simply adjusted to cover average warranty costs, and continued experience beyond warranty is never fed back to the manufacturer unless gross problems are evident.

\subsection{Types of Equipment and Performance Limitations}

Two basic types of converter, primarily intended for different applications, were included in the responses. As mentioned, the currentsourced line-commutated converter, which is mainly used for dc machine devices and controllable dc supplies, was Included by Westinghouse and 
Windworks. Only Windworks has promoted this converter technology for dispersed generation application. The voltage-sourced self-commutated converter, which is the staple of the UPS industry, was the type on which most information was made available.

The current-sourced converter naturally uses thyristors as switching devices and is almost invariably line-commutated. It then consumes lagging quadrature current from its ac source regardless of the direction of power flow and is also, as is well known, a prolific harmonic current generator. It may be regarded with favor because of simplicity and reliability, and has the attractions of low cost and high efficiency in its basic form. However, its ac interface deficiencies have caused it to be regarded by most authorities as basically unsuited for this type of application. The deficiencies in question are:

- poor lagging power.factor operation

- high harmonic current injection

- susceptibility to commutation faults as a result of ac line disturbances

The first two of these are well known, and their severity in the light of requirements is discussed in detail in Section 5 where designs meeting ac interfacing needs are executed. The commutation fault problem is often overlooked. It arises because the converter depends on the existence of a externally provided ac voltage source for its operation specifically, for commutation. If that voltage drops below a certain value for a specific (sub-cycle) time, a commutation failure occurs and the dc current will rise rapidly with the ac source being subjected to the dc fault current for at least one cycle. If the dc source is of limited current capacity, as is the case with a solar photovoltaic array, then it is subjected to dc terminal voltage reversal (back-bias) by the faulted converter. In this case, it is possible to recover the converter to proper operation at the next attempted commutation if the ac voltage has by then recovered from the disturbance (and if the unidirectional current injection during the fault cycle did not cause ac system outage). 
However, a sustained disturbance willcreate a sustained fault, and if proper control measures are not invoked the fault may be sustained at the dc terminals, in the form of a dc side short circuit through conducting converter devices, even if the ac voltage does recover. This is a serious problem for current-sourced converters operating as inverters long recognized and difficult to protect against except by the use of suitable dc fault interrupting devices.

The vultage sourced self-(or force) commutated converter is commonly implemented with either thyristors or transistors as the controllable elements of its switches. When thyristors are used, 1mpulse(force-) commutating circuits have to be used; these involve passive components, inductors and capacitors, and often extra auxiliary thyristors ("commutating thyristors"). It is, therefore, generally conceded to be advantageous to use transistors when equipment power rating allows. In the Category I range, both thyristors and transistor implementations are presently marketed for UPS and related applications. The thyristor verslons are for the most part older designs which achieve the ac terminal performance required by these applications by the use of a ferroresonant transformer. It is not possible to parallel two such designs with a utility supply unless either

a) a very high reactive lmpedance is placed betweeli converter and utility to limit reactive current flow

or

b) control is added to the ferroresonant transformer.

The transistor designs generally use a high frequency switching technique to reduce the filtering needed for acceptable ac voltage quality in the UPS application. Earlier designs use natural sampling pulse-width modulation (PWM), and need "carrier" frequencies in the 3-10 kHz range. Later versions use the now sophisticated programmed-waveform technology, achieving the same results with switching frequency reduced to the $780-$ $1500 \mathrm{~Hz}$ range. These converters are sometimes designed for parallel tie with the utility, and find no basic difficulty in so doing. They can, 
because they are self-commutated, be operated at any desired power factor. Because they are basically harmonic voltage sources, their harmonic current injection is basically dependent on the combinedinternal converter impedance and utility source impedance; harmonic voltage distortion basically depends on the ratio of utility impedance to internal converter impedance. Since most realizations operate with lower order harmonics eliminated, it is considered easier for them to meet stringent harmonic requirements at an ac interface than it is for the current-sourced converters.

At their dc terminals the current-sourced converters have no difficulty in accommodating any desired voltage range. However, they reflect reduced dc voltage by increasing their lagging quadrature current demand, transferring the problem to the ac interface. They are ripple voltage generators at their dc terminals, and the ripple current driven into the dc source is defined by the series combination of its impedance and that of the current sourcing (filter) inductor used with the converter. Designs are usually such that the inductor dominates; where the dc source impedance is high, a shunt capacitor is employed to guarantee inductor domination and further limit ripple current in the source.

The versions of the voltage-sourced converters using thyristors as switches have considerable difficulty in accommodating ranges of output $d c$ voltage much in excess of the $1: 1.4$ or so for which they are commonly designed. This is in a large part due to the characteristics of the ferroresonant transformers they use, but even if that impediment is removed the difficulty remains because of commutating circuit design criteria and behavior. Even transistor versions have some difficulty in meeting wide input dc voltage range requirements, translating them into economic and loss impact on the transistors, other components and isolating transformers.

Voltage-sourced converters are ripple current sources at their dc terminals and limiting ripple current in the dc source can be difficult if source impedance is low. A shunt capacitor is invariably used, and may be all that is needed if source impedance is known to be high. Howcver, if 
source impedance is low, an inductor will be needed between the source and capacitor, forming a low-pass filter.

Any converter can be designed to meet any performance specification - there are no real "performance limitations". The effects of Inherent converter characteristics are reflected in varying economic (and efficiency) impacts. Thus for the current-sourced line-commutated converters stringent dc interface requirements of low ripple current and wide voltage range have little impact, but stringent ac interface requirements regarding harmonic and power factor have very great impact. For the voltage-sourced selfcommutated convertors, the converse is true. Stringent ac interface requirements have little impact, dc interface requirements have much more impact. However, because dc filtering is inherently cheaper than ac filtering and power factor correction, the impact of stringent specifications at both interfaces is usually far less for the voltage-sourced converter than it is for the current-sourced versions.

\subsection{Efficlency Dala}

Little reliable efficiency data could be obtained for the currentsourced converters. Most figures supplied were obtained, it was found, using highly suspect measuring techniques which either denigrated the converters or exaggerated their virtues. It is, however relatively easy to conclude that at $\mathrm{dc}$ in the $200 \mathrm{~V}$ range the converter losses should be no more than $1-2 \%$, with a further $2-4 \%$ for the current sourcing inductor plus whatever losses are present in the isolation transformer, typically $4-5 \%$ or so at the $10 \mathrm{~kW}$ level. Thus the efficiency of a converter including isolation might be expected to be between $89 \%$ and $93 \%$; careless design could make it lower, judicious conservation methods might make it somewhat higher. These estimates do not, of course, include any additional losses associated with interface specifications and the design modifications needed to meet them. They pertain strictly to a basically operational converter, and since all the design modifications needed to meet ac interfacing requirements cause added losses, systems meeting specifications 
much beyond the inherent capabilities of the basic convertor will have lower efficiencies than those indicated above. Since most of the losses in a basic current-sourced converter are of the load loss varlety, rather than excitation loss, it generally maintains high efficiency to quite low percentage load if the load variation occurs as a current swing, but has a quite rapid fall in efficiency with declining load if the dc voltage falls while the current remains essentially constant.

A good deal of presumably reliable information was furnished on the full load efficiencies of the voltage-sourced converters presently being marketed. Transistor versions ranged from $80 \%$ to $90 \%$, the 1ower figures being more typical of PWM and the higher of programmed-waveform versions. Thyristurs and ferroresonant transformer efficiencies range from $73 \%$ to $83 \%$. The variation is presumably due to differences in commutating circuit losses, some of the older (or less intelligent) designs having particularly high commutating circuit losses, and perhaps in part to differences in transformer losses. Even with transistors as switches a converter using a ferroresonant transformer would have a lower efficiency than one without.

Although no information was supplied regarding part- and no load losses for these converters, these basic behaviors are well understood. Their full load loss generally contains a higher excitation loss contribution than does that of a current-sourced converter, and hence the fall-off in efficiency with load tends to be faster for voltage-sourced converters when current is reduced but somewhat slower when dc voltage is reduced. However, programmed waveform transistor inverters show a preponderance of load loss at full load, similar to that of the basic current-sourced converter, and thus tend to have loss versus load behavior much like a current-courced converter.

\subsection{Cost Data}

No company actually supplied data on manufacturing costs - all furnished selling prices. Since the latter are highly dependent on selling policies, which in turn depend on market conditions, it is difficult to 
translate one into the other with any degree of confidence - the same multipliers will not be used by all manufacturers, and the multiplier variation may be large, $\pm 30 \%$ or more, if the market is not one of strong competition between suppliers. Further, there is the fact that even in a highly competitive market, the multiplier used by a large company usually is substantially greater than that used by smaller competitors when production volumes are low to moderate.

For voltage-sourced self-commutated converters, the lowest selling prices were quoted for the old, well established technology of thyristor converters with ferroresonant transiormers, from $\$ 315 / \mathrm{kVA}$ at $10 \mathrm{kVA}$ rating to $\$ 437 / \mathrm{kVA}$ at $3 \mathrm{kVA}$ rating for the dc to ac conversion function (inverter). The highest prices, as might have been expected, were quoted for the new programmed-waveform converters using transistors, an approach which may be regarded as still developmental. These prices ranged from $\$ 1190 / \mathrm{kVA}$ at $10 \mathrm{kVA}$ to $\$ 1600 / \mathrm{kVA}$ at $3 \mathrm{kVA}$. All prices were for quantities of $1-10$ on equipments made in 10 's or 100's per year in most instances.

Current-sourced line-commutated converter prices are not strictly relevant, since such converters are not currently made to meet the existing interface requirements of this application. Windworks did not supply prices in their response to our solication, and the only other prices available are for dc drives, a rather specialized application area. In fact, most single phase input dc drives are non-regenerative, i.e. do not possess inversion capability, making their price structure even less relevant. Typically they are listed at about $\$ 300 / \mathrm{kW}$.

It might seem from the above that the thyristor-ferroresonant transformer technology has the best chance of meeting cost goals for solar photovoltaic power conditioning equipment. This would be a dangerous conclusion, for that technology is mature and very material intensive with little hope foi future cost reductions except those created by increasing volume. The transistor technology is currently both material and labor intensive because of very low volume and its developmental character. It would stand to benefit considerably from device cost reductions, technology 
improvements and volume induced cost reductions. Hence although present prices are 4-5 times those for the older technology, present costs are probably lower than these price ratios might indicate, and there is a good chance for the transistor programmed-wave technology to be significantly cheaper, ultimately, than the thyristor-ferroresonant transformer designs.

\subsection{Size and Weight Data}

It could be expected that inverters with ferroresonant transformers would be much heavier than those without. They are in fact heavier, but not by so much as might be expected because the weight of single phase low power conversion equipment tends to be markedly influenced by cabinet and supporting hardware weight. For example, an open frame $10 \mathrm{kVA}$ transistor inverter was quoted at $35 \# / \mathrm{kVA}$, while an enclosed version of the same type of unit weighted in at 52\#/kVA. Ferroresonant transformer designs are typically at 70 \#/kVA at $10 \mathrm{kVA}$ rating, fully encolsed. At $3 \mathrm{kVA}$ rating, transistor versions run 60"k/kVA, ferroresonant design about $112 \# / k V A$.

Values are highly dependent on packaging philosophy, and tend to vary widely. For lowest overall product line cost, many companies package all their single phase units in one cabinet, allowing much wasted space at the lowest powers. As a result, volumes for transistor equipment range from $\simeq 1$ to about $2.5 \mathrm{cu}$. $\mathrm{ft} / \mathrm{kVA}$, while those for ferroresonant transformer designs range from $\simeq 2.5$ to $6 \mathrm{cu}$. ft/kVA. Even at this latter figure, the volume occupied by a $10 \mathrm{kVA}$ unit would not be an embarassment in a residential installation, and a $10 \mathrm{kVA}$ transistor unit at the $1 \mathrm{cu}$. $\mathrm{ft} / \mathrm{kVA}$ would be almost invisible. 


\section{INTERFACE REQUIREMENTS}

\subsection{General Considerations}

In addressing ac and $d c$ interface requirements for residential solar photovoltaic installations, the study focused almost completely on the strictly technical issues. Institutional issues were not considered except when they became a dominant factor in determining a technical performance requirement. Safety issues, ever present in any electrical equipment specifications, were also largely left aside. However, the provisions of the National Electric Code were taken into account, and known unsafe practices were avoided. It should be recognized, nonetheless, that the various authorities concerned with the safety of such equipment and installations may ultimately impose requirements exceeding, and possibly conflicting with, those addressed in this study.

\section{2 the DC Interface.}

There are a wide variety of dc interface considerations which impinge on power conversion equipment design and specifications. The most important are now listed:

- absolute dc voltage level

- operating dc voltage rangeș, minimum to maximum ratio

- ripple current injection into the dc source

- grounding of the dc source

- fault protection and protective coordination

- voltage and current transient exposure and protection

- safety of operators and maintenance personnel

Some of these inevitably interact with ac interface considerations, being constrained by or imposing constrants on that interface as will become apparent. They are also not completely independent, some 
influencing others. Discussion will proceed in the order listed, which should not be construed as a ranking either of importance or in terms of associated difficulties.

Both the National Electric Code (Article 250-3) and Underwriters Laboratories regard voltages in excess of $300 \mathrm{~V}$ as "unsafe" in the residential environment. Hence the maximum dc voltages at the interface should be held below this level. Voltages below $50 \mathrm{~V}$ are regarded by all authorities as nonthreatening, and hence give designs and installations complete flexibility as to grounding and exposure of live parts. However, the impact on converter efficiency and cost would be substantial if a $50 \mathrm{~V}$ upper limit were imposed, and we do not believe it to be feasible. Converter costs increase, and efficiencies decrease quite markedly as the dc voltage is reduced below 150-200 V. It therefore seems that a choice which places the "nominal" voltage at or above $200 \mathrm{~V}$ but keeps the maximum below $300 \mathrm{~V}$ is indicated. Such a choice also permits direct, transformerless, ac connection for most converter technologies, if ac interface considerations will permit.

The operating range impacts converter cost and efficiency, generally the latter much more than the former. Almost all the dc sources considered for dispersed generation and storage have quite wide voltage ranges, and therefore call for a wide range converter. Solar arrays arc no exception; their-vnltage varies with insolation temperature and loading. Previous work ${ }^{1}$ has established that the range of peak power point voltages is about 1.5 to 1 , with the no load to peak power point ratio being about 1.25 to 1 . However, only power outputs < $4 \%$ of maximum are lost if the peak power point range is reduced to 1.33 to 1 , giving a total range of 1.67 to 1 . This range is compatible with most projected battery, fuel cell and wind generator sources. Unless significant economic benefits could be obtained for solar photovoltaic applications by further constriction, the loss of equipment versatility caused by designing to a narrower range would be disadvantageous. Although some converter technolngies might benefit from a narrower range, we believe that those most $1_{\text {Final Report, "Conceptual Design and System Analysis of Photovoltaic }}$ Power Systems", Westinghouse for ERDA, March, 1977 (Contract E(11-1)2744). 
likely to succeed in the application will not benefit sufficiently to offset the consequent reduction in array utilization in the solar application and general loss of equipment applicabllity to other sources. We recommend a design range of $1.5-1.7$ to 1 .

The level of source ripple current specified can have serious effects on converter costs, but generally has less effect on converter efficiencies. Most sources other than photovoltaic arrays can tolerate quite large ripple current levels, certainly up to $10 \%$ peak without problems and those which cannot (mainly dc generators) generally act themselves, because of high reactive impedance, to make it easy to constrain ripple current to lower levels. The key question with a photovoltaic array is "to what extent does ripple current affect array power output?". Figure 4.1 shows a typical power versus current curve for an array. It is easily seen that substantial ripple about the peak power point could appreciably reduce average power output, but an investigation and analysis of this phenomenon produced the curves of Figure 4.2. Based on the admittedly highly unlikely assumption of sinusoidal current ripple in the array these show that if the average dc current is slightly reduced below that at the peak power point, the power "loss" is almost negligible $(<0.5 \%)$ for ripple up to $5 \%$ peak. Control is not complicated - it is merely necessary to control for maximum average power with the ripple present. Moreover, consideration of the nonlinearity of the array impedance and the resulting asymetry likely in actual injected ripple current leads to the conclusion that power lost in an actual situation would be even less than that indicated by Figure 4.2. Hence we conclude that $5 \%$ peak ripple is certainly tolerable, and $10 \%$ peak based on the assumption of a fixed array impedance may well be. While $5 \%$ peak is more stringent than generally thought necessary for batteries and fuel cells, it does not impact convertor cost by more than a few percent and impacts efficiency hardly at all. We recommend a specification no tighter than $5 \%$ peak based on the lowest peak power point impedance of the array. 


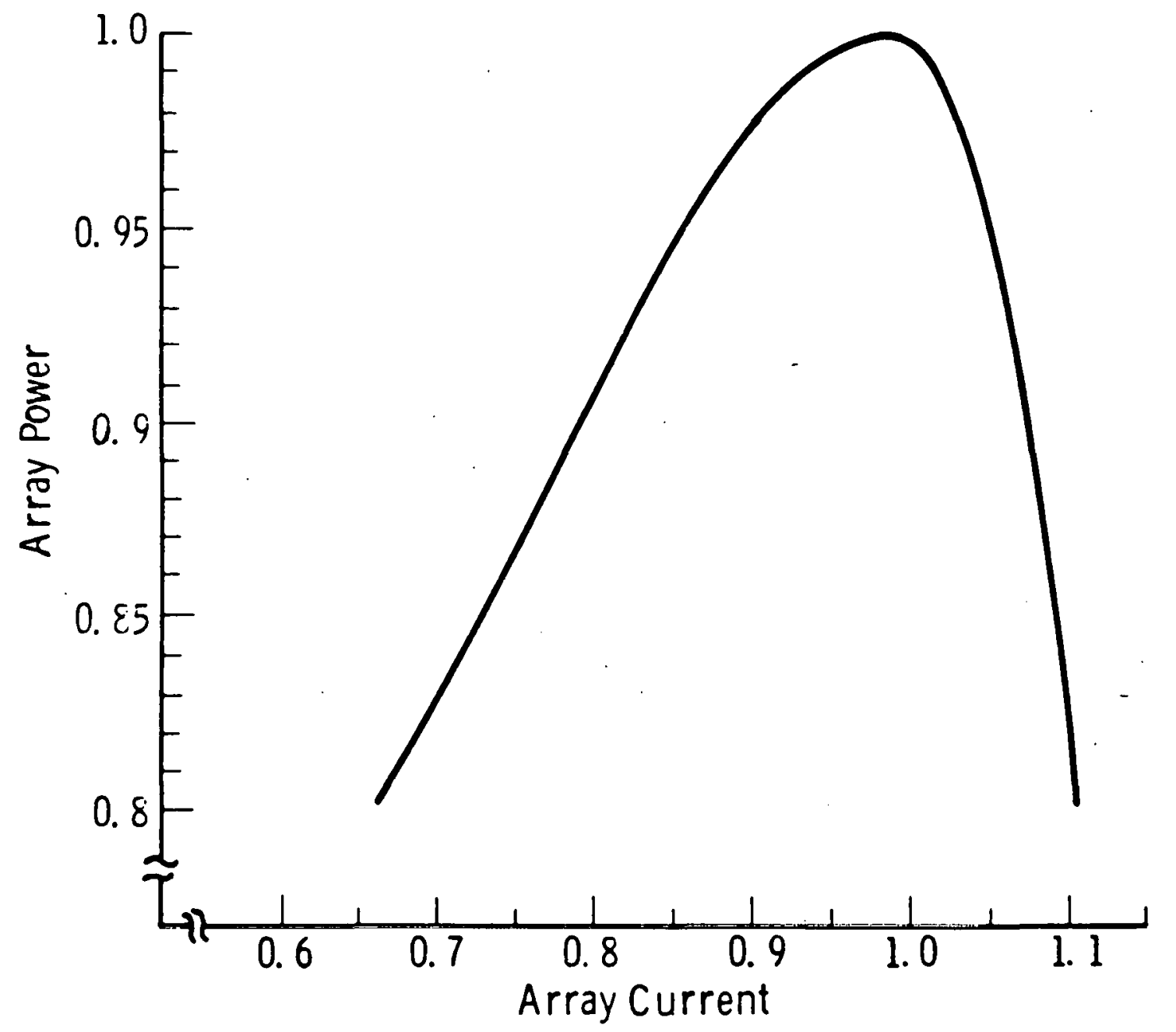

Fig. 4-1-Typical power vs current characteristics of solar cell array

23 


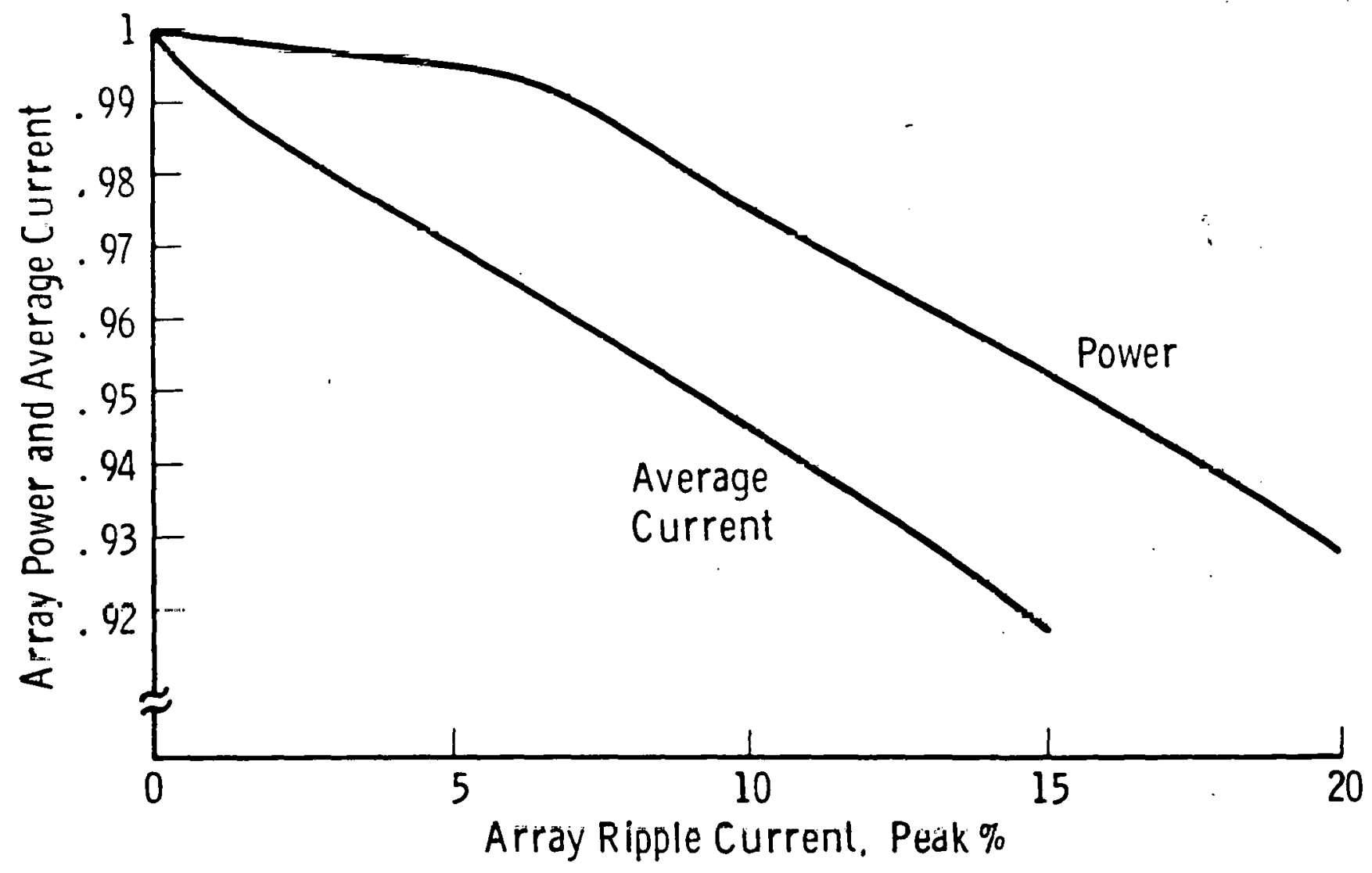

Fig. 4-2-Effects of sinusodal ripple on array power 
Both NEC and UI require that a source with voltage $>50 \mathrm{~V}$ must be grounded, although both admit the possibility that a "virtual ground" may be acceptable. If the conversion equipment contains an isolation transformer then the dc source can be grounded at any point desired without problems. If no firm ground is attached, a virtual ground will occur at or close to the midpoint of the array; however, this is a virtual dc ground only, and may undergo considerable (up to peak convertor ac voltage) common mode ac excursions with respect to true earth ground. The same is true if no isolation is used with a bridge configuration convertor. Only if a nonisolated midpoint convertor is used does the $\mathrm{dc}$ source become grounded by the ac system ground. We do not believe this configuration to be viable, for two reasons. First we believe the use it makes of the distribution (pole top) transformer is unacceptable, beyond the design capabilities of that component. A midpoint converter requires a transformer secondary winding kVA rating at least $\sqrt{2}$ times the converter power throughput; hence each $10 \mathrm{~kW}$ of converter would require $\simeq 14$ kVA pole-top transformer rating, and penetration would be limited by this fact. Also, since the midpoint converter causes harmonic and dc currents to flow in its transformer windings even if the combined wave is purely sinusoidal, the distribution transformer would be subjected to dc and harmonic winding currents that it is not designed to accommodate. Second, we do not believe that dc source ground via the ac system ground, 1.e., by means of the interconnection between array and conversion equipment, will be acceptable.

We recommend, therefore, for this and other reasons that full isolation be employed in the convertor and that the array be furnished with its own earth ground, on one terminal (probably the negative is most convenient from the impact of array construction and isolation) quite Independently of the connection to the conversion equipment. We recognize that NEC and UL requirements will force the case of the conversion equipment to be connected to the ac system ground inside the residence. This raises the possibility of potential in excess of $50 \mathrm{~V}$ dc developing on the case and ac ground in the event of a ground fault, hot lead to case, at the dc cable entry to the equipment if there is sufficient ground path 
resistance between array and ac system ground points. It is difficult to avoid this without creating a ground loop, and it seems that some form of dc ground fault interrupter is needed in the system.

Dc side fault protection on most conversion equipment is accomplished with fuses because of the expense and short life of dc interrupting electromechanical switchgear. For battery, fuel cell and wind-generator sources this philosophy is quite adequate, since fuses can easily be cleared by those sources. Solar photovoltaic arrays, however, have very limited short circuit current capability, typically only $15-20 \%$ above maximum peak power point current and well below that at lower insolations. It therefore becomes impossible to use fuses as the fault protection for strictly dc side faults. Even fault detection is made difficult because of the limited and variable short circuit current available, which will often be lower than maximum design operating current. There is, however, a saving factor. All except high resistance dc faults, for which there is no plausible detection/protection scheme (just as with high impedance ac faults), result in drastic reduction of power to the converter. Most will result in more than this - they result in a fault reflected to the ac system. In the latter event the ac protective devices will clear; they can be made to trigger the dc fault protective devices. In the event no ac fault is engendered the reduction in converter power, particularly dc voltage level, can be used to trigger the dc fault protection.

The question of detection settled, there remains the question of a protective device. Even a dc load break contactor, which is all that is really required, is an expensive and short lived device. A dc breaker would be even more expensive and have an even shorter life than that of the contactor. Triggerable fuses might be considered, but would need development and are of uncertain cost. We believe that an acceptable solution can be provided by a contactor, load make rated, shorting the dc source and thereby providing deliberate maintenance of the fault in a controlled manner until repair action is taken. There can be no doubt 
that it is the most economically implementable solution, triggerable fuses possibly excepted in the long term. It remains to be seen whether it will satisfy the authorities.

Voltage transient exposure of the dc interface could occur from either of two sources - ac system borne transients transferred by the conversion equipment or transients directly induced in the dc source or wiring by lightning or other large scale phenomena (large ac system faults. for example). With any conversion equipment technology the former should pose no problem. Quite apart from any transient voltage limiting at the ac interface, and there will always be some, the converter will always contain substantial shunt capacitance in the dc interface for source ripple current limitation. There will also always be an appreciable inductive reactance, transformer leakage if nothing more, between that capacitance and the source of the ac system borne transient. Hence the transient will suffer great attenuation at the capacitance terminals. Moreover, the capacitance will be the system component most susceptible to transient voltage damage. It follows that the converter design inherently protects the dc source and wiring from ac system borne transient, in the last resort by having excessively large ones destroy interfacing capacitance.

It is safe to say that it is very unlikely that the array, the dc wiring or the conversion equipment will survive a direct hit from lightning, and that no electrical protection can be provided which will safely absorb the energy involved in such an event. Induced surges due to nearby strokes are another consideration. The interface capacitance will again protect, in the last resort at the price of its own integrity, the conversion equipment and the wiring close thereto. It may not, and probably will not, protect the array and array connections. For that, suitable dc surge protection is required at the array terminals and possibly within the array. We do not consider this to be part of the conversion equipment, and consequently do not see a need for dc interface transient voltage protection in the conversion equipment provided the capacitors are properly selected. 
The safety of operators and maintenance personnel is not strictly a technical issue. However, there is one obvious requirement that impinges on conversion equipment design. It must be possible for anyone intending to do any repair or maintenance work on the array or the dc wiring to be certain that he cannot be exposed to shock hazard from either the ac system or the array. Also, anyone performing repair or maintenance work on the conversion equipment must have the same assurance.

Insofar as the array is concerned, the avoidance threat from array voltages to someone working on the array and its wiring must be the responsibility of the array designer - it is not possible for the conversion equipment to effect the necessary warranty, although the short circuiting switch proposed for fault protection will go some way toward meeting renuirements. For protection from ac system hazards, and to personnel working on the conversion equipment, both $\mathrm{ac}$ and $\mathrm{dc}$ disconnecting devices are required. We believe that present codes and practices require these $\therefore . . . \quad \therefore$ ible to the individual involved and to be not only operable by $\therefore \therefore . . \quad \therefore . u$ to be lockable by him so that other people cannot inadvertently ..: . . . te the hazard. This requirement rules out the use of disconnects within the converter. We recommend a dc disconnect outside the residence, lockable in the open position, and a "twist lock" plug connection for the dc cabling at the converter cabinet.

\subsection{The AC Interface}

As for the dc interface, there are a number of not entirely independent considerations surrounding ac interface design and specification. The most important are

- absolute voltage and operating voltage range

- operating power factor

- permissible harmonic distortion

- fault protection and protective coordination

- grounding

- transient voltage exposure and protection

- safety of operators and maintenance personnel 


\subsubsection{Voltage}

The voltage and voltage range are dictated by residential service standards, specifically ANSI C84.1. The voltage ranges for residential service are shown in Figure 4.3. The official definitions of the ranges shown are given in the excerpt from the standard presented as Figure 4.4 .

\subsubsection{Power Factor}

The permissible operating power factor is subject to both technical and institutional constraints. The primary technical constraint is voltage droop created by lagging quadrature current (or, less likely, voltage rise created by leading quadrature current) in the primarily reactive ac source impedance. A secondary technical constraint arises because of the increased conductor and transformer winding heating that may occur because of the quadrature current's presence. The situation is somewhat exacerbated as to both phenomena because utilities generally predicate an average load power factor very near unity (>.95) when designing residential distribution systems. They also rely on load diversity in sizing power service equipment so that its rating is typically only about $70-80 \%$ of the aggregate of customer load.

According to one reliable source. (the Westinghouse Transmission and Distribution Reference Book) the regulation at a consumer's Bervice tie may be about $10 \%$, of which $0.5 \%$ is in his tie, $3 \%$ in the secondary circuit, $2.5 \%$ in the distribution transformer, $2 \%$ in the primary feeder and $2 \%$ at the substation transformer. Although the $X / R$ varies for the various contribution, it is typically high enough overall to regard the source impedance as purely reactive for first order droop calculations. Thus if 0.95 power factor is assumed, and 0.8 per unit $\mathrm{kW}$ loading, the impedance is nearly $12 \%$ on service capacity base. At an average service capacity of $200 \mathrm{~A}$, or $46 \mathrm{kVA}$, for new construction, a $10 \mathrm{~kW}$ generator running at 0.8 power factor will cause an in phase voltage droop (or rise) of $\simeq 2 \%$ in addition to any load created droop. Running at 0.6 power factor 


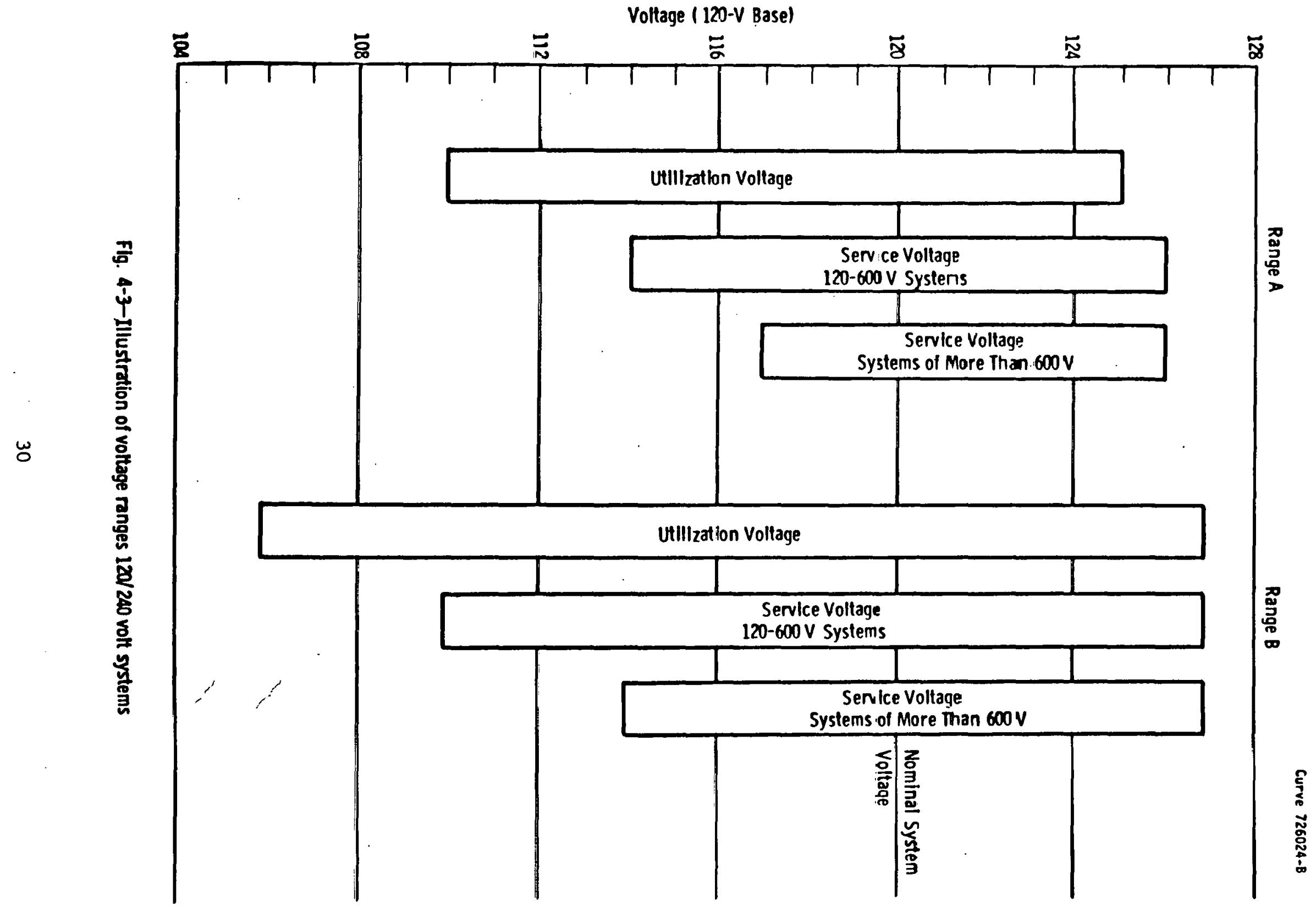




\subsection{Application of Voltage Ranges}

2.4.1 Range A - Service Voltage. Electric supply systems shall be so designed and operated that most service voltages will be within the limits specified for Range $A$. The occurrence of service voltage outside of these limits should'be infrequent.

2.4.2 Range A - Utilization Voltage. User systems shall be so designed and operated that with service voltages within Range A limits, most utilization voltages will be within the limits specified for this range.

Utilization equipment shall be designed and rated to give fully satisfactory performance throughout this range.

2.4.3 Range B - Service and Utilization Voltages. Range $B$ includes voltages above and below Range $A$ limits that necessarily result from practical design and operating conditions are a part of practical operations, they shall be limited in extent, frequency, and duration. When they occur, corrective measures shali be undertaken within a reasonable time to improve voltages to meet Range A requirements.

Insofar as practicable, utilization equipment shall be designed to give acceptable performance in the extremes of this range of utilization voltages, although not necessarily as good performance as in Range A.

It must be recognized that because of conditions beyond the control of the supplier or user, or both, there will be infrequent and limited periods when sustained voltages outside of Range B 11m1ts w111 occur. Utilization equipment may not operate satisfactorily under these conditions, and protective devices may operate to protect the equipment. When voltages occur outside the limits of Range $B$, prompt corrective action is recomended. The urgency for such action will depend upon many factors, such as location and nature of load or circuits involved, and magnitude and duration of the deviation beyond Range B limits.

Figure 4.4 Excerpt from ANST Standard C.84.1 
it will create $\simeq 31 / 2 \%$ additional in phase droop, at 0.5 power factor $\simeq 5 \%$. The tolerance of the system for additional droop is highly location dependent, of course, but if we assume $.8 \mathrm{pu}$ load $(36.8 \mathrm{kVA})$ at .95 power factor we have a normal droop of $10 \%$, of course. With $10 \mathrm{~kW}$ generation at the above power factors we develop the following table:

$\begin{array}{cc}\text { Convertor PF } & \text { Total Druup } \\ U .8 & 10.8 \% \\ 0.6 & 11.6 \% \\ 0.5 & 12.6 \%\end{array}$

For lower service capacity, the situation gets progressfvely worse since the generator represents an increasing fraction of system capacity. At 100 ampere service, the figures became:

$\begin{array}{cc}\text { Convertor PF } & \text { Tota1 Droop } \\ 0.8 & 11.8 \% \\ 0.6 & 13.8 \% \\ 0.5 & 16.5 \%\end{array}$

Fiun Llidia figures, it can br drdured that convertor power factors worse than 0.8 are unlikely to be technically tolerable, and that better power factor stipulations may be necessary in certain locations. If this conclusion is drawn, it eliminates any concern regarding excessive heating, but brings into play the institutional concern.

As previously stated, most utilities predicate (not without the justification of experience) quite high power factors for residential loads. The costs they bear in supplying the VAR's necessary to sustain the loads are factored into their rate structures, and do not appear anywhere else in the accounting system (nor do they monitor the residential VAR demand, individually or collectively except implicitly through network voltage control). Now if a customer reduces his real power demand but increases his VAR demand, the utility will not recover costs under present rate schedules. Even if his generator operates at unity power factor, the 
reduction of real power demand together with maintenance of any load created VAR demand penalizes the utility as to costs incurred versus revenue recovered. The only logical conclusion is that either:

(a) rate structures must be adapted specifically for customers with cogeneration

or

(b) the customer's generation must provide VAR as well as real power, so as to overhaul the average VAR demand of the load fraction it is capable of serving. In effect, this means that whenever operating it should create a unity power factor utility tie until load demand exceeds local generation capacity.

It is not clear to us that (a) above is economically or politically feasible, and therefore we have recommended the approach outlined in (b). This is, however, an institutional rather than a technical issue The impact on power conversion equipment is highly technology dependent. Voltage-sourced converters are virtually unaffected, preferring to run at unity power factor but able to generate VARs with little penalty. Current-sourced technology suffers far more, and were it the final selection the power factor issue would become one of considerable moment, to be resolved elsewhere.

\subsubsection{Harmonics}

The issue of harmonic injection is a technical concern of great importance. The concern is for the effects of harmonic distortion on utility equipment and the direct and indirect effects of harmonics on consumer's connected loads, those of the consumers with cogeneration and even more importantly, those of other consumers. The obvious criterion is that there should be no significant degradation of service or reduction of connected equipment life resulting from harmonic injection by the conversion equipment. The rub is that there is at present inadequate data (in fact almost no data) on which to base harmonic distortion levels which will satisfy this criterion. 
Measurements on distribution and transmission networks are alleged to show very wide variations in harmonic levels already existing In utility systems. However, a closer examination of available data reveals that except for some specific locations close to heavy concentrations of industrial converter loading, existing harmonic levels, under which present service standards and equipment life have been established, are very low. They are typified by the measurements illustrated hy figures 4-5 and 4-6 and are seen to be largely the result of transformer and machine magnetizing current contributions.

While 1ittle work has been done in the USA to determine tolerable harmonic levels much has been done in Western Europe and the Soviet Union. In fact, several European countries have had individual standards or recommended practices in place for some time; these have now been coalesced into a common CENELEC standard for most of western Europe, which is shown in Figure 4-7. United Kingdom recommendations existing prior to the CENELEC standards, and thought to be still applicable there in addition to the CENELEC standards, are shown along with the USSR standards in Figure 4-8. Some explanation and comments are called for. The CENELEC harmonic voltage standards refer to the distortion created by one converter or appliance connected to the standard impedance supply cited. The rather high value and low $X / R^{-}$of that impedance reflects European, particularly West Germany, practice of three-phase residential distributions with long radial secondary networks, large distribution transformers and no secondary networking or transformer banking. It also reflects the low service capacicy, compared to cypical US residential distributions, of European systems. The harmonic limits take into consideration the effects of multiple converters or appliances, but allow a substantlal diversity factor.

The UK recommendations are interesting from two aspects. First they call for harmonic current limitation and in so doing account for multiple converters without any diversity factor. Second, the voltage limit is quoted as arithmetic sum, not total rms. - We do not know the rationale for this clearly more stringent approach, and do not favor it. 
Sum of Harmonics ( 2 through 32) as a \% of the Fundamental

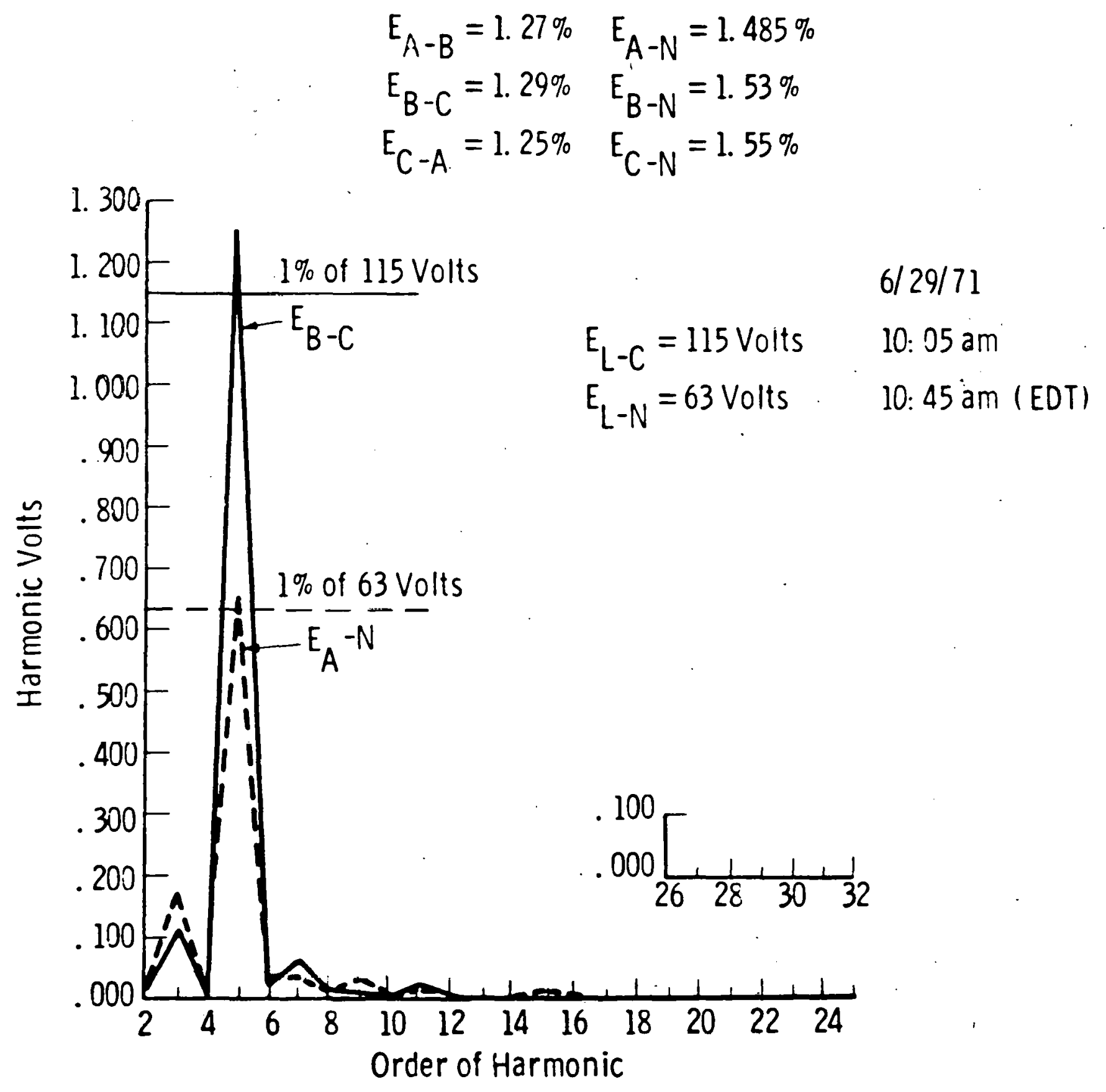

Fig. 4-5-Existing harmonics on distribution system 
Sum of Harmonic Voltages ( 2 through 32) as a $\%$ of the Fundamental

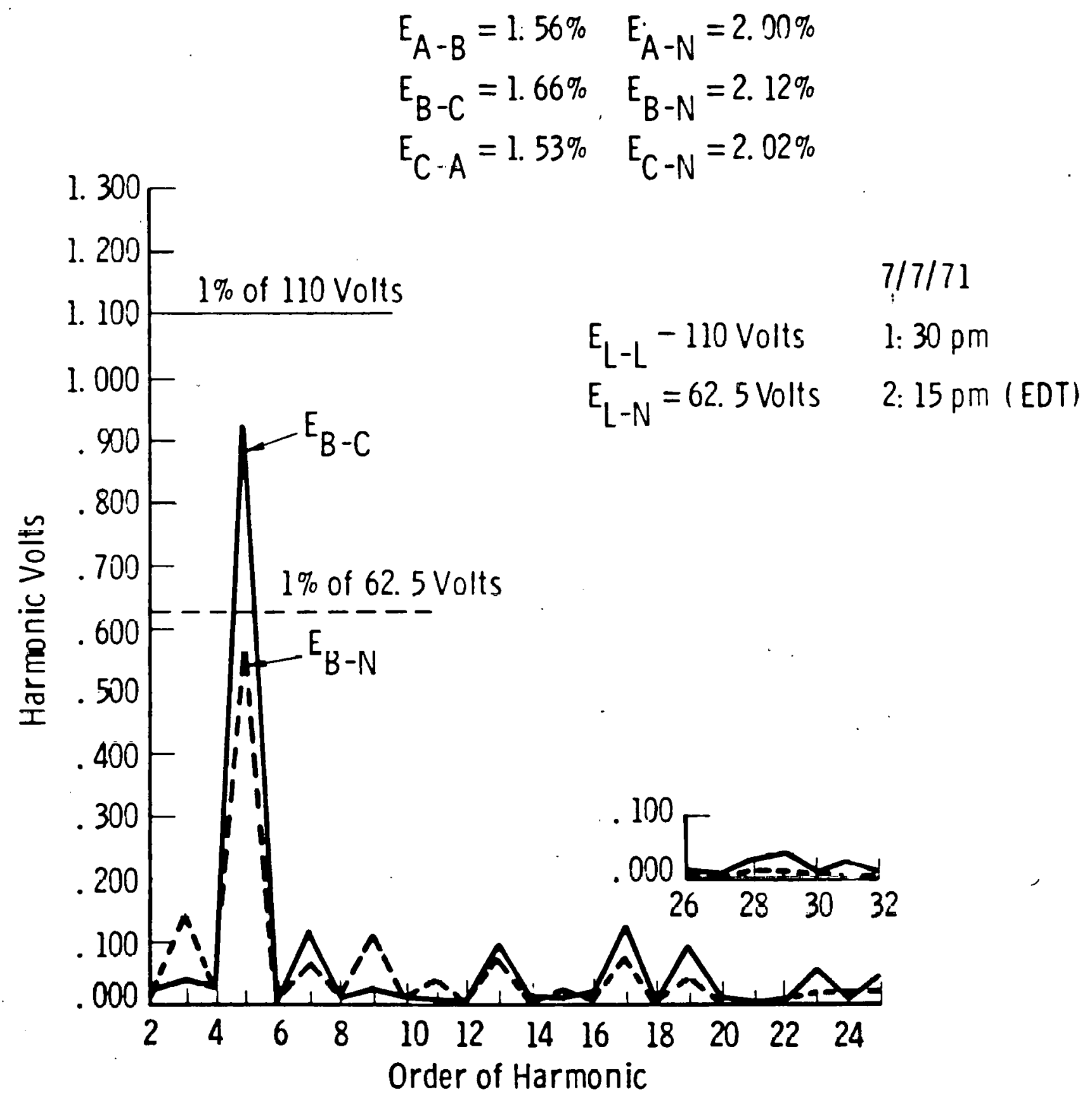

Fig. 4-6-Existing harmonics on distribution system 
Voltages $220 / 380 \mathrm{~V}$ Residential and light commercial 240/415 V distributions

HARMONIC ORDER

HARMONIC VOLTAGE LIMIT

3

$0.85 \%$

5

$0.65 \%$

7

$0.60 \%$

9

$0.40 \%$

11

$0.40 \%$

13

- -

$0.30 \%$

15 through 39 , odd

$0.25 \%$

2 through 40 , even

$0.20 \%$

No TIF requirement; standard supply impedance specified as $0.4+\mathrm{J} 0.25 \mathrm{~N}$ ohms for phase neutral, $0.24+\mathrm{J} 0.15 \mathrm{~N}$ ohms phase.

Figure 4-7 Cenelec Harmonic Standards

Voltages: All distributions up to $132 \mathrm{kV}$

Harmonics to be 1imited: Orders 2 to 25

Harmonic voltage limit: $2.5 \%$ arithmetic sum

Harmonic current limits: $100 / \mathrm{N}$ amps if short circuit current exceeds 6700 amps; $.015 \mathrm{I}_{s c} / \mathrm{N}$ amps if $I_{s c}$ is less than 6700 amps.

\section{USSR standards}

Vultages: All supplying consumers

Harmonics to be limited: Orders 2 to -

Harmonic voltage limit: $5 \%$ rms thd

Figure 4-8 United Kingdom Electrlc1ty Cuuncil

(Comprehensive Supply Industry Recommendation G5/3) 
Since it is in fact harmonic current that creates problems, we do favor a harmonic current limit specification for solar photovoltaic installations. It is harmonic current that causes joule heating effects, spurious torque in machines and that induces EMI in communication and data processing equipment. The UK limits for individual harmonics seem reasonable, and the implied total rms for a converter producing monotonically declining odd current harmonics is $.725 \%$ of the short circuit current. For a converter producing monotonically declining odd voltage harmonics and working into an inductive tie impedance the implied total rns current distortion is $0.34 \%$ of the short circuit current. These percentages are computed simply by taking the root of the sum of the squares of the permitted (UK specifications) individual component percentages over a sufficient number of times that the per term change in the sum occur beyond the sixth significant figure. The resulting total rms distortion limit that can be derived for a converter obviously depends on converter rating relative to $\mathrm{I}_{s \mathrm{C}}$. In the US, typical short circuit capacities per residence (the individual residence's share of a common short circuit current, not the short circuit current available into an isolated fault in that one residence) may range from 800 to 2000 amperes rms symmetrical. The current rating for a $10 \mathrm{~kW}$ generator running at (say) 0.9 leading or lagging power factor is 48.3 amps rms, giving $I_{s c} / I_{c o n} \simeq 16.6$ to 41.4 and the implied total rms current distortion, relative to converter current, could range from $5.6 \%$ to $30 \%$ for a $10 \mathrm{~kW}$ converter.

However, the efferts on loads, particularly contiguous consumer connected loads, will probably not allow total distortions beyond the lower end of this range; this can be deduced if the harmonic voltage developed in the source impedance is considered, for its magnitude implies that a considerable portion of the harmonic currents would flow in local connected loads. Based on this rationale, we are recommending a total rms current distortion specification of $5 \%$, but with individual components limited in accordance with the UK recommendations to avoid concentration of the distortion in one specific higher order harmonic. This specification is admittedly open to question; it should serve as a reasonable basis for convertor technology comparisons, being neither so 
lax as to give rise to the anticipation of serious problems nor so stringent as to influence converter economics and efficiencies unduly.

Factory measurement for compliance should be made to a "short circuit" - an infinite bus. This will insure that the specification is met or bettered in installation unless a local resonance.is encountered at some harmonic; this is a special case which has to be treated as a site specific aberration. The infinite bus can be successfully approximated by an ac supply with a capacity very much larger ( 210 times) than the converter rating, and avoids the necessity for defining an arguahle "standard residential source impedance."

\subsubsection{Fault Protection}

Fault clearing in ac systems is easier than in dc circuits, but caution is in order when converters are involved. Fault behavior 1s dependent on converter type - voltage- or current-sourced and has some dependence on converter topology. Two basic types of faults must be considered - an ac system disturbance and an internal converter fault. There is also the matter of reflection of dc source, wiring and component faults as faults to the ac system.

The last named is easily accomnodated, provided the converter includes isolation. Any fault so reflected will be easily cleared by normal ac protective devices, fuses or breakers, and since converter components are far more sensitive to fault current damage than utility network components, the coordination problem is internal to the converter. Its protective device(s) must clear in time to prevent internal device or component damage, and in sn ding will easily beat any of the normal utility protective devicès.

Internal converter faults present a similar picture. However, if isolation is not employed then both types of faults so far discussed can impose fault current with a pronounced dc component at the converter ar. terminals. Such currents cannot be cleared by normal ac clearing devices; but can :be with the special high-speed current-limiting fuses used for semiconductor device protection. It is unlikely that any utility 
component or connected load will be affected by the very short duration fault current which ensues in such a case. There is, of course, no difficulty in clearing conventional breakers or fuses, or the high-speed fuses, when the utility system is the fault current supply.

Greater difficulties are met when considering protection of the converter in the event of a faulted ac network. It is in these cases that the behavior of line- and self-commutated converters differs radically, as will now be discussed. In both types of converter the basic effect of serious ac supply disturbance or fault is to engender a commutation fault. In a current-source line-commutated converter a commutation fault will inevitably develop, with the fault current produced by the dc source current flowing into the faulted ac system. If isolation is not used in the converter, this dc fault current presents a substantial problem to the converter's ac fault clearing devices, particularly if the dc source is a solar array with its limited short circuit current capability. Isolation removes this problem, since although, the fault current may not reverse at the isolation transformer secondary (as viewed from the converter - the winding connected to the utility), it will most certainly go to zero without being forced by a fault interrupting device's arc. The problem of dc interruption then falls on the dc protective device(s), where it belongs, and that has already been discussed.

In a voltage-sourced self-commutated converter it is usual to avoid commutation faults by operating in an ac current-1imiting mode when ac supply faults occur. This is because a commutation fault in a voltage-sourced converter is a catastrophic dc fault. Even with a limited capacity dc source, the dc interfacing capacitance will supply sufficient short term fault energy to destroy the converter's semiconductor switches. When these are thyristors, high-speed currentlimiting fuses may be used to clear the dc fault without danger to the devices; when transistors are used, this is not generally the case. Even with thyristors, the incidence of ac disturbances capable of causing 
commutation faults is sufficient to make the fuse replacement an expensive embarrassment.

In consequence, controls for voltage-sourced converters almost. invariably employ current limiting techniques. The limiting is generally accomplished by allowing the convertor to generate a square wave at a frequency much higher than $60 \mathrm{~Hz}$ (its "carrier" frequency, in all probability, if it is a programmed waveform converter) and relying on the primarily inductive impedance seen by the convertor to limit the the current resulting. By doing this it is usually possible to maintain converter operation indefinitely into short circuited ac terminals, but in the present application this course would be most undesirable. Normal ac network protective devices are not designed to interrupt high frequency currents, even of limited amplitude, and preferably should not be subjected to such currents while clearing. Fortunately, a self-commutated converter can also turn off altogether. Thus for these applications it should first current-limit in case the ac disturbance is merely a short duration transient, but should cease to operate at all after a very short time period, perhaps 1-2 cycles at $60 \mathrm{~Hz}$, of current limiting operation.

Summarizing, we see in particular a need for coordinating converter ac fault protection with existing devices in the residence and the utility network. To protect the converter's internal parts, converter ac clearing or other protective action has to be much faster than normal ac protective devices. For current-sourced line-commutated converters we recommend high-speed current-limiting fuses with a conventional breaker as back-up protection. For voltage-sourced self-commutated convertors we recommend appropriate control action with a breaker as back-up. In both cases the breaker is not intended to protect the converter from damage, but will prevent "burn down" in the system in the event other devices fail to clear. In all cases we recommend an isolation transformer in the converter so that ac protective devices cannot be exposed to a converter produced fault current with dc content. 


\subsubsection{Grounding}

At the ac connection ground is established by the residential distribution. If the converter's connection is two wire, to the phase terminals of the consumer's tie, a virtual ground results (at the center point on the transformer winding, or at approximately the mid-point of the dc source if no isclation transformer is used). A three wire connection will establish a hard ground connection. If no 1solation is used, it will also create a ground loop if the array has to be furnished its own separate earth connection.

Consequently, we recommend that the only direct connection from ac system ground to the conversion equipment be to the converter case, that full isolation be used in the converter and that the connection be two wire to the consumer's phase terminals.

\subsubsection{Transient Voltage}

The ac connection is subject to considerable transient voltage exposure, mostly due to lightning induced surges. As for the dc terminals, no protective device will enable equipment or wiring to survive a direct hit. For less severe conditions, behavior is highly dependent on the converter technology.

A current-sourced converter exposes its semiconductor switches (thyristors for the line-commutated case) to the full impact of ac line borne transient voltages, and passes those voltages directly to its dc terminals so as to impose them also on its current-sourcing inductor. A voltage-sourced converter, on the other hand, has device voltage stresses determined strictly by its dc voltage source (usually its input capacitor). Hence, line borne transient voltages appear on a voltage-sourced converter's switching devices only to the extent of the ratio of dc loop inductance to ac source inductance. This ratio is very small, especially when an isolating transformer is used, and so the transient voltage transfer to the devices and the dc terminals is very small for a voltagesourced converter. However, because of the unidirectional voltage 
blocking, bidirectional current carrying capabilities of the switching devices in a voltage-sourced converter, incoming ac line borne voltage transients are converted into current transient stresses on the switches and the dc source (capacitor). The magnitudes of these transient currents depend on the magnitudes and durations of the voltage transients and the value of the ac source inductance.

Figure 4.9 shows the median exposure of residential circuits to voltage surges. The wiring breakdown limit is typically 6-8 kV, from 30-100 year incidence level. There is a spark gap built into the watthour meter which limits surge voltages within the residence to $2-3 \mathrm{kV}$ ) for lower current surges (3-5 kA). It seems clear that conversion equipment should be designed to withstand the same surge levels as the wiring if dispersed generation is to be of acceptable reliability.

For current-sourced converters, this can only be done by applying suitable surge limiting devices, selenium, zinc oxide or silicon carbide-spark gap, at the converter side of the isolation transformer and using thyristors with voltage ratings higher than the peak discharge voltage of the surge limiting device used. Voltage surge limiting devices cannot be economically applied to the utility side of the converter transformer because of the high surge energy levels which can exist there and because coordination with existing utility installed devices would be needed. The current sourcing inductor must also be designed to withstand that peak discharge voltage.

A typical surge waveform is the classic " $1 / 2 \times 40 "$ wave ( 1 1/2 us rise time, 40 us decay time to $50 \%$ of peak value) on transmission and distribution lines. At the lower system levels transients terid to become "stretched" because of the cumulative effects of reactances, series inductive and shunt capacitive, In the system, so that an " $8 \times 20 "$. wave is more representative.

However, this stretched wave has a rather high source 1mpedance, the characteristic impedance of the conglomerate transmission and distribution 


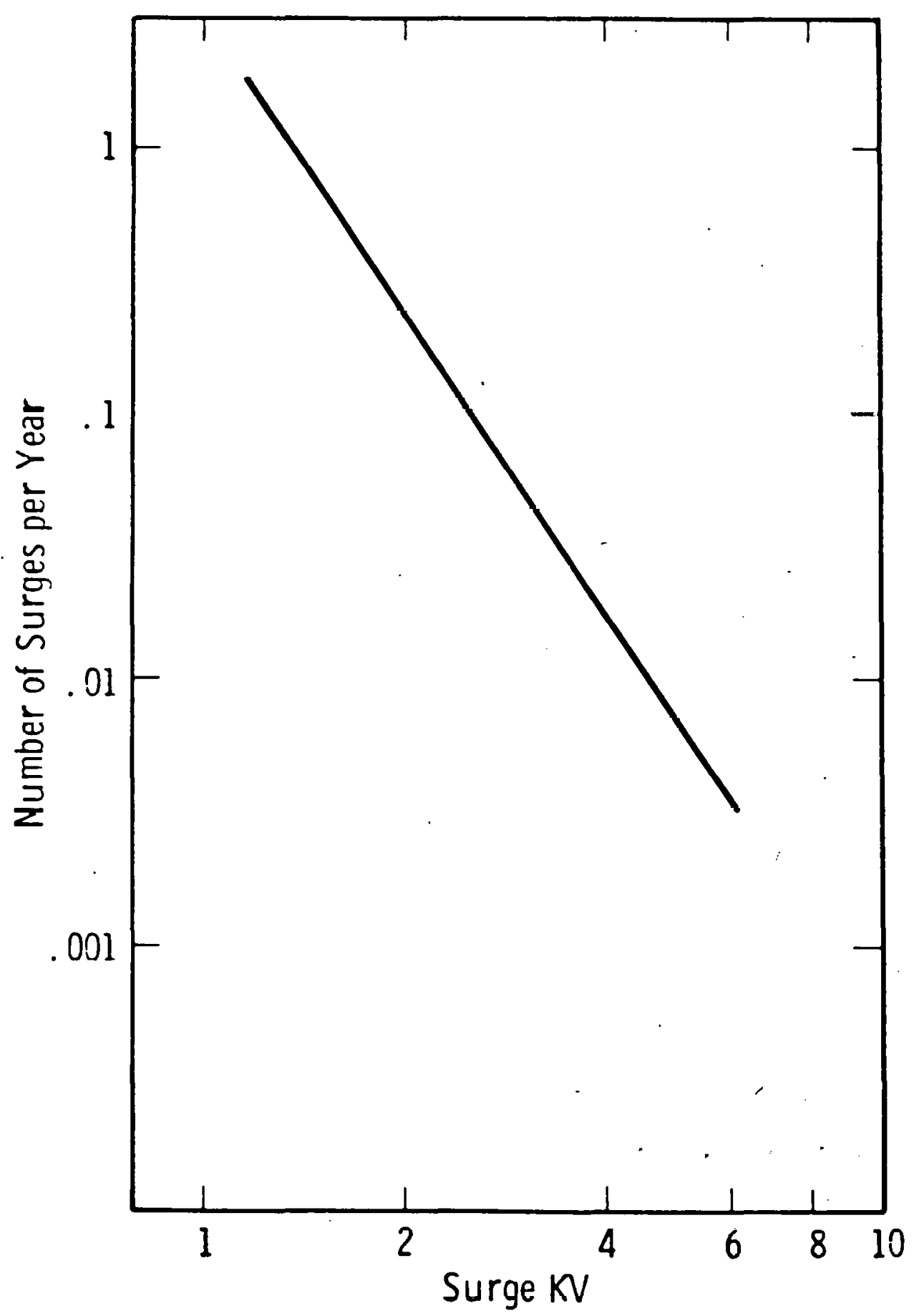

Fig, 4-9-Median exposure of residential circuits to voltage surges - from NEMA draft standard IEC-P587.1/D1, 
system delivering it, and hence calculations on peak current and transient energy are best done using the " $11 / 2 \times 40 "$ format and the 1mpedance of the connected equipment. For a $240 \mathrm{~V}, 10 \mathrm{kVA}$ transformer with $4 \% 1$ leakage the resultant peak current is close to $600 \mathrm{~A}$ with a peak transient energy in a $600 \mathrm{~V}$ clamp of about 115 joules when the peak surge voltage is 10 $\mathrm{kV}$. Designing for a $6 \mathrm{kV}$ peak surge voltage reduces the current to about 450 amps peak, the energy to about 90 joules; then increasing transformer leakage to $6 \%$ reduces peak current to 300 amps but does not further reduce the energy absorption required.

These numbers indicate that the problem is not trivial, although it is manageable. For the voltage-sourced converter, an impedance higher than even $6 \%$ transformer leakage is highly desirable; fortunately, it will normally be present because of harmonic filtering; a total of 20 to $30 \%$ impedance can be anticipated, resulting in peak transient currents of 60-100 amperes, not significantly greater than usual operating currents. The energy absorption will take place at a lower voltage, the converter's dc terminal voltage, and will be largely nondissipative, a decided plus for the voltagesourced technology.

Thus for current-sourced converters we recommend a higher than normal transformer leakage, an adequate voltage surge suppressor and appropriately rated converter devices. For voltage-sourced converters no protection should be necessary provided the total tie impedance is large enough.

\subsubsection{Safety}

Safety is as significant a concern at the ac interface as it is at the dc. Code compliant design and installation practices, including the converter case grounding previously recomended, ensure hazard free operation for the consumer. However, service personnel must also be protected, and it is in this area that major problems may arise.

Basically, there are two types of service personnel to consider, those performing maintenance or repair on the converter and those performing the same functions on the utility system. The former need verifiable 
disconnects from both the ac supply and the solar photovoltaic array before gaining access to normally live parts. The latter need verifiable disconnection of the converter from the ac system before performing their necessarychores. In this latter respect, line-commutated converters are preferable since they inevitably fault in the event the ac system faults and hence will not "backfeed" a faulced ac 11ne afler a utility fault clearing device opens. Self-commutated converters designed to current limit in the event of an ac supply fault are more of a problem, since once the ac supply protective device opens they are capable of resuming normal operation (provided the total local load is within their caparity) and thus making the distribution system downstream of the fault clearing device "live". It has been suggested that disconnects external to the residence(s) are needed to obviate this possibility, and in any case the NEC (Articles 230 and 700) requires such disconnects for customer owned generation (second service connections). Even this may not be considered adequate, for it requires the utility crew check each residence before beginning work on the distribution system. We believe the converter should automatically cease to function, just as does a linecommutated converter, in the event of an ac supply fault followed by protective device clearing. This can be accomplished, easily if unity power factor converter operation is the norm, and with somewhat more difficulty if it is not. If a group of converters are backfeeding à network, then some of them will be providing reactive power and some consuming it since their controls are linked only by the network voltage. This being so, they can be tripped off in sequence on the basis of VAR supply it they normally operate at unity power factor - as one supplying VAR trip, another must pick up the VAR and will then trip and so on. If they normally supply VAR, this simple avenue is closed.

The converter serviceman is easy to protect, at the expense of suitable verifiable disconnects at the converter. 


\subsection{Operational Considerations}

The dc and ac interfaces are not the sum total of the electrical specifications for the conversion equipment. There are a number of operational considerations of some importance. Chief among these are the automation of start-up, shut-down and normal control procedures. Fault behavior has already been discussed in conjunction with the interface specifications. Although it has been suggested that peak-power tracking may not be absolutely essential, the extra cost of its implementation over that associated with any other form of control (constant voltage has been touted) is so small as to make it unlikely that peak power tracking will not be the norm. We do not believe that significant savings accrue, in the long term, from abandoning peak power tracking in favor of "simpler" control techniques.

The automation of daily start-up ("wake-up") and shutdown procedures is an obvious necessity. Equally obvious is its dependence on the converter's ability to perceive array capabilities. It would be very complex to have the converter system capable of assessing array power capability before turning on; all it can do sensibly is sense array voltage. Given a threshold dc voltage level at which a converter will attempt turn-on, subsequent behavior is converter technology dependent.

A11. voltage-sourced self-commutated converters have the capability of maintaining operation even if their sources do not have any power capability. Hence converters using such technology can be expected to turn on and remain on until the array does develop energy supply capability; some reasonable time may be allowed after which the converter will turn-off again, presuming a cloudy day or some array malfunction. In general, however, start-up for a voltage-sourced converter is simple and straightforward and, while it may involve some energy consumption from the utility (converter tare losses) for a brief period whenever a start or restart occurs, will not necessitate repeated "trials". Such is not the case when current-sourced line-commutated technology is used. Apart from transformer excitation and harmonic filter losses these converters cannot substain operation unless their dc sources 
will deliver power, except at zero dc voltage or by operating in the rectifying quadrant (reversing the dc terminal voltage). This being the case, a current-sourced converter attempting to start-up on an array. with insufficient power capability will pull the array beyond the peak power point (into the high source resistance region) if it is not shut. down. There arise two possible starting modes. One involves starting, running to peak power point and shutting down again if the array has not sufficient power capability for sustained operation, then trying again after some prescribed time interval. The other involves starting and putting the converter and array into short circuit operation until the short circuit current level indicates sufficient power capability is available. This latter mode presents some minor control difficulties when actually starting to deliver power, for it is necessary to back up beyond the peak power point (toward the open circuit condition) before releasing the peak power tracking feedback loop.

Shutdown is very simple for either type of converter. Once the array power falls below a preset level with the converter operating, shutdown can be initiated. There may. be some on-off cycling of a system on partly cloudy days, but this is unavoidable. The cycle time is a system rather than converter issue - the conversion equipment will impose a minimum, certainly less than one second, but system considerations will dictate the design value(s). It is clear that an internal disconnect must be provided so that the converter's connection to the ac supply is broken on shutdown, else the transformer, filter (and VAR compensation in the case of a line-comnutated converter) excitation losses will be drawn from the utility overnight and on cloudy days, seriously reducing net energy delivery.

\subsection{Baseline Specification}

The baseline specification which arises out of the foregoing interface and operational considerations is now summarized. It is as follows: 
- dc interface:

Minimum voltage: $150 \mathrm{~V}$

Maximum voltage: $250 \mathrm{~V}$

Range: $1.5: 1$ minimum $1.67: 1$ maximum

Design range selected: $160 \mathrm{~V}-240 \mathrm{~V}$

Ripple current: $5 \%$ peak

Fault protection: shorting switch across array

Safety: array grounded single pole dc disconnect at inverter

- ac interface

Voltage range: $216-254 \mathrm{~V}$

Transient voltage: $6 \mathrm{kV}$ peak $1-1 / 2 \times 40$ wave

Harmonics: $5 \%$ total rms current individual component $15 / \mathrm{N}$ amps, $\mathrm{N}$ the harmonic order

Power factor: to supply controllable VARs up to the level corresponding to 0.833 power factor lagging load

Fault protection: standard breaker used as visible disconnect external to residence

fuses internal to inverter

Safety: breaker outside residence disconnect contactor at breaker converter cabinet grounded full insolation transformer

- Operational

peak-power tracking

automatic start-up at array open-circuit voltage of $180 \mathrm{~V}$ automatic shutdown if array power < $10 \%$ of nominal

- Efficiency - Full load $\geq 91 \%$, half load $\geq 88 \%$.

- Environmental - Ambient temperature $0^{\circ} \mathrm{C}$ to $45^{\circ} \mathrm{C}$ Humidity $90 \%$

Permissible acoustic noise 


\section{BASELINE DESIGN}

The baseline design was selected to be a good example of existing technology which would not need significant development effort tor its implementation. It was thought to have as good a chance, if not better, as any converter technology currently in use of meeting cost and efficiency goals when designed to meet the specification. A voltage-sourced programmed-wave converter approach was chosen because of the relative ease with which that technology can meet all specifled requirements. However, because development in pattern optimization and control implementation is needed to effect a design capable of handling the combined dc and ac voltage variations, a fixed pattern dc to ac converter was preceeded by a dc to dc boost regulator. Transistors were chosen as the switching devices because they are now available with high enough $V \times$ ratings to make a $5 \mathrm{~kW}$ half bridge, $10 \mathrm{~kW}$ bridge, and thyristor commutation circuits are both expensive and inefficient. The elemental schematic is shown in Figure 5.1. The major components and sub-assemblies for this design are as follows:

- Output transformer - $6 \mathrm{kVA}$ for $5 \mathrm{~kW}, 12 \mathrm{kVA}$ for $10 \mathrm{~kW}$ rating, presuming capability to supply 0.833 power factor load

- Output filter - simple T configuration

- Inverter switches - each comprises a transistor and inverse parallel connected diode with an auxiliary cransistor to create the Darlington configuration for enhanced power gain. In addition, there are base network diodes forming a Baker clamp and an appropriate base drive circuit together with the heat sink and snubber. There are twu switches for a $5 \mathrm{~kW}$ unit, 4 for a $10 \mathrm{~kW}$ (half-bridge and bridge configurations respectively)

- Dc link capacitor - inverter ripple filter; must be centertapped for $5 \mathrm{~kW}$ half-bridge. 


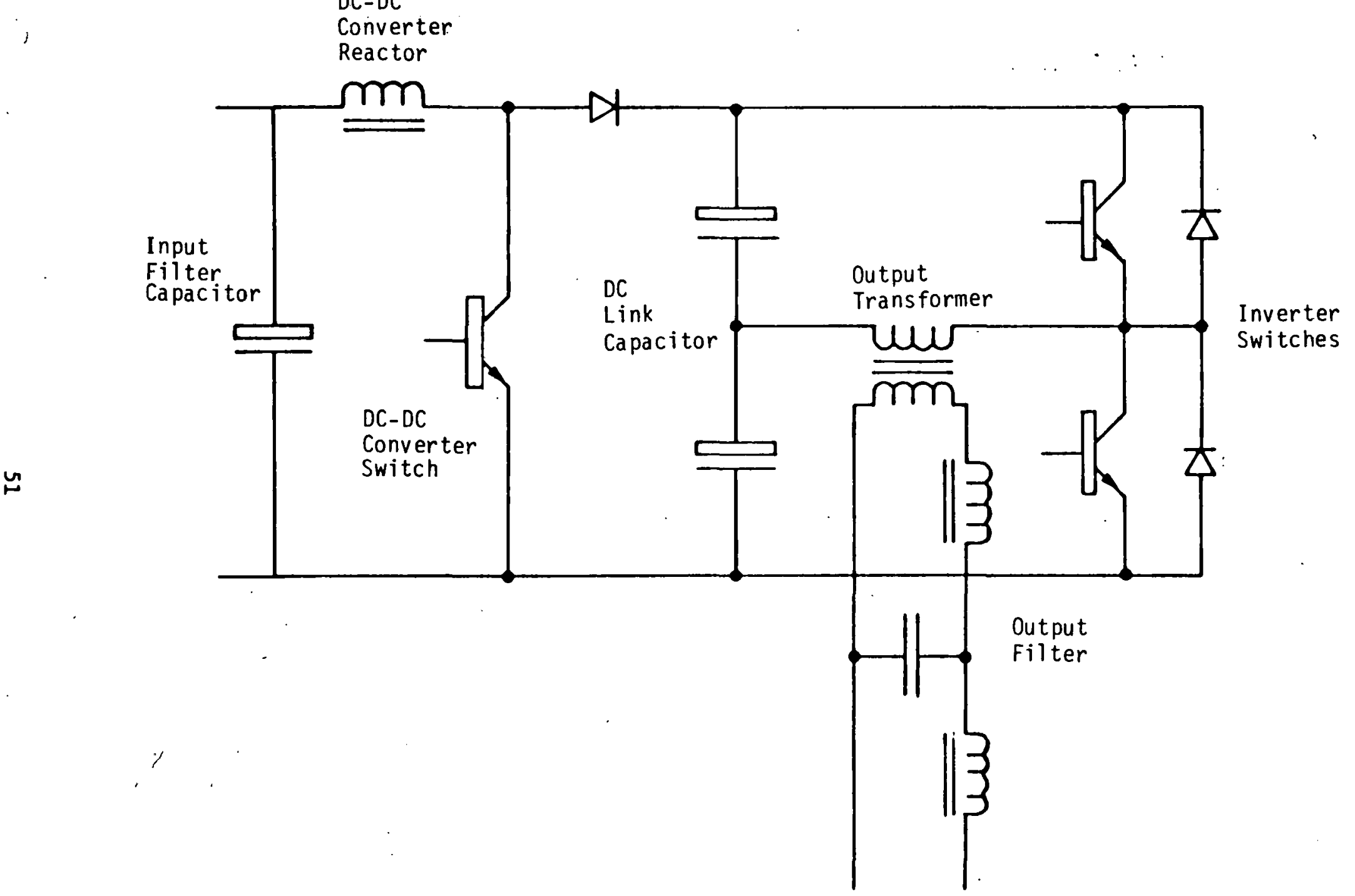

Fig. 5-1-Baseline scheme 
- Dc-dc converter switch - essentlally identical to inverter switch except diode is not in direct inverse parallel connection; one switch for $5 \mathrm{~kW}$, two for $10 \mathrm{~kW}$ rating

- Dc-dc converter reactor - current sourcing reactor for boost dc to dc converter

- Input filter capacitor - provide ripple limitation in dc source

- Control "estimated at two 6" x 8 1/2" PC carde ucing conventional hybrid circult designs

- Ac and de swiechgcar - cxtcrnal ac brcalcer, internul ac contactor, single pole dc disconnect and single pole array shorting switch

- Transducers - ac voltage and current, dc voltage and current

- ruses - protection in ac intèrfácé

- Meter, lights, on/off and meter function selection switch status mointoring for operator

- Enclosure, mounting hardware, connecting wire and cable (internal), connectors

Before calculating costs and efficiencies for the baseline design, two major questions had to be answered. First, al whal swililing frequencies should the invertor and the dc to dc converter operate? Second, should the controllable switching devices be bipolar or MOSFET transistors? (Thyristors having been ruled out for low power conversion equipment of this technology). Since the answer to the second question depends on the findings relative to the first, the switching frequency question should be addressed first.

The answer depends on the trade-off between filter costs and losses and converter switch costs and losses. As the switching frequency is increased in a fixed pattern converter, more low order harmonics can be eliminated and so filter costs and losses can be reduced. At the same time, switch ratings and switching losses increase. Figure 5.2 shows filter cost versus switching frequency; filter losses behave in a similar fashion. It can be seen that major gains are made for modest frequency increases, but that the curve rapidly flattens at higher frequencies. A further point of some importance is that the ability to produce the 


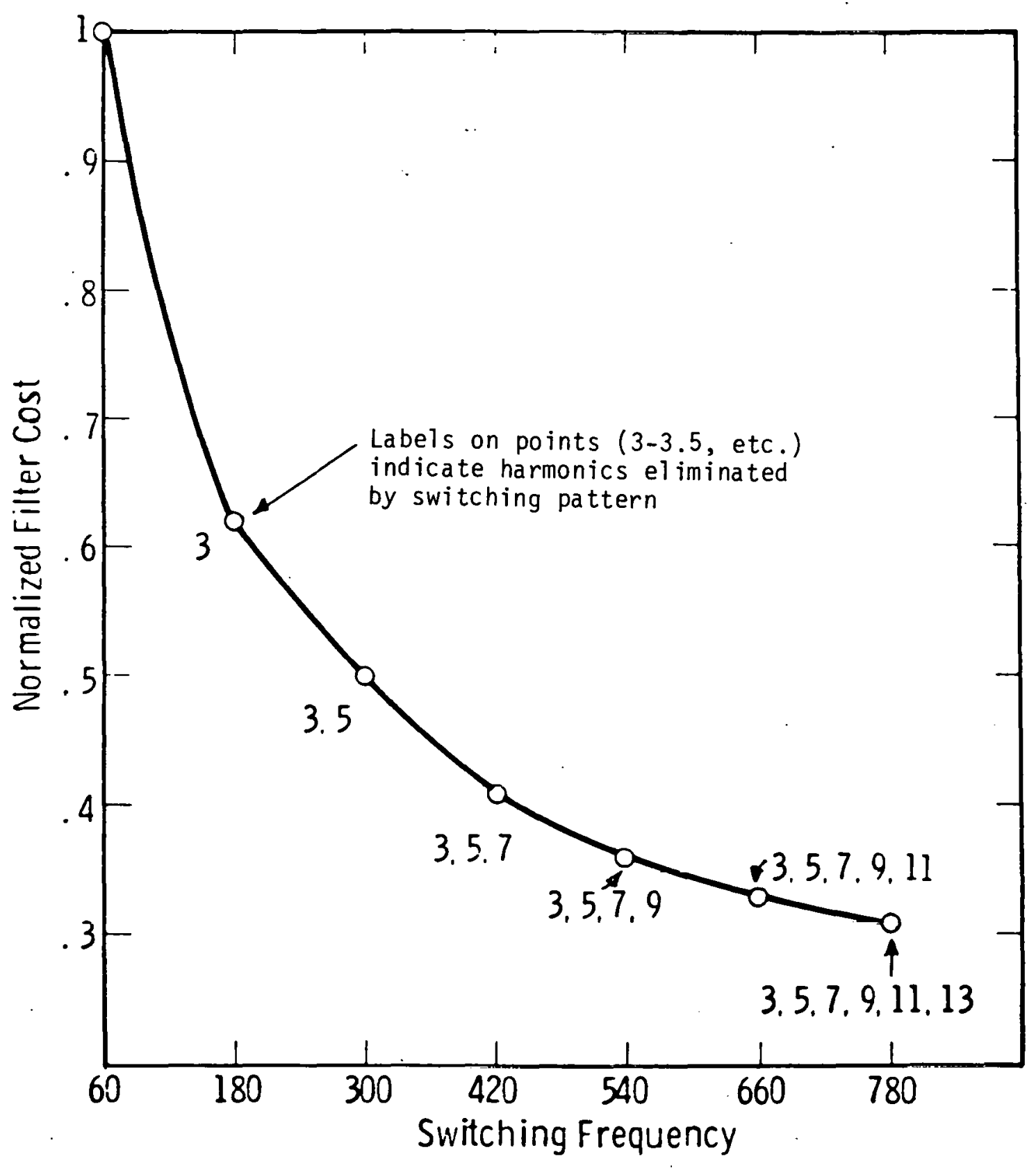

Fig. 5-2-Filter cost vs switching frequency 
required switching pattern is reduced as switching frequency is increased. This is because each additional "notch" Introduced in the converter voltage wave must be of shorter duration and more precise positioning to achieve the harmonic elimination desired. Switching device imperfections and control resolution limit the degree to which proper pattern conditions can be attained, more and more as switching frequencies, and the number of notches, are increased.

Hence it would seem that for a fixed pattern Inverter a cholce lying in the range 540 - $780 \mathrm{~Hz}$ is indicated; control and switch imperfection problems incline the choice to the low end of this range, and so $540 \mathrm{~Hz}$ has been selected for the designs. Now the contest between bipolar and MOSFET transistors can be reduced to one of total losses, it being prima facie evident that for equivalent $V \times$ I ratings the devices should have equal costs. Figure 5.3 shows the results of theoretical studies on total losses, conductive plus switching, of these devices as functions of operating frequency. It can be seen that bipolar are far superior to MOSFETs at low oeprating frequency; MOSFETs become better at frequencies greater than about $10 \mathrm{kHz}$, but we are not interested in frequencies even remotely approaching this. Hence our choice of bipolar devices.

Whenever a dc-dc converter is used upstream of a dc to ac converter, significant problems can occur in feedback control loop stabilization if the switching frequencies of the two converters are not harmonically related. For this reason, and bearing in mind that interface component cost versus frequency for a dc todc converter will closely parallel the ac filter cost versus frequency curve of Figure 5.2, we elected to use $1080 \mathrm{~Hz}$ as the boost converter switching frequency.

Cost estimates were arrived at for the components of the baseline designs by obtaining verbal quotes from one or more qualified vendors. Assembly labor estimates were arrived at by using established estimating techniques based on current average shop labor rates: (Including overhead). The resulting "direct product cost (DPC)" estimates are now presented; they are based on yearly production quantities in the low 1000's, and presume a small plant almost totally dedicated to the product. 


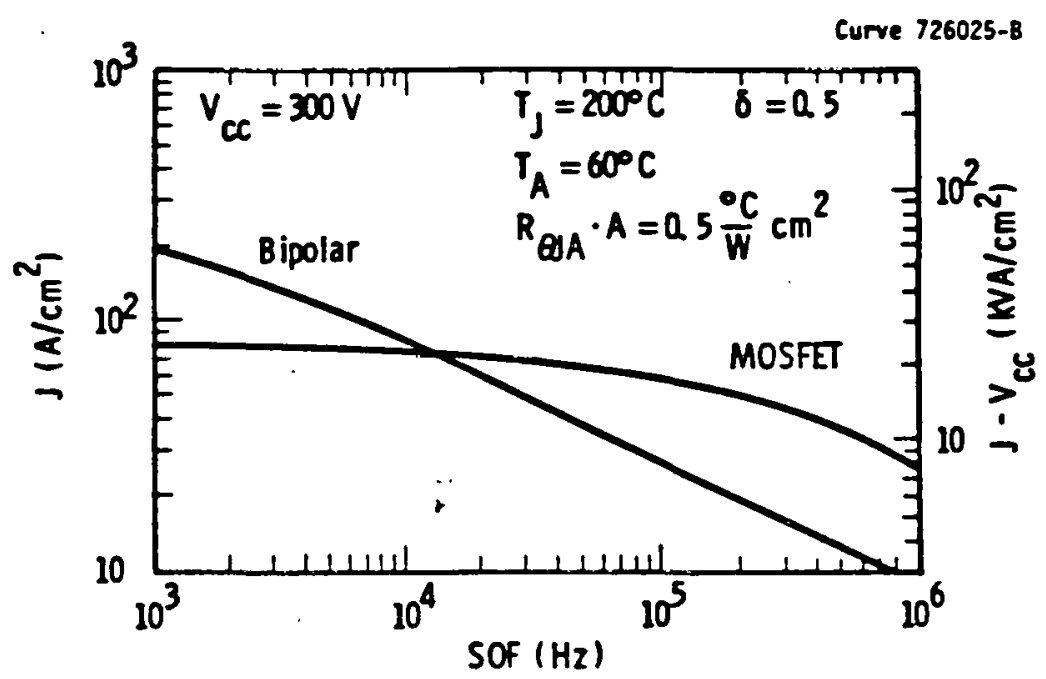

Current Density vs Safe Operating Frequency tor the Bipolar and MOSFET

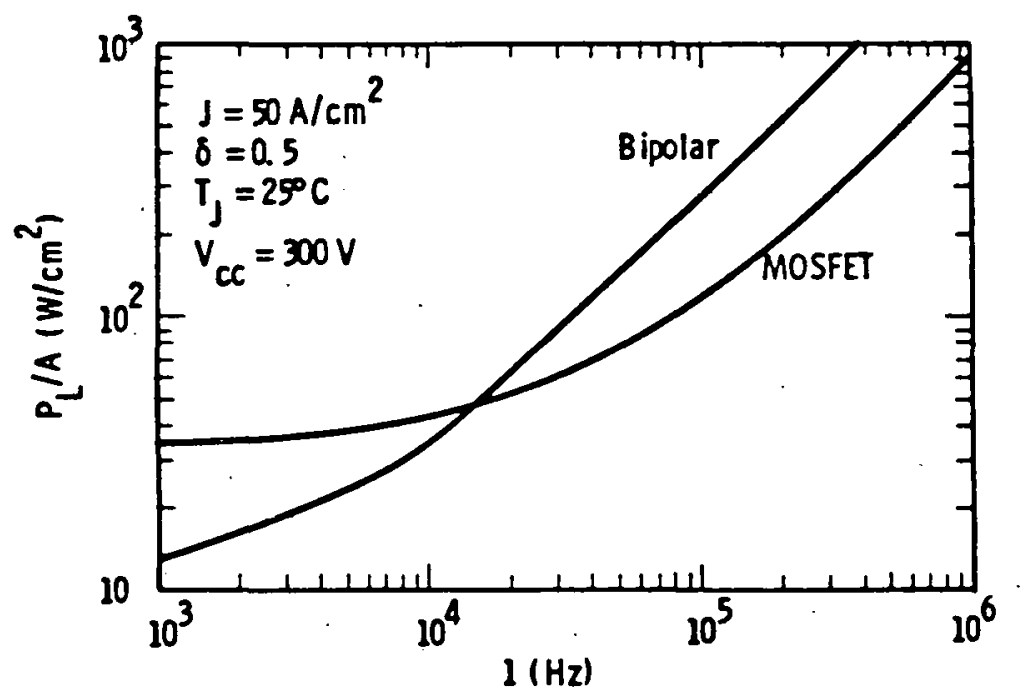

Power Loss per Unit Area vs Frequency. $T_{J}=290 \mathrm{C}$

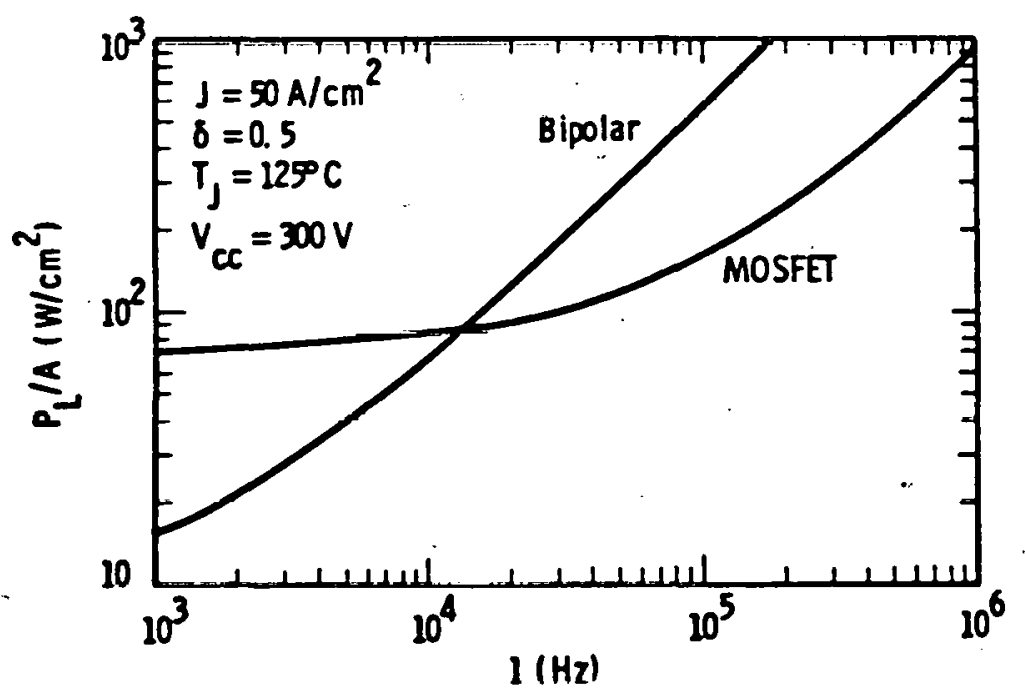

Power Loss per Unit Area vs Frequency. $T_{J}=129 \mathrm{C}$

Fig 5-Power transistors Bipolar vs MOSFET 
Costs for $5 \mathrm{~kW} / 6 \mathrm{kVA}$ Design

Component/Sub Assembly

Transformers

Output filter inductors

Input filter capacitors

Inverter switches

Dc link capacitor

Dc-dc converter switch

Dc-dc converter reactor

Input filter capacitor

**Control PC cards

* Ac and de swlicligear

*Transducers

*Meter, indicators, switch

*Fuses

*Cabinet, hardware, cable \& wire Totals
Material Cost (\$)

106

35

17

444

85

222

53

18

160

65

94

67

10

200

1576
Assembly lahor Cost (\$)

20

10

10

120

40

60

10

10

120

20

25

25

10

40

520

Sum total "direct product cost (DPC)" $\$ 2096$, or $\simeq \$ 419 / \mathrm{kW}$. Items marked *, it should be noted, are essentially independent of the converter technology and only slightly dependent on converter rating; they account for $\$ 556$, or $\simeq \$ 117 / \mathrm{kW}$, more than $25 \%$ of the "DPC" and more than $50 \%$ of the cost goal. The control, marked $\star *$, is also essentially independent of converter technology and is totally indeperident of converter rating. A $10 \mathrm{~kW} / 12 \mathrm{kVA}$ design produces more favorable specific cost figures as shown below:

Component/Subassembly

Transformer

Output filter inductors

Input filter capacitors

Inverter switches

Dc link capacitor

Dc to dc converter switches
Material Cost (\$)

194

64

34

888

45

444
Assembly Labor Cost (\$) 20

10

20

200

20

100 
Dc to dc converter reactor

Input filter capacitor

Control boards

*Switchgear

*Transducers

*Meter, indicators, switch

$\star$ Fuses

*Cabinet etc
20

20

120

20

25

25

10

60

670

For total DPC of $\$ 3174$, or $\$ 317 / \mathrm{kW}$; the "balance of plant" (technology independent) costs marked * now account for $\$ 672$, or $\$ 67 / \mathrm{kW}$, one-third of the cost goal of $\$ 200 / \mathrm{kW}$.

Relating DPC to selling price (FOB factory) is not easy, as was discussed in Section 2. Multipliers vary widely, dependent on organization. However, for a small organization dedicated to the product, the multiplier for the range 1000-3000 units peryear should be in the range 1.6-1.9, giving factory price ranges of $\$ 3354-\$ 3982$ for $5 \mathrm{~kW}$ units, $\$ 671 / \mathrm{kW}-\$ 796 / \mathrm{kW}$, and $\$ 5078 \$ 5030$ for $10 \mathrm{~kW}$ units, $\$ 508 / \mathrm{kW}-\$ 603 / \mathrm{kW}$; even at the most optimistic estimate the cost goal is exceeded by a factor of 3 for $10 \mathrm{~kW}$ units, by over 3 for $5 \mathrm{~kW}$ units.

The efficiencies were calculated at full and part $10 a d(20 \%$, $40 \%, 60 \%$ and $80 \%$ ) to determine how close the baseline came to meeting efficiency goals and how good or bad its part load behavior was. The results are presented below, with major contributions identified. Calculations were made on the basis of both dc voltage and current variations in the solar array source, assuming peak power tracking over a range of solar insolations and temperatures. 
Losses for $5 \mathrm{~kW}$ Rating Unit

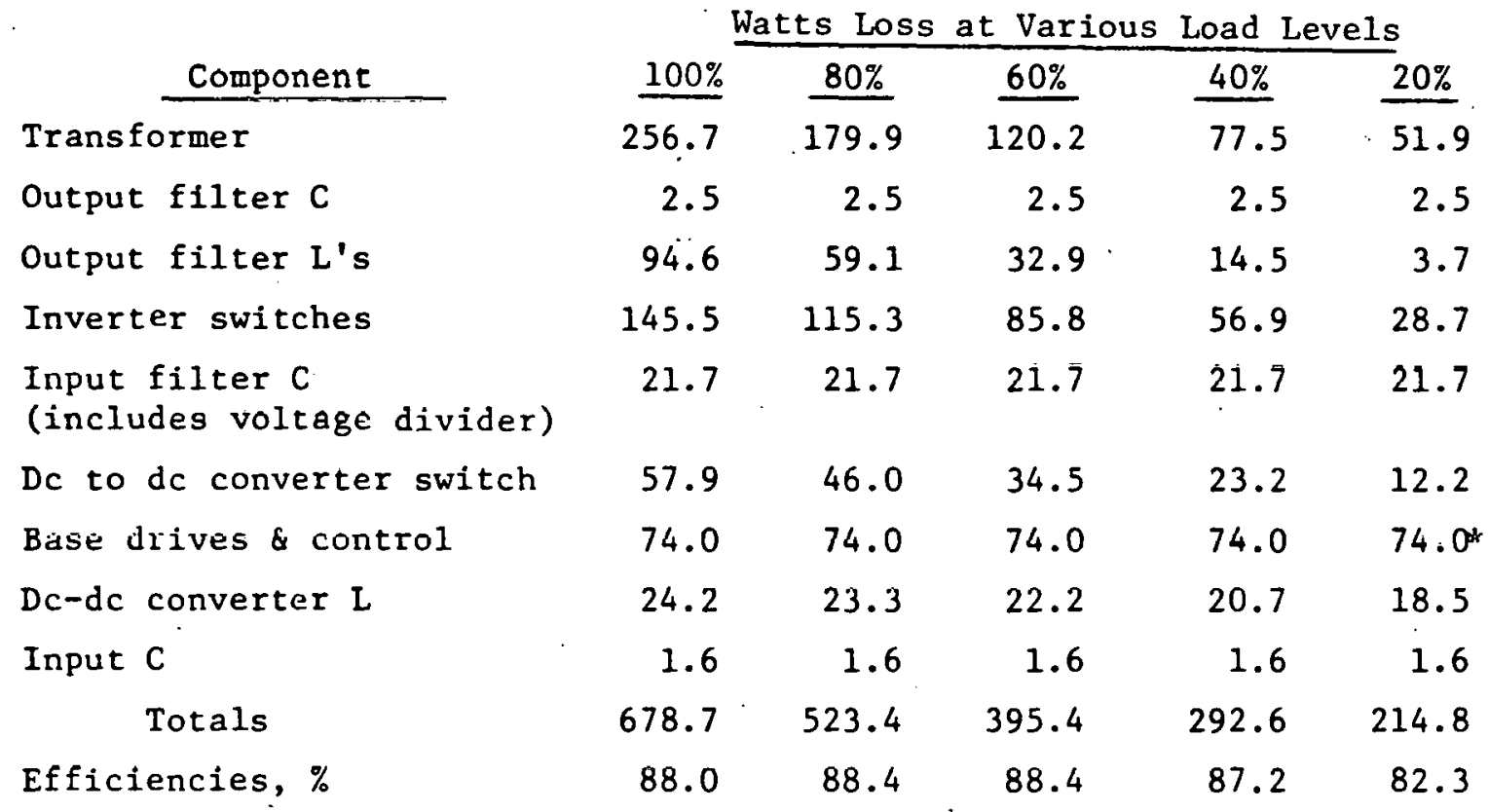

It can be seen that although the efficiency is below the target figure, the behavior with load variation is quite good. It should be observed that all magnetic components were "designed" for minimum cost; their full load losses could be reduced for extra material cost, but part load behavior is not then quite so favorable. The transformer alone produces the following loss pattern if designed for minimum 1093

$\begin{array}{lrrrrrr}\text { Transformer e \% Load } & \frac{100 \%}{n n n} & \frac{80 \%}{153.5} & 126.5 & \frac{60 \%}{105.4} & \frac{40 \%}{90.4} & \frac{20 \%}{78.1} \\ \text { Loss, watts } & 89.7 & 89.5 & 88.7 & 86.7 & 80.6\end{array}$
(inversion equipment)

The extra cost of a minimum loss $6 \mathrm{kVA}$ transformer is $\$ 52$.

Just as for cost, a $10 \mathrm{~kW}$ unit looks better than a $5 \mathrm{~kW}$ unit for losses, although not so dramatically. The reasons for improvement are the magnetic component losses and the reduction in dc link capacitor losses due to elimination of the center tap. Results are below with minimum cost magnetics?

*It was assumed that fixed base drives would be used, hence the constant losses. 
Losses for $10 \mathrm{~kW}$ Rating Unit

Watts Loss at Various Load Levels

\begin{tabular}{|c|c|c|c|c|c|}
\hline Component & $100 \%$ & $\underline{80 \%}$ & $60 \%$ & $40 \%$ & $20 \%$ \\
\hline Transformer & 391.3 & 278.9 & $191: 6$ & 129.1 & 91.7 \\
\hline Output filter $\mathrm{C}$ & 5.0 & 5.0 & 5.0 & 5.0 & 5.0 \\
\hline Output filter L's & 143.5 & 89.2 & 49.5 & 21.8 & 5.6 \\
\hline Inverter switches & 291.0 & 230.6 & 171.6 & 113.8 & 57.4 \\
\hline Input filter C & 4.6 & 4.6 & 4.6 & 4.6 & 4.6 \\
\hline Dc to dc converter switch & 115.8 & 92.0 & 69.0 & 46.4 & 24.4 \\
\hline Base drives \& control & 136.0 & 136.0 & 136.0 & 136.0 & 136.0 \\
\hline Dc to $d c$ converter $L$ & 36.9 & 35.6 & 34.0 & 31.8 & 28.6 \\
\hline Input $\mathrm{C}$ & 3.2 & 3.2 & 3.2 & 3.2 & 3.2 \\
\hline Totals & 1127.3 & 875.1 & 664.5 & 491.7 & 356.5 \\
\hline Efficiencies & 89.9 & 90.1 & 90.0 & 89.1 & 84.9 \\
\hline
\end{tabular}

Again, minimum loss magnetics can improve efficiency at extra cost; the premium, as in the $5 \mathrm{~kW}$ transformer case, is roughly $\$ 1 /$ watt of full load loss.

These conceptual designs were done for free convection cooled equipment in a vented cabinet with a maximum ambient temperature of $45^{\circ} \mathrm{C}\left(113^{\circ} \mathrm{F}\right)$. Such a design is certainly adequate for basement or subground garage installed equipment anywhere in the USA. It may not suffice for indoor above ground installations in the southwestern USA, and will certainly not be adequate for outdoor installation in many areas. The ambient temperature problems of outdoor equipment are such as to strungly mitigate against such installations unless water cooling is used, and we would advise against that practice for residential installations. Provided air circulation is good, indoor dbove ground installations should be satisfactory. However, if air circulation is poor in the building wherein the conversion equipment is installed, ambient temperatures in excess of $130^{\circ} \mathrm{F}$ can easily be experienced in many regions. It is cheaper to circulate air than to design equipment to tolerate such conditions. 
The foregoing cost and loss analyses of the baseline designs show that although it is probably possible to meet, or come very close to efficiency goals there appears to be little hope of meeting cost goals with such a design. Two key questions now arise, which subsequent sections of this report attempt to answer. First, are there alternative converter technologies offering better prospects? Second, what improvements might be realized in design, components and manufacturing methods and organization to bring the goals within reach?

There is one other pertinent observation from the cost and loss analyses. The isolation transformer cannot be regarded as a major cost contribution; at the $5 \mathrm{~kW}$ level its cost represents $\simeq 6 \%$ of the total cost, at the $10 \mathrm{~kW}$ level $\approx 6.1 \%$. It is therefore unlikely that designs not using isolation, or technologies achieving the isolation at high frequency to reduce transformer sizé and cost, scand much bercer chances of methluy cost goals. However, the $60 \mathrm{~Hz}$ isolation transformer is a major loss contributor. Its elimination would result in efficiency goals being exceeded by a comfortable margin; high frequency isolation, and consequent reduction of transformer losses, might prove a means for reaching efficiency goals if other losses are not increased by adopting such a technology. 


\section{ALTERNATIVE TECHNOLOGIES}

In view of the future of the baseline design to offer any great hope of meeting cost goals, we have asked the question "are there any alternative converter technologies with better prospects?" The answer must come in two parts. First, it is necessary to determine what alternative technologies will meet the baseline specification, then their costs and losses must be evaluated.

While there are few, if any, converter technologies capable of meeting the specifications if implemented in their basal forms, almost any conceivable dc to ac conversion technology can be made to meet the requirements by some combination of addenda and design refinements. Hence the problem becomes one of selecting concepts and topologies which appear prima facie to have as good a chance or better than the baseline.

It is a known fact that there are only two generic types of dc to ac converter, current-sourced and voltage-sourced. Either type can. be line-commutated or self-commutated, but at this point comes the first practically imposed restriction. The difficulties in self-commutating a current-sourced converter are formidable and not amenable to reduction by using transistors or gate-controlled swltches in its circuit. It is almost always cheaper, and more efficient, to apply passive VAR correction at the converter's ac terminals than to attempt to make the converter selfcommutated. Hence current-sourced converters are almost invariably linecommutated, and should be so for this application.

The reverse is true for voltage-sourced converters. The difficulties attending reliable line-commutation of a voltage-sourced converter are, if anything, even more formidable than those found in making current-sourced. converters self-commutated. Hence voltage-sourced 
converters are almost invariably self-commutated and should be so for this application.

The two basic dc to ac converters which are potentially viable candidates are, then, the voltage-sourced self-commutated and the currentsourced line-commutated. In its basal two pulse (single phase) realization, neither is capable of meeting the specification for this application. We have shown, in the baseline design, one set of design refinements and additions making the voltage-sourced converter applicable.

The current-sourced converter may be made applicable simply by adding passive harmonic fllcering and VAR cumpeusation at its ac terminals and by suitably designing its dc interface. This is one option we shall explore. It may also be made applicable by preceeding it with a dc to dc converter run at fairly high frequency and used to waveshape the input current and allow the converter to run at unity power factor. This "HF front end" approach will also be examined. A less obvious variant having little prima facie merit but some possible technical attractions is the use of dc to three phase ac current-sourced cunverter with a controlled three phase to single phase ac interface (Steinm balancer).

The voltage-sourced converter has the very obvious possibility of, with control development and pattern optimization, being used as a multi-pattern, programmed-waveform converter withour a dc to dc converter preceeding it. This is the only voltage-sourced option which will be pursued.

Apart from current- or voltage-sourced converters preceded by dc to dc converters, there are compound converters which mighe be considered. Indeed, if a high-frequency isolation transformer is to be used, a compound converter is needed. Such a system must comprise a dc to high frequency ac converter followed by an ar to ac converter interfacing the high frequency with the $60 \mathrm{~Hz}$ utility. This type of approach will now be dismissed by rational argument before the cost and 
loss analyses of other options are presented.

If the dc-to-hfac-hfac-to $60 \mathrm{~Hz}$ approach is attempted, then clearly the dc-to-hfac converter must handle the total power. In that case, it would be just as capable of performing the dc-to-60 $\mathrm{Hz}$ inversion required, save perhaps ac interface requirements. In fact, because of higher frequency switching the converter switches may be more expensive and will certainly have more losses than those in a simple dc-to-60 $\mathrm{Hz}$ converter. We can conclude that the cost and loss savings obtained in a high frequency transformer as opposed to a $60 \mathrm{~Hz}$ transformer should not be overhauled by the costs and losses incurred in hfac-to-60 $\mathrm{Hz}$ conversion. Now it would be most unreasonable to suppose that the cost of hfac-to-60 Hz conversion is any less than the cost of the simplest form (current-sourced line-commutated) of dc-to-60 Hz conversion; in fact, most ac-to-ac converters would be considerably more expensive. It is clear from the current-sourced converter costing which is presented later that this simplest current-sourced dc-to-ac converter costs far more than a $60 \mathrm{~Hz}$ isolation transformer. Hence the obvious conclusion that the compound converter approach offers no economic benefits.

Losses in the current-sourced converter devices are certainly less than those of the $60 \mathrm{~Hz}$ transformer; however, we have observed that the dc-to-hfac conversion brings increased losses, and the losses in a $5 \mathrm{kHz}$ transformer are about $30 \%$ of those in the corresponding $60 \mathrm{~Hz}$ transformer. Hence it would be most unreasonable to assume that significant loss savings accrue to the compound converter approach. Exploring this point a little further, the full load loss of a $6 \mathrm{kVA} 60 \mathrm{~Hz}$ transformer, minimum cost design, has been put at 256.7 watts. The full-1oad loss of a $6 \mathrm{kVA}, 5000 \mathrm{~Hz}$ transformer is found to be 71 watts, a net saving of 185.7 watts in the transformer. However, the losses of the switches in a simple current-sourced converter are 53.1 watts, reducing the saving to 133.6 watts, and the gate drive circuits absorb a further 12 watts, reducing the net to 120.6 watts. This means that the increased switching losses in the dc to ac conversion must be held below 120 watts, in a minimum of two devices, for net efficiency benefit to result. Now at $5 \mathrm{kHz}$ there are $\simeq 83$ switchings per half cycle of $60 \mathrm{~Hz}$; thus, the 
power loss must be held to less than 0.75 watts/per switching, the energy loss to < .012 watt-seconds per switching. A device switching $240 \mathrm{~V}$, 20 Amperes in $1 \mu \mathrm{sec}$ exhibits a loss of .0048 watt-seconds per switching exclusive of associated snubber losses; a simple R-C snubber with an 0.1 $\mu F$ capacitor dissipates $\simeq .006$ watt-seconds per switching. The likelihood of significant efficiency improvement is clearly not great.

We conclude from the above that a compound converter using high trequency isolation has nothing to recommend it as regards cost and little to recommend it as regards efficiency; and clearly such an approach has nothing to recommend it if no isolation is used. We therefore reject such a concept, and concentrate efforts on the three obviously potentially viable candidates and the one "outsider"previously discussed, namely

- current-sourced converter with harmonic filtering and controllable VAR correction

- HF front end current-sourced converter

- Three-phase current-sourced converter with balancer interface

- Multi-pattern programmed-waveform voltage-sourced converter

Cost and loss analyses were performed for these in exartly the same manner as for the baseline design-in fact, many cost and loss items are directly transferrable.

\subsection{Current-Sourced Converter with Filtering and VAR Correction}

For the current-sourced converter, it is instructive to proceed in stages, first taking the basal converter and then adding VAR correction and harmonic filtering. Figure 6-1 shows the develnpment nf the configuration; costs are as follows: 


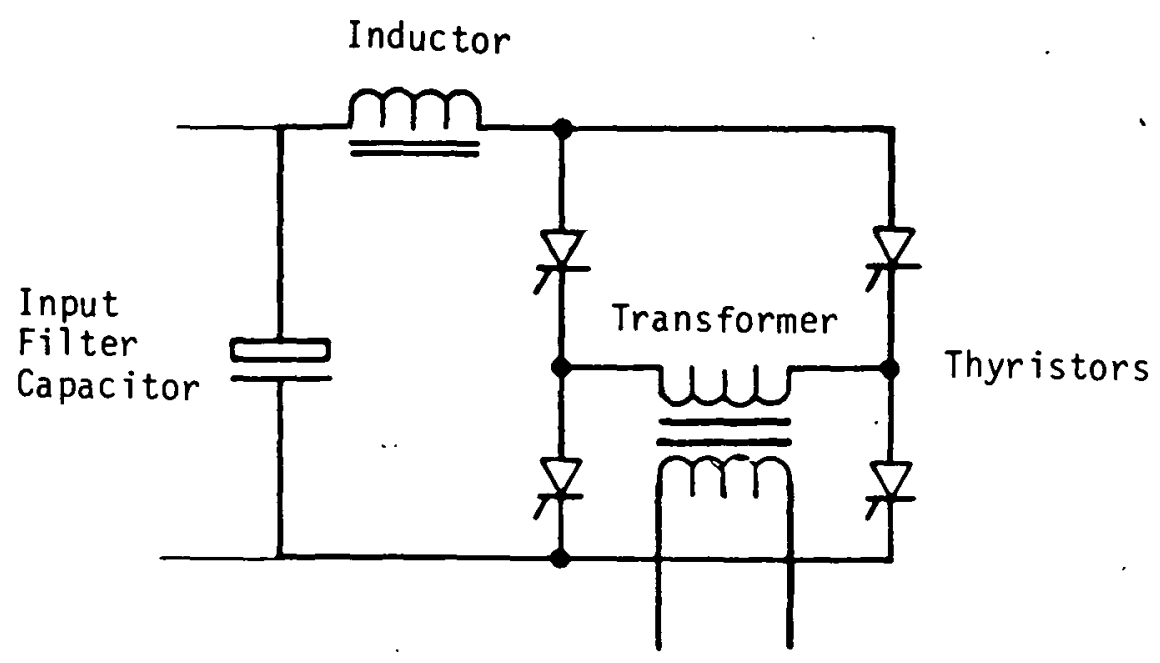

(a)-Basic 5 kW Converter

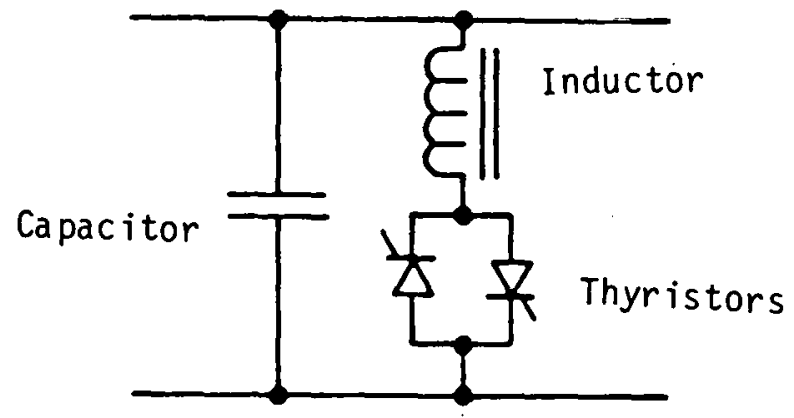

(b) Controlled VAR Compensation

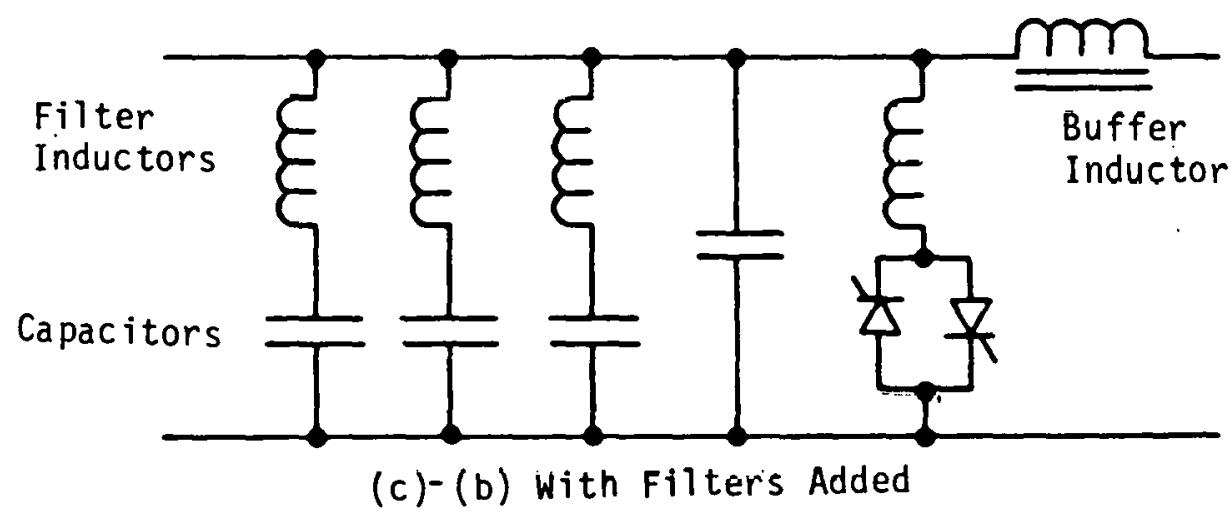

Fig. 6-1-Current sourced converter 
Basic $5 \mathrm{~kW}$ converter

Component/subassembly

Transformer

Thyristors

Gate drives

Controls

Inductor

Input filter capacitor

Balance of plant

Totals
Matertal Cost (\$)

106

93

100

160

124

49

436

1068
Labor Cost (\$)

20

10

40

120

20

15

120

345

For a total of $\$ 1413$ with an estimated FOB factory price of from $\$ 452 / \mathrm{kW}$ to $\$ 537 / \mathrm{kW}$.

Adding controlled VAR compensation with the capability of supplying 0.833 power factor loading produces the following increases:

\section{Component}

Capacitors

Inductor

Thyristors

Gate drives

Total for VAR control

Total with VAR control
Material Cost $(\$)$

104

82

37

50

277

1341
Labor Cost (\$)

30

20

10

20

80

425

For a total DPC with VAR control but no harmonic filtering of $\$ 1766$. Adding harmonic filtering to specifications causes further increases of:

Component

Increased capacitor costs

(due to split for filters)

Filter inductors

Buffer inductor

Total for design to specification
Material Cost (\$)

37

46

8

1432
Labor Cost (\$)

10

15

5

455 
The DPC is estimated at $\$ 1887$; this is clearly competitive with the baseline. A $10 \mathrm{~kW}$ unit again shows economies of scale; its cost tabulation is:

Component

Transformer

Thyristors

Gate drives

Controls

Inductor

Input filter $\mathrm{C}$

Balance of plant

Total, basic inverter

For VAR connection:

Capacitors

Inductor

Thyristors

Gate drive

Totals with VAR control

Adding for filters:

Increase in capacitors

Filter inductors

Buffer inductor

Totals
Material Cost (\$)

194

150

100

160

227

98

532

1461

208

150

55

50

1924

74

84

15

2097
Labor Cost (\$)

20

10

40

120

20

30

140

380

60

20.

10

20

490

20

15

5

530

This gives a total DPC of $\$ 2627$, slightly higher (but by an amount well within the probable error of the cost estimates) than the haseline,

We can conclude that the current-sourced converter in this form is competitive with, but not clearly superior to, the baseline. One reason for this is the "normal" design of the converter, with a large and costly dc sourcing inductor limiting the peak ripple current in the converter to $10 \%$, and operating well in the continuous current region. 
A possible technical (and to some extent economic) objection to this conversion equipment design lies in the use of tuned harmonic filters. These obviously have to be accurately tuned to be effective, and probably create more labor burden than has been allowed in the estimates. More important, for every zero in the network 1mpedance there is a corresponding pole, and network zeros and poles as viewed by the utility are not in the same places in the frequency domain as when viewed from the converter. It is well known that such filters in high power systems can develop severe problems due to excitation of not overly well damped resonances (impedance poles) by non-canonical converter harmonics or through excitation by other harmonics on the transmission or distribution system. This problem has recently been seen to be very much more severe, creating considerably more trouble in reaching an acceptable design compromise, when two contiguous similar filter networks were applied at the secondaries of similar but independent transformers. We fear the problems attending the connection of a multiplicity of such filters, each viewing the others and the ac system through the converter transformer and then aggregate groups intertied via line impedance and possibly poletop transformer impedances, could be quite unmanageable.

Thic potcntial problem, whereof llie mytultude cannot be cruly established within this study, can be avoided if common filters are made to serve all the converters in a given neighborhood. If this were done, there would be some saving in filter costs but an offsetting increase in converter transformer costs. However, adopting such an approach raises institutional issues (planning, ownership, maintenance) beyond the scope of this study.

The problem does not totally disappear, but is make much more manageable if a simple $\mathrm{T}$ filter, like that used in the baseline design, can be used. For this to be done with the current-sourced converter, there must be a substantial reduction in the inherent harmonic current generation, particularly as regards the third and fifth harmonic components. 
Previous work ${ }^{1}$ had established that the ac harmonic current of a two pulse converter could indeed be reduced at the expense of increasing lagging quadrature current demand. That work addressed only continuous current operation, from ideal (zero ripple) to critical (current zero just reached). Further analytic effort was now expended on the discontinuous current region, normally avoided for converter operation except at very light load, with a view to determining for what design criteria minimum harmonic distortion exists, and what savings, if any, could be accomplished by revamping the design.

The results are shown in Figure $6-2$; it is clear that minimum total rms distortion occurs just in continuous conduction, but that VAR penalty is quite severe. However, the lower level of harmonic injection makes it possible to eliminate tuned filters, particularly since it demands greater amounts of passive leading VAR to correct the converter's demands.

It was decided to cost this revised design; tabulated results

for a $5 \mathrm{~kW}$ rating are as follows:

$\underline{5 \mathrm{~kW} \text { unit: }}$

\section{Component}

Basic inverter less inductor

New inductor

Increase in input capacitor

VAR capacitors.

VAR inductors

VAR thyristors

Gate drive

$$
\text { Material Cost (\$) }
$$$$
944
$$$$
20
$$$$
24
$$

100

50

1.306
Labor Cost (\$) 325

1 "An Analysis of the Effects of DC Terminal Ripple on the AC Line Currents of 2 Pulse Converters", P. Wood, 1977 PESC Conference Record (IEEE). 


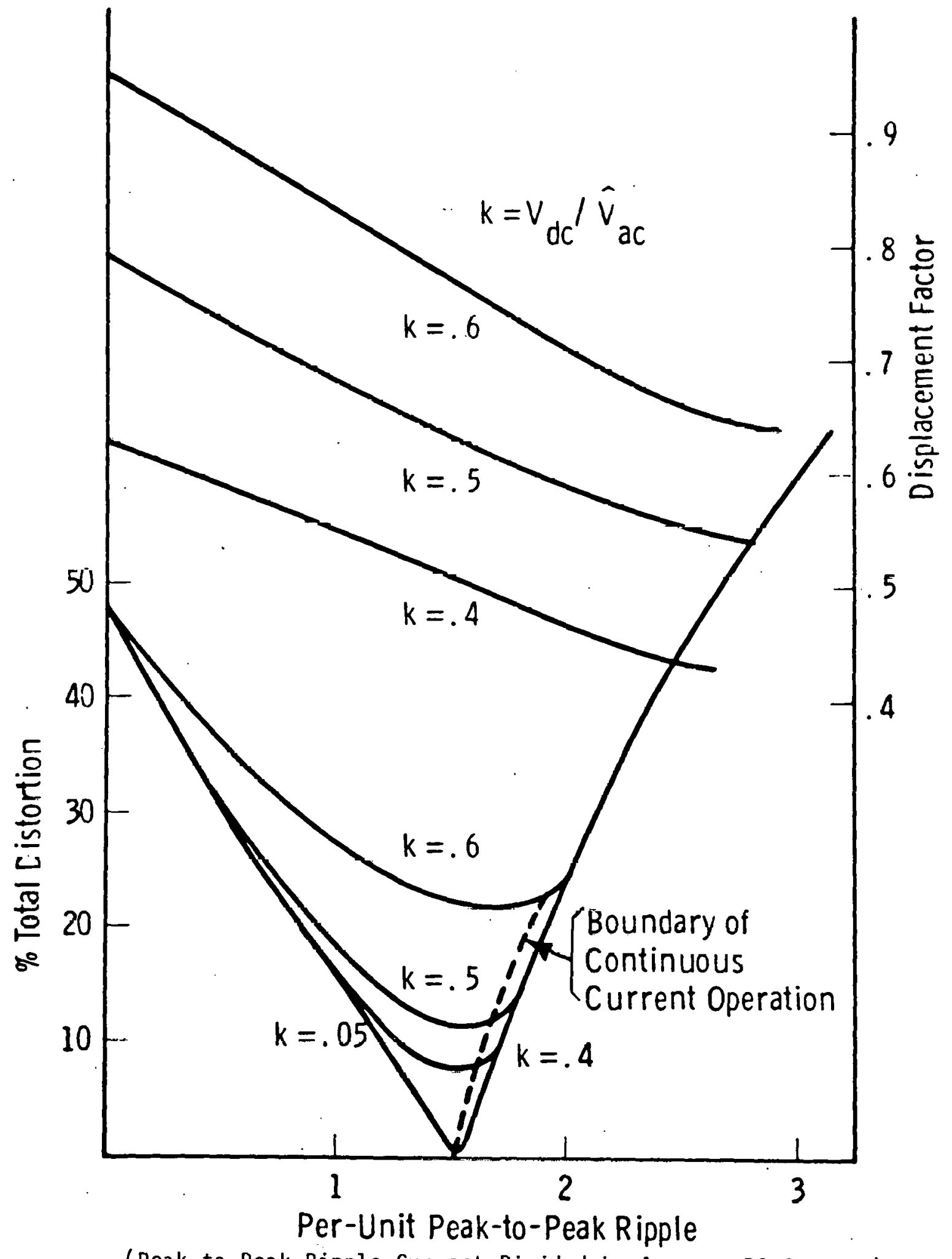

(Peak-to-Peak Ripple Current Divided by Average DC Current)

Fig. 6-2-2 Pulse converter effect of $D C$ terminal ripple on $A C$ current distortion and displacement factor 
A total DPC of $\$ 1741$ arises, less than the "standard" design and comparativelyfree from.technical problems.

Costs for a $10 \mathrm{~kW}$ rating are as follows:

Component

Basic converter less inductor

New inductor

Increase in input capacitor

VAR capacitors

VAR inductor

Thyristors

Gate drive

Totals
Material Cost (\$)

1234

37

48

262

183

50

50

1864
Labor Cost (\$)

360

10

20

80

20

10

20

520

This gives a total DPC of $\$ 2384$, now less than the baseline.

This revised current-sourced design is clearly competitive with the baseline. Equally clearly, it gives little hope for meeting. cost goals unless substantial cost improvements can somehow be made. Efficiency calculations yield the following results (under the same load and source conditions as used for the baseline).

Losses and Efficiency for $5 \mathrm{~kW}$ Revised Design

$\begin{array}{lrrrrr}\text { Component } & \text { Watts } & \text { Loss at } & \text { Various } & \text { Load Levels } \\ \text { Transformer } & 100 \% & \underline{80 \%} & \underline{60 \%} & \underline{40 \%} & \underline{20 \%} \\ \text { Thyristors } & 256.7 & 179.9 & 120.2 & 77.5 & 51.9 \\ \text { Gate drive \& control } & 24 & 24 & 24 & 24 & 24 \\ \text { Inductor } & 53.1 & 50.8 & 48.1 & 43.9 & 39.2 \\ \text { Input Capacitor } & 4.9 & 48.2 & 44.0 & 38.0 & 32.0 \\ \text { VAR capacitors } & 25.2 & 25.2 & 25.2 & 25.2 & 25.2 \\ \text { VAR 1nductor } & 145.1 & 120.4 & 111.7 & 111.7 & 120.4 \\ \text { Thyristors } & 25.2 & 22.0 & 20.7 & 20.7 & 22.0 \\ \text { Gate drive } & 6 & 6 & 6 & 6 & 6 \\ \text { Buffer inductor } & 22.5 & 14.4 & 8.1 & 3.6 & 0.9 \\ \text { Totals } & 614.2 & 495.1 & 410 & 351.6 & 322 \\ \text { Efficiencies, \% } & 89.1 & 89.0 & 88.0 & 85.0 & 75.6\end{array}$


Losses and Efficiency for $5 \mathrm{~kW}$ Revised Design

Watts Loss at Various Load Levels

\begin{tabular}{|c|c|c|c|c|c|}
\hline Component & $100 \%$ & $80 \%$ & $60 \%$ & $40 \%$ & $20 \%$ \\
\hline Trans former & 391.3 & 278.9 & 191.6 & 129.1 & 91.7 \\
\hline Thyristors & 106.2 & 101.6 & 96.2 & 87.8 & 78.4 \\
\hline Gate drive \& control & 24 & 24 & 24 & 24 & 24 \\
\hline Inductor & 77.8 & 72.4 & 66.4 & 57.7 & 48.9 \\
\hline Input capacitor & 9 & 8.4 & 4 & 2 & .8 \\
\hline VAR capacitors & 50.4 & 50.4 & 50.4 & 50.4 & 50.4 \\
\hline VAR inductor & 227.6 & 191.5 & 178.7 & 178.7 & 191.5 \\
\hline Thyristors & 50.4 & 44 & 41.4 & 41.4 & 44 \\
\hline Cute drive & 6 & 6 & 6 & 6 & 6 \\
\hline Buffer inductor & 33.9 & 21.7 & 12.2 & 5.4 & 1.4 \\
\hline Totals & 976.6 & 798.9 & 670.9 & 582.5 & 537.1 \\
\hline Efficiencies, \% & 91.1 & 90.9 & 89.9 & 87.3 & 78.8 \\
\hline
\end{tabular}

This technology is seen to be slightly more efficient at full load than the baseline design, but with somewhat worse behavior as load is reduced. Obviously, it must be considered a contender. In part, its poorer light load loss is accounted for by the presence of the controllable VAR supply at the ac terminals.

\subsection{HF Front End Current-Sourced Converter}

'The Hr tront end technology is depicted, in elemental schematic form, in Figure 6-3. It might be considered a "hybrid" circuit involving elements of the baseline design, namely the $d c$ to $d c$ converter. and elements of the current sourced converter. In this approach the dc to dc converter is used to shape the current for the dc to ac converter -- to act as an active current source. In consequence, the dc to ac converter runs at close to unity power factor and operates essentially without commutations -the current is zero, or very close to zero, when transfer of conduction occurs between thyristors in the dc to ac converter. This system can in fact only operate at very close to unity power factor, even on a sub-cycle basis. Any reversal of energy flow in the dc to ac converter will cause serious problems because there is no provision in the dc to dc converter for reverse energy flow and no passive element in the dc interface between the converters with sufficient energy absorption (storage) capacity to absorb any such reverse energy flow. 


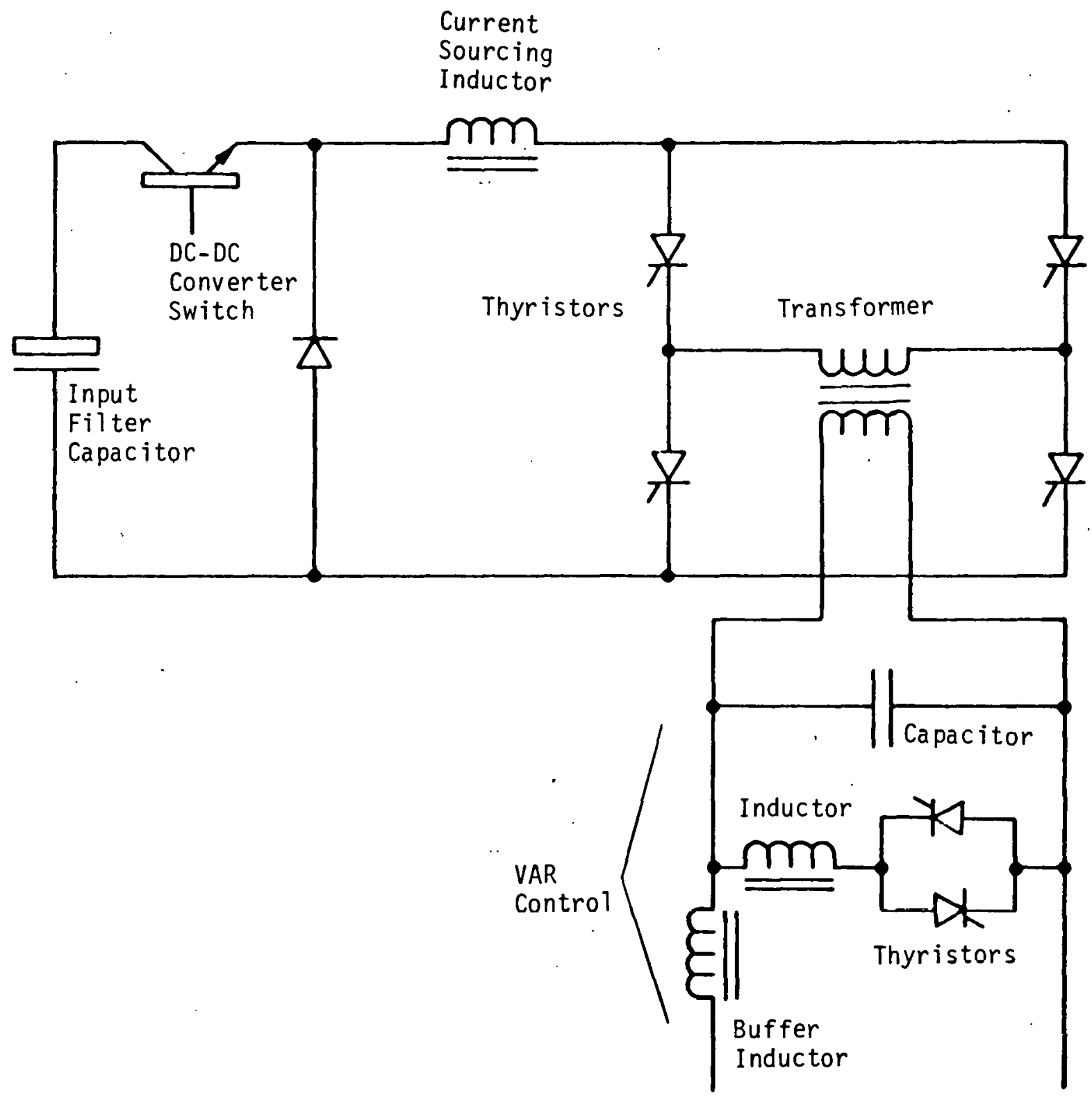

Fig. 6-3-Current sourced converter fed by waveshaping DC-DC converter ("HF Front End") 
Because of these facts, we are doubtful of the viability of this technology. To meet the specification we have generated, a way must be found to permit off unity power factor operation. This could be done in two ways. One is to make the dc to dc converter a two quadrant converter, thereby permitting the sub-cycle reverse energy flow associated with reactive power. However, if this is done the dc to dc converter becomes equivalent in capability to a dc to ac converter, and the scheme can be rejected on the same grounds that were used to eliminate other compound converterschemes. The brute force technique, which we have chosen to cost, is to place a controlled VAR generator (capacitor Inductor - thyristor) at the ac terminals. As for the current-sourced converter, we have segregated costs so that the Impact can easily be seen.

Even if the reactive power requirement were eliminated, removing the need for the VAR generator, the inability of this type of converter to handle even momentary power flow reversal gives cause for concern. This means that the converter is perpetually "walking a tightrope" with regard to ac interface conditions; should those cond1c1ons change so as to create reverse power flow in the dc to ac convercer at a time when the dc interface current is too high for the dc to dc converter to reduce quickly, disaster strikes in the form of a rapid and sustained rise in the dc interface voltage coupled with a commutatiun failure in the dc to ac converter. It is probable that destruction of the dc-dc converter switch and the inverter thyristors would occur. This is certainly a conceivable scenario; only operating experience will tell how frequently such transients occur, and how damaging they are, but we are not optimistic about the reliability of such a technology.

Despite these reservations, we present cost and loss estimates below; they were generated in exactly the same manner as those preceding. 
Costs for a $5 \mathrm{~kW} \mathrm{HF} \mathrm{Front} \mathrm{End} \mathrm{Converter} \mathrm{are} \mathrm{as} \mathrm{follows:}$

\section{Component}

Transformer

Output filter capacitor

Thyristors

Gate drives

Current sourcing inductor

dc-dc converter switch

Input filter capacitor

Controls

Balance of plant

Basic (unity pf) converter
Material Cost ( $\$$ )

106

7

93

100

32

222

73

160

436

1229
Labor Cost (\$)

20

5

10

40

10

60

25

120

120

410

Thus a DPC of $\$ 1639$, quite the lowest yet seen; however, to add VAR capacity we have

Component

Capacitors

Inductor

Thyristors

Gate drive

Totals (VAR only)

Totals for conversion

equipment to specification
Material Cost (\$)

35

35

37

50

157

1386
Labor Cost (\$)

10

10

10

20

50

460

We have a DPC of $\$ 1846$, essentially competitive; a $10 \mathrm{~kW}$ unit

costs as follows: 


\section{Component}

Transformer

Output filter C

Thyristors

Gate drives

Current sourcing inductor

$\mathrm{dc}$ to $\mathrm{dc}$ converter switches

Input filter capacitor

Controls

Bilance of plant

VAR capacitors

VAR Inductor

Thyristors

Gate drive

Totals (to specification)
Material Cost (\$)

194

14

150

100

58

444

146

160

532

70

64

37

50

2019
Labor Cost (\$)

20

5

10

40

10

100

50

120

$1 / 10$

20

10

10

20

555

The rocal IPC here is $\$ 2574$, IuL yuile as competitive as the

$5 \mathrm{~kW}$ unit. This technology clearly also has a long way to go if cost goals are to be met. Efficiency calculations give the following results:

Losses and Efficiencies for $5 \mathrm{~kW} \mathrm{HF}$ Front End Converter

\begin{tabular}{|c|c|c|c|c|c|}
\hline Component & $\begin{array}{l}\text { Watts } \\
100 \%\end{array}$ & $\begin{array}{c}\text { Loss at } \\
80 \%\end{array}$ & $\begin{array}{c}\text { Various } \\
60 \%\end{array}$ & $\begin{array}{c}\text { Load I } \\
40 \%\end{array}$ & $\begin{array}{l}\text { Levels } \\
\qquad 20 \%\end{array}$ \\
\hline Transformer & 256.7 & 179.9 & 120.2 & 77.5 & 51.9 \\
\hline Output filter C & 0.8 & 0.8 & 0.8 & 0.8 & 0.8 \\
\hline Thyristors & 120 & 95.4 & 71.2 & 47.5 & 24.0 \\
\hline Gace drive \& control & 24 & 24 & 24 & 24 & 24 \\
\hline Current sourcing inductor & 40 & 30.8 & 23.7 & 18.6 & 15.5 \\
\hline $\mathrm{dc}-\mathrm{dc}$ converter switch & 109.5 & 95.6 & 81.2 & 66.8 & 55.6 \\
\hline Rase drive & 18 & 18 & 18 & 18 & 18 \\
\hline Input filter $C$ & 4 & 2.7 & 1.7 & 1 & .3 \\
\hline *VAR capacitors & 6.7 & 6.7 & 6.7 & 6.7 & 6.7 \\
\hline *VAR inductors & 15.2 & 26.5 & 37.8 & 49.2 & 60.5 \\
\hline
\end{tabular}

*Assuming 0.9 power factor load. 
$5 \mathrm{~kW}$ unit (con't.):

\begin{tabular}{|c|c|c|c|c|c|}
\hline Component losses at & $100 \%$ & $80 \%$ & $60 \%$ & $40 \%$ & $\underline{20 \%}$ \\
\hline Thyristors & 3.2 & 5.6 & 8.00 & 10.4 & 12.8 \\
\hline Gate drive & 6 & 6 & 6 & 6 & 6 \\
\hline Totals & 604.1 & 492 & 399.3 & 326.5 & 276.1 \\
\hline Efficiencies, \% & 89.2 & 89.0 & 88.3 & 86.0 & 78.4 \\
\hline
\end{tabular}

Losses and Efficiencies for $10 \mathrm{~kW}$ Front End Converter

\begin{tabular}{|c|c|c|c|c|c|}
\hline Component & $\begin{array}{c}\text { Watts } \\
100 \%\end{array}$ & $\begin{array}{c}\text { Loss at } \\
80 \%\end{array}$ & $\begin{array}{c}\text { Various } \\
60 \%\end{array}$ & $\begin{array}{c}\text { Load L } \\
40 \%\end{array}$ & $\begin{array}{l}\text { els } \\
20 \% \\
\end{array}$ \\
\hline Transformer & 391.3 & 278.9 & 191.6 & 129.1 & 91.7 \\
\hline Output filter $\mathrm{C}$ & 1.6 & 1.6 & .6 & 1.6 & 1.6 \\
\hline Thyristors & 240 & 190.8 & 142.4 & 95 & 48 \\
\hline Gate drive \& control & 24 & 24 & 24 & 24 & 24 \\
\hline Current sourcing inductor & 63.8 & 50.4 & 40 & 32.5 & 28 \\
\hline dc to dc switch & 219 & 191.2 & 162.4 & 133.6 & 111.2 \\
\hline Base drive & 36 & 36 & 36 & 36 & 36 \\
\hline Input fitler $\mathrm{C}$ & 8 & 5.4 & 3.4 & 2 & .6 \\
\hline VAR capacitors & 13.4 & 13.4 & 13.4 & 13.4 & 13.4 \\
\hline «VAR inductor & 23.2 & 40.4 & 57.6 & 75 & 92.2 \\
\hline *Thyristors & 6.4 & 11.2 & 16 & 20.8 & 25.6 \\
\hline Gate drive & 6 & 6 & 6 & 6 & 6 \\
\hline Totals & 1032.7 & 849.3 & 694.4 & 569 & 478.3 \\
\hline Efficiencies, \% & 90.6 & 90.4 & 89.6 & 87.5 & 80.7 \\
\hline
\end{tabular}

*Assuming 0.9 power factor load.

This technology is also seen to be as close to efficiency goals as others which are cost competitive, and to have only slightly worse part load loss behavior than the baseline. The higher thyristor losses in the dc to ac converter, as compared with the simple current-sourced converter, are caused by the need to run at low average dc terminal voltage, and hence high average dc current. Operation at low dc terminal voltage is 
necessary because the $d c$ to dc converter must be able to waveshape the current. To do so it must always be able to apply forcing voltage to the current sourcing inductor, even at minimum dc source voltage and maximum (peak of) ac supply voltage. Whth the dc to ac converter operating at minimum delay,this calls for an average dc terminal voltage $<(2 / \pi) \times 160$, since the peak of the new converter voltage wave must be less than the minimum array operating voltage. Allowing the average voltage to be $0.9 \times(2 / \pi) \times 160 \Omega 92 \mathrm{~V}$, the average de current for $5 \mathrm{~kW}$ is $\simeq 60 \mathrm{~A}$ in this scheme, compared with $\simeq 23 \mathrm{~A}$ ( $5 \mathrm{~kW}$ @ $220 \mathrm{~V} \mathrm{dc}$, say), in the simple current-fed inverter.

The operating frequency of the dc to dc converter was set at $=5 \mathrm{kHz}$ in these designs. There may be some slight cost benefits, with loss penalties, in going higher, and the converse in reducing that frequency. Operation much below $5 \mathrm{kHz}$ would not be possible -- the cycle time is more than that equivalent to two degrees at $60 \mathrm{~Hz}$, and waveshaping resolution will become a problem as the frequency is reduced.

\subsection{Three-Phase Current-Sourced Converter}

A familiar (to one accustomed to conducting equipment cost analyses) pattern is emerging. When designed to a specification which does not unduly favor any converter technology, the cost estimates are almost all competitive within the probable errors therein, and loss estimates also. To prove the point, and emphasize the fact that cost and loss estimates will not provide a sound rationale for technology selection, consider the cost estimate below for the prima facie outrageous scheme depicted, in elemental schematic, in Figure 6-4. This threephase to single-phase current-sourced approach is not seriously suggeated as a competitive technology - its disadvantages should be readily apparent. But, the cost estimate is as follows for a $5 \mathrm{~kW}$ unit: 


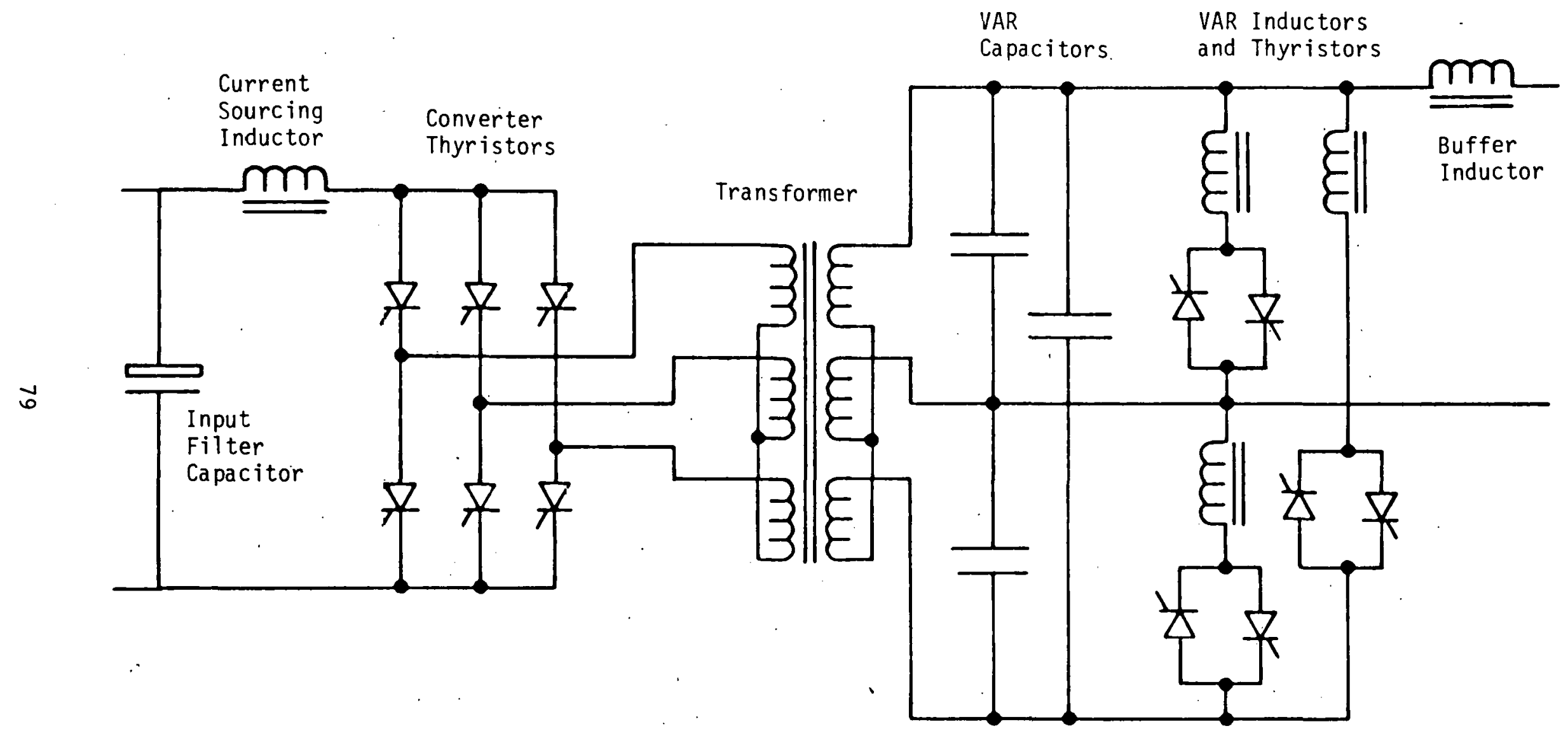

Fig. 6-4-Three phase to single phase current sourced converter 


\section{Component}

Iransformer

Thyristors

Gate drive

Controls

Current sourcing inductor

Input filter capacitor

Balance of plant

VAR capacitors

VAR inductors

Thyristors

Gate drives

Tuning inductors

Buffer Inductors

Totals
Material Cost $(\$)$

116

140

150

160

52

16

436

133

153

140

150

32

8

1686
Labor Cost (\$)

$$
20
$$

10

60

120

10

5

120

45

15

10

60

15

5

495

With a DPC of $\$ 2181$, this approach cannot be claimed competitive if all cost estimates are taken literally; however, it is less than $20 \%$ above the lowest estimates previously generated, and the probable error in estimates of this type should 1 le between $10 \%$ and $20 \%$. Hence, while this particular technology can legitimately be dismissed, the point should be taken that it would be dangerous indeed to base the technology selection for those so far estimated, and the one still to come, on the grounds of lowest estimated cost. A similar situation exists regarding calculated losses. Ultimately, we must find another, more compelling rationale.

\subsection{Multiple-Pattern Programmed-Waveform Converter}

Our last serious contender is the multiple-patcern programmedwaveform voltage-sourced converter. Essentially this is the baseline design with the dc to dc converter removed, the dc to ac converter switching frequency increased by $120 \mathrm{~Hz}$ to allow fundamental component magnitude control by pattern variation, the control properly developed to accomplish that and suitable modifications at the ac interface to accomodate the increased worst case harmonics. The elemental schematic is shown in Figure 6-5, in the half-bridge with center-tapped input capacitor that is used in the $5 \mathrm{~kW}$ version. The $10 \mathrm{~kW}$ version uses a full bridge and no center tap on the input capacitor.

Cost estimates for a $5 \mathrm{~kW}$ rating are as follows: 


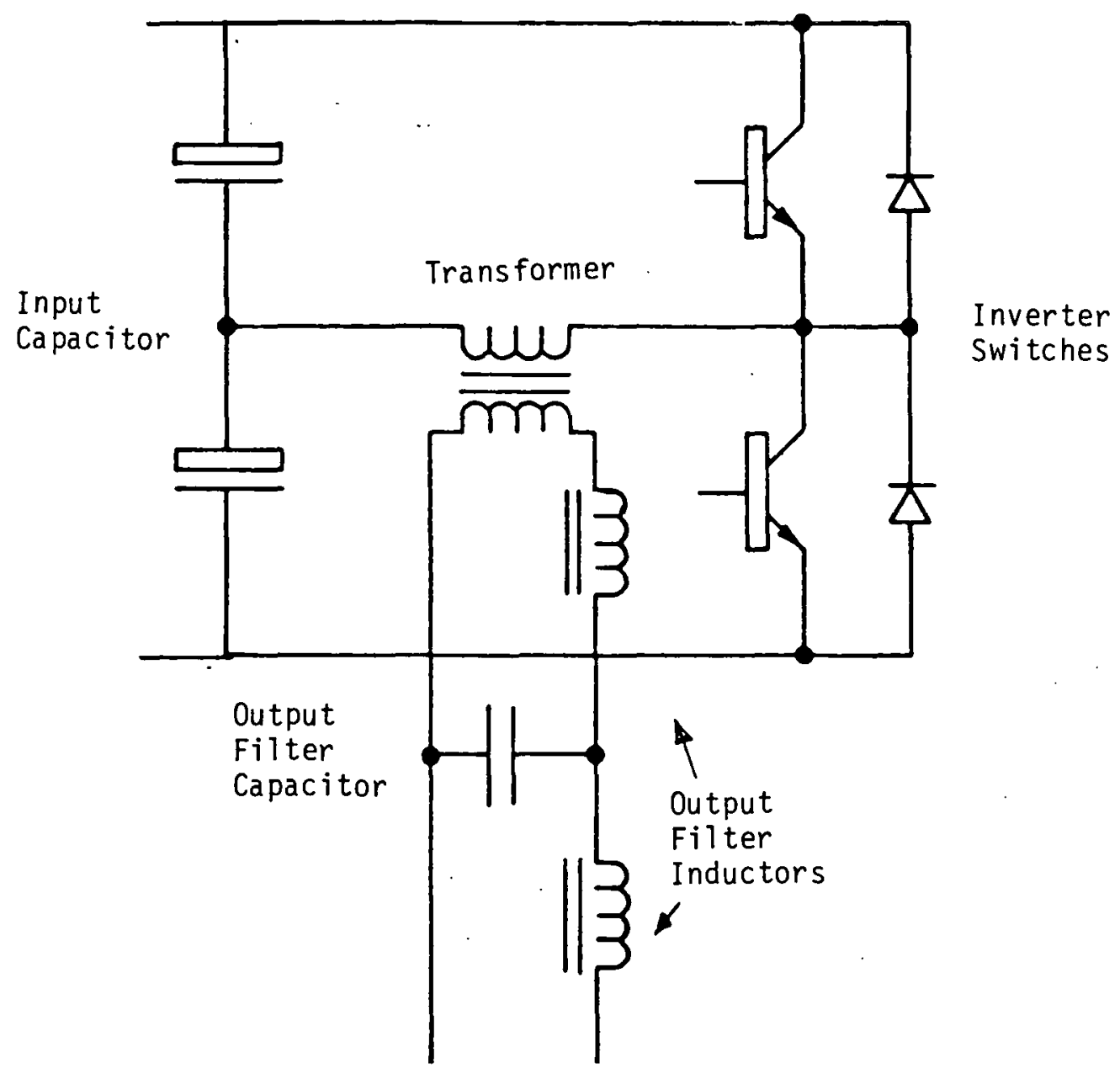

Fig. 6-5-Programmed waveform voltage sourced converter 


\begin{tabular}{|c|c|c|}
\hline Component & Material Cost $(\$)$ & Labor Cost (\$) \\
\hline Transformer & 106 & 20 \\
\hline Output filter capacitor & 34 & 20 \\
\hline Output filter inductors & 64 & 10 \\
\hline Inverter switches & 444 & 120 \\
\hline Controls & 160 & 120 \\
\hline Input capacitor & 85 & 40 \\
\hline Balance of plant & 436 & 120 \\
\hline Tótals & 1329 & 450 \\
\hline
\end{tabular}

This gives an eminently competitive DPC of $\$ 1779$.

For a $10 \mathrm{~kW}$ rating the costs are :

CumpunenL

Transformer

Output filter C

Output filter inductors

Inverter switches

Controls

Input capacitor

Balance of plant

Totals
Maleital Cuśl (\$)

194

68

117

888

160

57

532

2016
Labur Cost (\$)

20

40

20

200

120

20

140

560

Again a competitive DPC of $\$ 2576$.

Loss calculations produce the following results:

Losses and Efficiencies for $5 \mathrm{~kW}$ Programmed Waveform Converter

Watts Loss at Various Load Levels

\begin{tabular}{|c|c|c|c|c|c|}
\hline Component & $100 \%$ & $80 \%$ & $60 \%$ & $40 \%$ & $20 \%$ \\
\hline Transformer & 256.7 & 179.9 & 120.2 & 77.5 & 51.9 \\
\hline Output filter C & 5 & 5 & 5 & 5 & 5 \\
\hline Output filter L's & 135.9 & 84.9 & 47.3 & 20.8 & 5.3 \\
\hline Inverter switches & 155.5 & 123.3 & 91.7 & 60.8 & 30.7 \\
\hline Base drive \& control & 56 & 56 & 56 & 56 & 56 \\
\hline Input capacitor & 21.7 & 21.7 & 21.7 & 21.7 & 21.7 \\
\hline Totals & 630.8 & 470.8 & 341.9 & 241.8 & 170.6 \\
\hline Efficiencies, \% & 88.8 & 89.5 & 89.8 & 89.2 & 85.4 \\
\hline
\end{tabular}


Losses and Efficiencies for $10 \mathrm{~kW}$ Programmed Waveform Converter

Watts Loss at Various Load Levels

\begin{tabular}{lcccccc}
\multicolumn{1}{c}{ Component } & $\underline{100 \%}$ & $\frac{80 \%}{1.3}$ & & $\underline{60 \%}$ & $\underline{40 \%}$ & $\underline{20 \%}$ \\
Transformer & 391.9 & 191.6 & 129.1 & 91.7 \\
Output filter C & 10 & 10 & 10 & 10 & 10 \\
Output filter L's & 207.5 & 129.6 & 72.2 & 31.8 & 8.1 \\
Inverter switches & 311 & 246.6 & 183.4 & 121.6 & 61.4 \\
Base drive \& control & 100 & 100 & 100 & 100 & 100 \\
Input capacitor & 4.6 & 4.6 & 4.6 & 4.6 & 4.6 \\
Totals & 1024.4 & 769.7 & 561.8 & 397.1 & 275.8 \\
Efficiencies, \% & 90.7 & 91.2 & 91.4 & 91.0 & 87.9
\end{tabular}

These numbers are again within striking distance of efficiency goals, and this technology has the best part load behavior of all because it is load loss ( $I^{2} R$ loss or equivalent in effect) dominated.

6.5 Summary of Costs and Efficiencies

The results of the preceding cost and loss estimates are now consolidated for easy comparison and comment:

Costs of the Various Converter Approaches

\begin{tabular}{|c|c|c|c|c|c|c|}
\hline \multirow[b]{2}{*}{ Technology } & \multicolumn{3}{|c|}{$5 \mathrm{~kW}$ Unit } & \multicolumn{3}{|c|}{$10 \mathrm{~kW}$ Unit } \\
\hline & $\begin{array}{c}\$ \\
\text { Material } \\
\end{array}$ & $\begin{array}{c}\$ \\
\text { Labor } \\
\end{array}$ & $\begin{array}{c}\$ \\
\mathrm{DPC} \\
\end{array}$ & $\begin{array}{c}\$ \\
\text { Matérial } \\
\end{array}$ & $\begin{array}{c}\$ \\
\text { Labor }\end{array}$ & $\begin{array}{c}\$ \\
D P C \\
\end{array}$ \\
\hline Baseline & 1576 & 520 & 2096 & 2504 & 670 & 3174 \\
\hline Current sourced & 1306 & 435 & 1741 & 1864 & 520 & 2384 \\
\hline $\mathrm{HF}$ front end & 1386 & 460 & 1846 & 2019 & 555 & 2574 \\
\hline Programmed wave & 1329 & 450 & 1779 & 2016 & 560 & 2576 \\
\hline
\end{tabular}

Efficiency of Various Approaches at $5 \mathrm{~kW}$ Rating

\begin{tabular}{|c|c|c|c|c|c|}
\hline & \multicolumn{5}{|c|}{ Fercent Luad } \\
\hline & $100 \%$ & $\underline{80 \%}$ & $60 \%$ & $40 \%$ & $20 \%$ \\
\hline Baseline & 88.0 & 88.4 & 88.4 & 87.2 & 82.3 \\
\hline Current sourced & 89.1 & 89.0 & 88.0 & 85.0 & 75.6 \\
\hline HF front end & 89.2 & 89.0 & 88.3 & 86.0 & \\
\hline Programmed wave & 88.8 & 89.5 & 89.2 & 89.8 & \\
\hline
\end{tabular}




\section{Efficiency of Various Approaches at $10 \mathrm{~kW}$ Rating}

\begin{tabular}{lccccc} 
& \multicolumn{5}{c}{ Percent_oad } \\
Technology & $100 \%$ & & $80 \%$ & $\frac{60 \%}{40 \%}$ & $\frac{40 \%}{20 \%}$ \\
Baseline & 89.9 & 90.1 & 90.0 & 89.1 & 84.9 \\
Current sourced & 91.1 & 90.9 & 89.9 & 87.3 & 78.8 \\
HF front end & 90.6 & 90.4 & 89.6 & 87.5 & 80.1 \\
Trugrammed wave & 90.7 & 91.2 & 91.1 & 91.0 & 87.9
\end{tabular}

It can be seen that all three alternative technologies appear to offer some cost benefits and perhaps some efficlency improvements over-the baseline. It can also be seen that neither cost nof efficiency, on the basis of these estimates, provides a rational ground for selection of the best technology. It is also apparent that no technology will come within a factor of two of meeting cost goals, unless significant reductions can somehow be accomplished.

All flirt with the short term full load efficiency goal of $91 \%$ and exceed the half load target of $88 \%$. The long term goals of $93 \%$ and $90 \%$, for fuli and half load respectively, may well be achieviable.

Tr may have heen observed that the current-sourced and HF front end technologies used thyristor bridge assemblies. Cost and loss reductions could ostensibly accrue by going to the mid-point. (center tapped cransformer) configuration. However, doing so increases transformer costs and losses, resulting in an overall standoff (more or less). It is important to observe also that doing so decreases the chance for cost reduction, for it removes components (thyristors and gate drives) which may be amenable to long range cost improvement and substitutes a component (transformer) which most decidedly is not going to undergo long term cost reduction. 


\section{POSSIBLE COST IMPROVEMENTS}

We now turn attention to areas in which cost improvements can be obtained, and a comparison of the three "best candidate" technologies, the current-sourced converter, the HF front end converter, and the programmed wave converter. We must bear in mind, when making a final choice, the technical reservations expressed in regard to the HF front end approach.

There seems little, if any, hope for cost reduction of conventional passive components. The only avenue for reducing passive component costs would be redesign to reduce passive component ratings. This cannot be done with the current-sourced approach. The HF front end may benefit from increased $d c$ to $d c$ converter switching frequency, but only in the current sourcing inductor which represents only $2.3 \%$ to $2.6 \%$ of total cost. It can therefore be considered rather pointless to pursue this avenue for the $\mathrm{HF}$ front end. In the programmed-wave converter, increased switching frequency could reduce output filter costs, but only slightly as seen in Section 6 . Since they only represent 7.2 to $8.5 \%$ of total cost, passive component cost reduction would not seem a very worthwhile avenue to explore for this technology.

What are we left with? The switching devices, gate or base drives, controls and manufacturing methods are the areas in which cost improvements might be made. In addition, when it comes to selling price assessment we might consider going to work on the multiplier applied to DPC to arrive at an FOB factory price.

First consider switching devices. Thyristors of all sizes can be considered mature products, and those of the voltage and current ratings used in these converters are extremely mature. They are manufactured for a variety of applications in relatively high volume certainly 10's of 1000's per year - and it would be unrealistic to expect significant reductions in thyristor costs in the current-sourced and HF front end technologies. In fact, their present low cost is 
one reason for the relatively low cost of ferroresonant transformer UPS equipment.

Transistors deserve different consideration; fast switching power transistors of the $\simeq 400 \mathrm{~V}, \simeq 80 \mathrm{~A}$ ratings required are as yet a very immature product; this is one reason for the current high price of PWM on programmed-wave UPS equipment. Moreover, the "switch" required in the voltage-sourced (programmed-wave) converter or the dc to dc converter (HF front end) comprises far more than just a transistor. Its composition and cost can be broken down as follows:

$\begin{array}{lr}\text { Main transistor (D60T or equivalent) } & \$ 100 \\ \text { Auxiliary transistor to make Darlington, } & \$ 33 \\ \text { Inverse diode } & \$ 33 \\ \text { Base and Baker clamp diodes } & \$ 11 \\ \text { Snubbing and heat sink } & \$ 11 \\ \text { Base drive circuit } & \$ 34 \\ \text { Assembly labor } & \$ 60 \\ \text { Total per switch } & \$ 282\end{array}$

This can be attacked with a view to reducing cost. First, a Darlington chip should be developed, saving $\$ 33$ and $\$ 5$ in assembly labor. Second, the inverse diode can be eliminated by using che cullectur $\cdots$ base junction of the transistor, with suitable modification of the base contact and lead, saving $\$ 33$. Third, the trangistor currently coste \$lon only because of low volume production and the relatively low yield of a , new semiconductor product. It can, with maturity and higher volume, be predicated at $\$ 50$, saving $\$ 50$. Finally, if the switch is put together by a semiconductor manufacturer as a multi-chip assembly, in one encapsulation instead of at least five, $\$ 30$ in assembly labor can be saved. If all these measures are taken, and all are possible for an item selling in close to 10,000 volume per year for its application and also saleable for other applications, mainly ac machine drives, the total saving is $\$ 151$ and a transistor switch total cost, material and labor, reduces to $\$ 131$. The effect is to produce new DPC's as shown below: 


\begin{tabular}{|c|c|c|}
\hline & $5 \mathrm{~kW} \mathrm{( \$ )}$ & $10 \mathrm{~kW}(\$)$ \\
\hline Baseline & 1643 vs. 2096 & 2268 vs. 317 \\
\hline Current sourced & 1741 vs. 1741 & 2384 vs. 238 \\
\hline HF front end & 1695 vs. 1846 & 2272 vs. 257 \\
\hline Programmed-wave & 1477 vs. 1779 & 1972 vs. 25 \\
\hline
\end{tabular}

For the first time, we see a DPC which dips below the selling price goal of $\$ 200 / \mathrm{kW}$. Also, we begin to see a ranking apparently emerging, as a result of the varying susceptibilities of the technonogies to cost reduction by reducing transistor switch costs.

Now to gate and base drives, and controls. It is fair to say that the state of the art in these items is not state-of-the-art. By this we mean that current designs are, for the most part, quite elderly. It costs, generally, some $\$ 100,000-\$ 150,000$ to develop and get into successful production of a new converter control or a new gate or base drive circuit. Because of this, once a manufacturer has a successful design in production he is reluctant to make the investment needed to create a more advanced version of the same thing until market forces become overwhelming and great potential product cost reduction can be demonstrated.

Most gate and base drive circuits in use are more than ten years old, few less than five. If modern transistor technology is fully exploited, it is conceivable that costs could be substantlally reduced the transformer alone could probably be cost reduced by a factor of three in many instances: Intelligent circuit design to mate with modern control circuits could achieve further savings in active device and passive component usage. We believe that, just as the generation of gate and base drive circuits that emerged in the late $60^{\prime} \mathrm{s}$ and early $70^{\prime} \mathrm{s}$ were cheaper than those of the late $50^{\prime}$ 's and early $60^{\prime}$ 's, so circuits developed for the $80^{\prime}$ 's using the best available techniques could have material costs reduced by a factor of two. This would result, of course, in a concomitant reduction of associated assembly labor costs, particularly 
for a moderate to high volume product where some degree of assembly automation can be introduced. If we predicate a similar labor reduction, factor of two, then the DPC contribution of a gate drive reduces from $\$ 35$ to $\$ 17.50$ and that of a transistor base drive from $\$ 54$ to $\$ 27$. The conversion equipment DPC's are reduced from those of page 87 in the amounts depending on the number of gate and/or base drive channels they contain, to the followine :

$5 \mathrm{~kW}$ Unit (\$)

Baseline

Current-sourced

HF front end

Programmed-wave
1562

1671

1598

1423
$10 \mathrm{~kW}$ Unit (\$)

21.06

2314

2148

1864

Converter control circuits presently in use are also generally based on outdated technology. Constructed using a mix of analog and digital small integrated circuits and discrete components, they are certainly amenable to the same order of cost reduction, factor of two, in material and labor that was predicated for the gate and base drive circuits. In this case, most of this reduction will come about through the effective use of existing large scale integrated circuitry (LSI), including microprocessors and their peripherals. Since control is the same cost for all technologies (although the detailed internal functions vary, the overall functional requirements and complexity do not), this reduction, from $\$ 280$ to $\$ 140$, is across the board on the costs above and results in the following DPC's:

\begin{tabular}{lcc} 
& $5 \mathrm{~kW}$ Un1t $(\$)$ & $10 \mathrm{~kW} \mathrm{Unit}(\$)$ \\
\cline { 2 - 3 } Baseline & 1412 & 1966 \\
Current-sourced & 1531 & 2174 \\
HF front end & 1458 & 2008 \\
Programined-wave & 1283 & 1724
\end{tabular}

We see that a "clear winner" is appearing if these estimates are considered valid. A clear loser, the current-sourced technology, 
also appears evident. We also see that the two technologies using compound conversion, the baseline and the HF front end, are certainly too close to call relative to each other but are enough worse than our winner, the programmed-wave voltage-sourced converter, to give fair confidence in its selection. It is, unfortunately, also apparent that even with the cost improvements predicated, the best candidate will not meet cost goals with a 1.6 - 1.9 multiplier from DPC to FOB factory price - the range for a $5 \mathrm{~kW}$ unit is $\$ 411 / \mathrm{kW}$ to $\$ 488 / \mathrm{kW}$, over twice the $\$ 200 / \mathrm{kW}$ goal. A $10 \mathrm{~kW}$ unit is better, with estimated factory price ranging from $\$ 288 / \mathrm{kW}$ to $\$ 328 / \mathrm{kW}$, but is still at best only just within a factor of 1.5 higher than the goal.

It is fair to ask whether the balance of plant costs, totalling $\$ 556$ for a $5 \mathrm{~kW}$ unit and $\$ 672$ for a $10 \mathrm{~kW}$ unit, may not be subject to reduction since they now represent $\simeq 43 \%$ and $\approx 39 \%$, respectively, of equipment DPC. We think that if the items making up these costs are considered, it is clear that it is very unlikely any reduction can be effected unless items can be eliminated. We doubt this can be done, considering that we already have a "bare-bones" design.

The items in question are:

- cabinet - obviously necessary, well matured product

- wire, cable, terminations-obviously necessary, possibly subject to some slight reduction but certainly not sufficient to really inpact the cost picture

- $d c$ and ac voltage and current transducers - necessary for the operation and control of the converter; also used to provide status information, so serve double duty. These are mature products unlikely to be cost reduced

- a meter, three indicator lights (dc power connected, ac line connected, equipment operating) and an on/off/meter function selector switch - we think the minimum necessary, and in any case not all that significant in cost. These are mature products. 
- dc and ac disconnecting and fault protecting switchgear. The only arguable item is the external, lockable open, ac breaker. This we think is needed for safety; we have not charged its field installation cost to the equipment. Eliminating it will not save its total cost, for the breaker function must he present in the equipment. The dc disconnect and ac contactor are clearly needed. The array shorting switch (for dc fault protection/isolation) may be arguable, but wc doubt that a cheaper way of effectively protecting can be found. All are mature products.

- fuses - necessary to prevent catastrophe in the event of failure of other protective means and measures. These are also mature products.

In view of the foregoing, we reiterate that we think it unlikely that reductions can be made in balance of plant costs. This does not mean that efforts should not be made; every penny that can be taken off will move the equipment closer to the cost goal. However, the balance of plant items are present for all converter technologies, and so whether they are reducible or not they do not affect our final selection.

The only thing which might affect the selectlun is the VAR specification for the converter. As far as the current-sourced converter is concerned, it is not possible to eliminate VAR compensation entirely converters running at power factors ranging from 0.4 to 0.6 would create unacceptable voltage regulation on the distribution system. However, if unity power factor or slightly lagging power factor converter operation were permitted, both the current-sourced and HF front end technologies would benefit more than the programmed-wave converter. The currentsourced converter would benefit further if VAR control requirements were dropped, 1.e. if fixed compensation could be used. This is certainly not a viable option if peak-power tracking control is used. It is, perhaps, a tenable proposition if degraded performance is acceptable with "constant dc voltage" control, for example. Exploring the impact of such specification changes, we get the following DPC's", reduced from those of the lower table on page 88: 
For unity power factor converter operation:

$5 \mathrm{~kW}$ Unit (\$) $10 \mathrm{~kW}$ Unit (\$)

\begin{tabular}{|c|c|c|}
\hline Baseline & 1396 & 1948 \\
\hline Current-sourced & 1461 & 2039 \\
\hline HF front end & 1286 & 1762 \\
\hline Programmed-wave & 1267 & 1706 \\
\hline
\end{tabular}

Allowing the current-sourced converter to operate at 0.9 lagging power factor further reduces its DPC to

$5 \mathrm{~kW}$ Unit (\$) $10 \mathrm{~kW}$ Unit (\$)

Current-sourced

1405

1931

at $0.9 \mathrm{pf}$

The imposition of VAR control still makes the current-sourced technology apparently non-competitive. If we allow degraded performance and specify fixed compensation to 0.9 power factor at peak load, the DPC for the current-sourced technology becomes

$5 \mathrm{~kW}$ Unit (\$) $10 \mathrm{~kW}$ Unit (S)

Current-sourced with $1275 \quad 1761$

fixed compensation,

$.9 \mathrm{pf}$

The efficiency of the current-sourced technology, particularly at part load, will increase with these changes, especially the last thereof.

Now we see that for unity power factor converter operation, the $\mathrm{HF}$ front end becomes identical to the programmed-wave, and the currentsourced converter does also when its performance degraded as regards VAR behavior. However, our selection stands. Neither competition gains an advantage over the programmed-wave approach - they merely manage to match it. They have no perceptible efficiency advantage at full or part load, and the programmed-wave converter is operationally more 
flexible (1t can still run off unity power factor and still control VARs the others cannot) and more reliable.

This last statement is based on two considerations. First, the programed-wave converter contains fewer components, particularly active power handling components. : Ergo it must be more reliable. Second, it is far less susceptible to ac line transient induced converter faults, and possible consequential component (especially actịve deviçe) damage. Therefore, it is not only more reliable but also will have higher availability.

Our case rests. Under the specification we think applicable, the programmed-wave converter is clearly superior. Degrading the specification to favor the other technologies does not enable them to win, only to draw equal in cost. Reliability and availability clearly favor the voltage-sourced programmed-wave converter, and it suffers from no significant technical problems in the application while affording greater operational flexibility than other converter technologies. It is clearly and unequivocally the technology to pursue. Unfortunately, neither this nor any other technology. is perceived as having a good chance of meeting the cost goals. 


\section{INFORMATION MATRIX SUPPORTING THE CONCLUSIONS}

1. Calculated efficiencies of the converter technologies $5 \mathrm{~kW}$ Rating

\begin{tabular}{llllll} 
& \multicolumn{6}{c}{ P kW Rating } & \multicolumn{2}{c}{ Percent Load } \\
Technology & $\frac{100 \%}{88.0}$ & $\frac{80 \%}{88.4}$ & $\frac{60 \%}{88.4}$ & $\frac{40 \%}{87.2}$ & $\frac{20 \%}{82.3}$ \\
\hline Baseline & 89.1 & 89.0 & 88.0 & 85.0 & 75.6 \\
Current-sourced & 89.2 & 89.0 & 88.3 & 86.0 & 78.4 \\
HF front end & 88.8 & 89.5 & 89.8 & 89.2 & 85.4 \\
Programmed-wave & & & & &
\end{tabular}

$10 \mathrm{~kW}$ Rating

\begin{tabular}{llllll} 
& \multicolumn{6}{c}{ Percent Load } \\
\cline { 2 - 7 } Technology & $\underline{100 \%}$ & $\underline{80 \%}$ & $\underline{60 \%}$ & $\frac{40 \%}{80 \%}$ & $\underline{20 \%}$ \\
Baseline & 89.9 & 90.1 & 90.0 & 89.1 & 84.9 \\
Current-sourced & 91.1 & 90.9 & 89.9 & 87.3 & 78.8 \\
HF front end & 90.6 & 90.4 & 89.6 & 87.5 & 80.7 \\
Programmed-wave & 90.7 & 91.2 & 91.4 & 91.0 & 87.9
\end{tabular}

Conclusion: there is no significant difference; no technology is clearly better, and all have a equal chance of meeting long range goals.

2. Cost estimates prior to predicated improvements

$\begin{array}{lcc} & 5 \mathrm{~kW} \text { units } & \frac{10 \mathrm{~kW} \text { units }}{\text { Baseline }} \\ \text { Current-sourced } & \$ 2096 & \$ 3174 \\ \text { HF front end } & \$ 1741 & \$ 2384 \\ \text { Programmed-wave } & \$ 1846 & \$ 2574 \\ & \$ 1779 & \$ 2576\end{array}$

Conclusion: the alternative, technologies seem better than the baseline, but no one of them is superior to the others. 
3. Cost estimates after predicated improvements

\begin{tabular}{|c|c|c|}
\hline & $5 \mathrm{~kW}$ units & $10 \mathrm{~kW}$ un1ts \\
\hline Baseline & $\$ 1412$ & $\$ 1966$ \\
\hline Current-sourced & $\$ 1531$ & $\$ 2174$ \\
\hline HF front end & $\$ 1458$ & $\$ 2008$ \\
\hline Programmed-wave & $\$ 1283$ & $\$ 1724$ \\
\hline
\end{tabular}

Conclusion: the current-sourced converter is a loser, the programed-waveform voltage sourced converter is the best rational selection.

4. Cost estimates after eliminating VAK requirements and -degrading current-sourced converter performance

\begin{tabular}{|c|c|c|}
\hline & $5 \mathrm{~kW}$ units & $10 \mathrm{~kW}$ units \\
\hline Baseline & $\$ 1396$ & $\$ 1948$ \\
\hline Current-sourced & $\$ 12 / 5$ & $\$ 1761$ \\
\hline HF front end & $\$ 1286$ & $\$ 1762$ \\
\hline Programmed=wave & siंti7 & $\$ 1706$ \\
\hline
\end{tabular}

the best candidate.

5. Reliability: fewer power circuit components, expecially semi-conductors, in programmed-wave converter

6. Availability: programmed-wave converter less susceptible to outages due to ac line transients

7. Operational: programmed-wave converter häs greater flexibility - can still transiently VAR control, retains peak-power tracking, no wake-up problems, no significant technical application problems. 
8. Final conclusion: No technology can meet cost goals unless further improvements prove possible. Programmed-wave converter has best chance, is currently as close as any other, ultimately closest. All meet or could with slight improvement, short term efficiency goals. Al1 have equal chance of meeting long term efficiency goals. Reliability, availability and operational considerations strongly favor programmedwave voltage-sourced converter. It needs development, but is an unequivocal choice. 
APPENDIX A

STATEMENT OF WORK

TASK 1 - REVIEW AND EVALUATION OF POWER CONDITIONING TECHNOCOGY

The capabilities and characteristics of currently manufactured PC equipment will be assessed in Task 1 . The goal is to provide a data base and analyses and correlations of the data in order to create a basis from which the technology may be advanced.

\section{A. Acquire Data Base}

Data will be collected on the types, ratings, performance, costs, efficiencies, sizes, weights, and reliability records of power conditioning equipment now manufactured for a variety of applications with power requirements in the range of interest.

\section{B. Determine Performance Limitations}

From the data, the performance limitations of present technology PC equipment will be estabilshed; the causes of these limitations will be identified.

C. Establish Production Cost Patterns

From the data, the costs of the various types of Power Conditioning equipment currently manufactured will be established. These costs will be analyzed to detcrmine the influence of technology and manufacturing methods.

D. Explore Reliabilities Achieved

From the data, estimates will be made of the reliability achieved by present PC technology. These estimates will be compared with formally 
calculated reliabilities based on component data. A correlation will be established to permit a reliability assessment of advanced conceptual design.

E. Investigation of Unique Equipments

Unique PC equipments made or adapted specifically for solar photovoltaic (PV), wind, fuel cell, and battery sources will be investigated to determins in what ways they differ from and transcend convenlional implementations. Any technology advances will be identified and chelp Impacts will le defined.

TASK 2 - INVESTIGATION OF INTERFACE REQUIREMENTS

Data will be acquired on dc source characteristics from the manufacturers and a study of the literature. Data will be acquired on ac network characteristics from Westinghouse internal resources, electric utility inputs, and a literature search.

B. Characterize Source Steady-State Behavior

From the data, the steady-state characterise1cs of the de sources will be established.

C. Determine Transient and Fault Characteristics

The transient behavior, fault susceptibility, and fault capacities of the dc sources will be determined.

D. Establish Parametric Kanges

The ranges of steady-state, transient, and fault parameters which PC equipment must tolerate at the dc interfaces will be established. 


\section{E. Explore Responses to Converter Imposed Stresses}

The tolerances of the dc sources to electrical stresses - both steady-state and transient - imposed by the PC equipment will be determined. The predilections of the sources to produce EMI and acoustic noise as a result of converter imposed stresses will be examined.

\section{F. Prepare DC Interface Specifications}

Specifications will be prepared for converter dc interface performance capable of meeting application needs.

\section{G. Define Acceptable Power Quality}

The required steady-state behavior of the converter at the ac interfaces will be established, including permissible harmonic injection, permissible VAR consumption, and generation and ac voltage range requirements.

\section{H. Evaluate Protective Requirements and Coordination}

The measures needed to protect conversion equipment from ac network disturbances and to protect the network from converter transients will be determined. Coordination of these measures with normal ac network protective devices will be explored; a combined protection philosophy will be established.

I. Prepare AC Interface Specifications

Specifications will be prepared for converter ac interfaces with the ability to meet applications needs.

\section{TASK 3 - SELECTION AND CONCEPTUAL DESIGN OF BASELINE}

In Task 3, baseline PC equipment designs will be produced. These designs will use present technology, and will be capable of meeting the interface requirements developed in Task 2 and all other application constraints. 


\section{A. Define Baseline Performance}

The performance requirements of the baseline designs will be established from the interface specifications and application constraints.

\section{B. Investigate Switching Device Capabilities}

The characteristics of available semiconductor switching devices will be examined; a determination will be made of the best types of devices to be used in the baseline designs.

C. Design and Describe Circuitry, Components, and Package Conceptual baseline designs for PV systems will be executed and docoribed.

D. Determine Production Costs

Using the information from subtask 1.C productions costs for the baseline designs will be esclmated.

E. Determine Size, Weight, and Efficiencies

The efficiencies, sizes, and weights of the baseline designs will be calculated; these calculations will be continuously cross-correlated with the data from subtask 2.A to ensure a realistic assessment.

F. Determine Reliability and Life

The reliabilities and projected useful lives of the baseline designs will be calculated using the techriques and data established in subtask 1.D.

\section{G. Establish Environmental Requirements}

The environemental needs and tolerances of PC equipment built to the baseline designs will be determined. 


\section{H. Define Installation and Maintenance Requirements}

The installation and maintenance requirements of baseline PC equipments will be defined.

\section{Define and Discuss Modifications for Non-PV Sources}

Modifications to the baseline designs needed to enable accommodations of wind, fuel cell, and battery sources will be defined; the impact of these modifications on equipment cost, efficiency, size, weight, reliability, environmontal tolerance, and installation and maintenance requirements will be discussed.

TASK 4 - INVESTIGATION OF ADVANCED PC EQUIPMENT

Using the baseline designs as a starting point, the various possibilities for improving PC equipment for application needs will be examined. Improvements, both those within the framework of present technology and those requiring technology advancement, will be explored.

\section{A. Explore Possible Switching Device Improvements}

Improvements in switching device behavior and fabrication can significantly affect PC equipment costs, efficiencies, reliabilities, and other aspects of total application performance, Some improvements will be identified, and the probabilities of their being achieved, in the near and long terms, will be assessed.

\section{B. Identify Concepts with Reduction Potential}

Concepts of power circuit design, control philosophy and implementation, cooling and packaging, and manufacturing and assembly which have potential for reducing PC equipment costs will be identified; their various capacities to reduce costs will be discussed and assessed. 


\section{Identify Concepts with Efficiency Improvement Potential}

As in subtask 4.B concepts which could improve efficlency will be identified, discussed, and assessed.

E. Identify Concepts with Maximum Modularity Potential

Concepts having the potential to create maximum commonality and modularity, in equipments of various ratings and for application with the several dc sources, will be identified, discussed, and assessed.

F. Select Concepts offering Greatest Overall Potential; Establish Development Efforts Needed to Implement These Concepts Those concepts (identified and assessed in subtask 4.B, 4.C, 4.D and 4.E) which offer the greatest overall potential for improvement will be selected. Any development effort needed to implement such concepts w11l be identified and estimated.

G. Define Control and Protection Reyuilements

The centrol and protection requirements of advanced PC equipment ucing the roncepts identified will ve defined and discussed.

\section{H. Determine Optimal Configurations}

For advanced designs based on the concepts identified, optimum module sizes and system configurations for the power and appiication range will be determined.

TASK 5 - CONCEPTUAL DESIGN

Conceptual designs for advanced PC equipment will be produced in Task 5. All application-related parameters will be determined, and the expected improvements assessed. 


\section{A. Define Design Options}

Design options for advanced PC equipment will be identified and explained; the best concepts emerging from Task 4 will be used.

\section{B. Select Most Promising Approäches}

The specific converter technologies offering the greatest promise will be selected.

\section{Execute Conceptual Designs}

Conceptual designs will be executed using the converter technology and concepts chosen to most effectively meet the total application requirements.

D. Determine Perfromance Limitations

Performance limitations of the advanced conceptual designs will be established and their causes identified.

E. Determine Costs, Efficiencies, Reliabilities, Sizes, Weights, Environmental Requirements and Tolerances, and Installation and Maintenance Requirements

All pertinent application-related parameters will be determined for the advanced designs. A comparison will be made with the baseline to establish the immediate, near term, and long term benefits expected.

\section{F. Establish Component Requirements}

Components needed to impelment the advanced designs will be defined; and special component requirements will be identified and discussed.

G. Define Modifications Needed for Use with Non-PV Sources Modifications necessary for the advanced designs to accommodate non-PV sources will be defined and discussed. 
TASK 6 - RESULTS, CONCLUSIONS, AND RECOMMENDATIONS

In Task 6, a concise summary of the results achieved and recommendations for further efforts to improve PC equipment will be provided.

A. Develop Matrix of Design and Performance Parameters

To facilitate understanding and comparison, a matrix of all design andperformance parameters for the baseline and advanced designs will be developed. This matrix will both support the concept and technology selections made in Tasks 4 and 5 , and provide a means for readily deducing the future efforts which should yield maximum benefits.

B. Make Recommendations on Effort and Means for Improving Implementations The development efforts, and any other means needed to still further improve the implementation of PC equipment, will be identified and discussed. Those paths expected to yield the greatest benefits will be clearly delineated.

C. Provide Cost and Rellability Estimates

Coct and reliability estimates will be provided for the advanced designs.

TASK 7 - REPORTING

Westinghouse will submit the contract reports called for in Exhibit II. 
DISTRIBUTION :

Dep. Asst. Secretary for Solar Energy

U. S. Department of Energy 1000 Independence Ave., SW Room 6C026

Washington, DC

Attn: R. San Martin

Division of Photovoltaic Energy Systems (3)

U. S. Department of Energy 1000 Independence Ave., SW Washington, DC 20585

Attn: $M$. Prince

A. Clorfeine

R. Santopietro

Division of Electric

Energy Systems (2)

U. S. Department of Energy

12 th \& Pennsylvania Ave., NW Washington, DC 20461

Attn: J. C. Smith

D. Roesler

DOE/Wind Systems

U. S. Department of Energy

Mail stop 404

600 E Street, NW

Washington, DC 20585

Attn: Oree Dyes

DOE/MHD

U. S. Department of Energy

Mail Stop F-338

Germantown, MD 20545

Attn: victor Dur

DROME-EA

USAMERADCOM

Fort Belvoir, VA 22060

Attn: Robert Williams

U. S. Department of Energy (6)

Albuquerque, NM 87115

Attn: D. L. Krenz, Director Special Programs Div.
SERI (3)

1536 Cole Blvd.

Golden, CO 80401

Attn: Library

P. Longrigg

Jet Propulsion Laboratory (25)

4800 Oak Grove Drive

Pasadena, CA 91103

Attn: R. Powell

K. Krauthamer

NASA/LeRC (2)

21000 Brookpark Road

Cleveland, OH 44135

Attn: Tom Klucher

R. Pickrell

MIT-Lincoln Lab (2)

Box 73

Lexington, MA 02173

Attn: M. Pope

C. COX

Wind Systems Program Rocky Flats Plant

P. O. Box 464

Golden, CO 80401

Attn: Art Eldridge

EPRI

3412 Hillview Avenue

Palo Alto, CA 94303

Attn: R. Ferraro

Argonne National Lab

$9700 \mathrm{~S}$. Cass Avenue

Argonne, IL 60439

Attn: Wayne Lark

2165 C. M. Coats

2167 W. I. Bower

2525 R. Clark

2533 A. Verardo

4700 J. H. Scott

4720 D. G. Schueler

4724 D. G. Schueler, Actg.

4724 T. S. Key (80)

4724 D. Chu

8214 M. A. Pound

3141 L. J. Erickson (5)

3151 W. L. Garner (3)

For DOE/TIC (Unlimited

Release)

3154-3 C. H. Dalin (25) (For DOE/TIC; Unlimited Releose) 


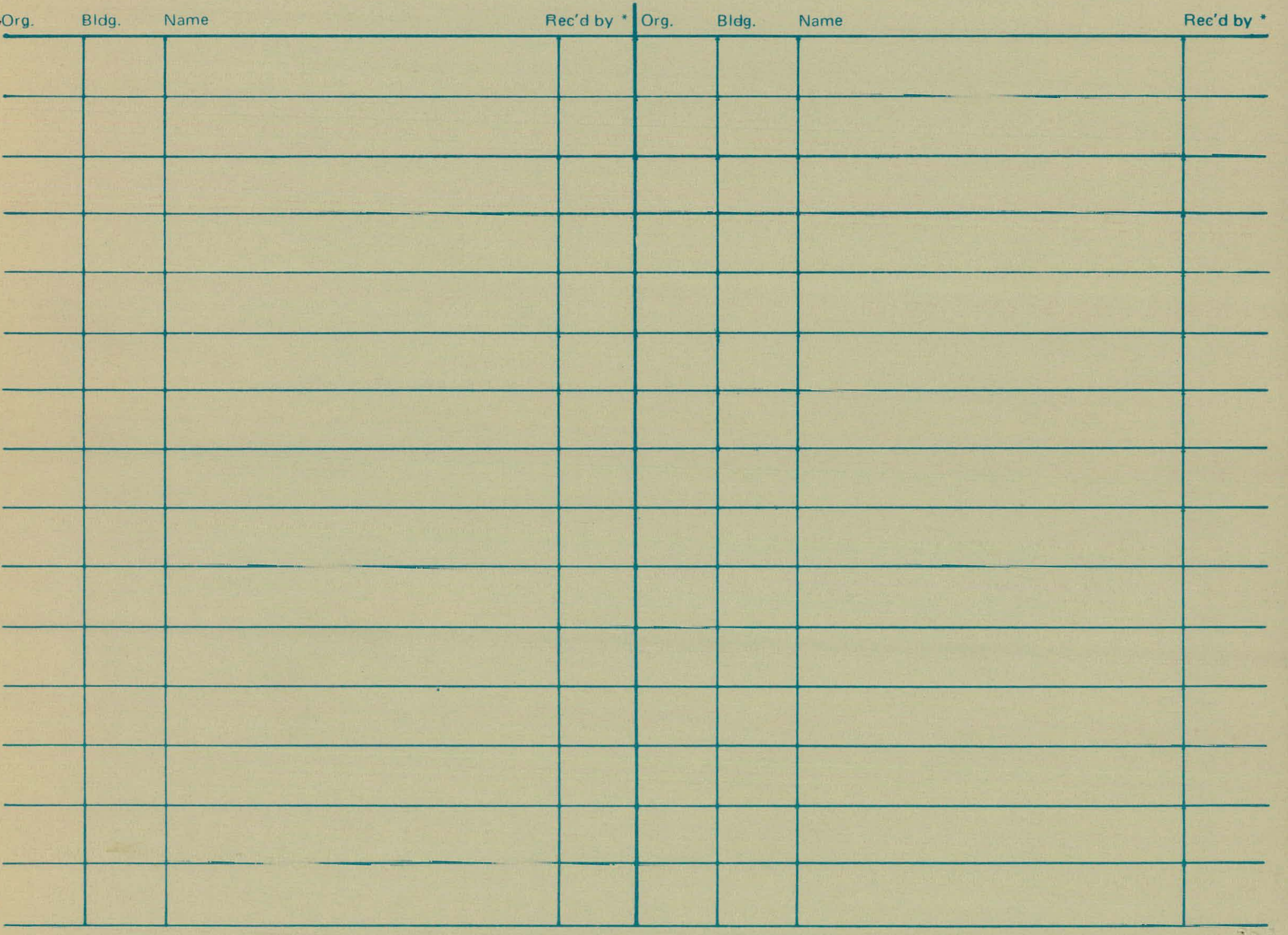

